

\title{
ENHANCING MAYA WOMEN'S DEVELOPMENT THROUGH COOPERATIVE ASSOCIATIONS: WHAT FACTORS SUPPORT OR RESTRICT THE CONTRIBUTION OF COOPERATIVES?
}

\author{
DISSERTATION
}

\begin{abstract}
to obtain
the degree of doctor at the University of Twente, on the authority of the rector magnificus,

Prof. dr. T.T.M. Palstra,

on account of the decision of the graduation committee, to be publicly defended

on Thursday $14^{\text {th }}$ of December 2017 at 12.45 hours.
\end{abstract}

by

María Cristina Osorio Vázquez

born on $28^{\text {th }}$ of May 1979

in Merida, Yucatan, Mexico 
This thesis has been approved by

Promoter: Prof. dr. Hans Th. A. Bressers

Co-Promoter: Dr. Maria Laura Franco Garcia 
Members of the Committee:

Chairperson: Prof. dr. T.A.J. Toonen University of Twente

Secretary: Prof. dr. T.A.J. Toonen University of Twente

Promotor: Prof. dr. J.T.A. Bressers University of Twente, BMS-CSTM

Co-Promotor: Dr. M.L. Franco Garcia University of Twente, BMS-CSTM

Member: $\quad$ Prof. dr. L.J. O’Toole University of Twente, BMS-CSTM

Member: $\quad$ Prof. dr. J.S. Clancy University of Twente, BMS-CSTM

Member: $\quad$ Prof. dr. C. Larrue Université Paris Est Créteil/Université Est

Marne-la-Vallée, École D’Urbanisme de Paris

Member: $\quad$ Prof. dr. M.K. McCall Universidad Nacional Autónoma de México, Centro de Investigaciones en Geografia Ambiental

Member: $\quad$ Prof. dr. ir. O.A.M. Fisscher University of Twente, BMS-PLD

The work described in this thesis was performed at the Department of Governance and Technology for Sustainability, Faculty of Behavioural, Management and Social sciences, University of Twente, P.O. Box 217, 7500 AE, Enschede, The Netherlands.

This research project was funded by the Nestle Foundation for the study of problems of nutrition in the world. 


\section{Colophon}

Cover image: En Pro de la Mujer

Printed by: Ipskamp Printers, Enschede, The Netherlands

(C) 2017 María Cristina Osorio Vázquez, University of Twente, BMS-CSTM.

No part of this publication may be reproduced, stored in a retrieval system, or transmitted, in any form or by any means, electronic, mechanical, photocopying, recording or otherwise, without prior written permission of the author.

ISBN: 978-90-365-4451-1

DOI: $10.3990 / 1.9789036544511$

\section{UNIVERSITY OF TWENTE.}

Faculty of Behavioural, Management and Social sciences (BMS) Department of Governance and Technology for Sustainability (CSTM)

Enschede, The Netherlands

E-mail (for correspondence): ma.cristina.osorio@hotmail.com 


\section{Contents}

List of Figures $\quad$ ix

List of Tables $\quad$ ix

List of Abbreviations $\quad$ xi

Acknowledgments $\quad$ xiii

Chapter 1. Introduction $\quad 1$

1.1 Background 1

1.1.1 Historical Antecedents of Cooperativism 3

1.1.2 The cooperative as an innovative organization 4

1.2 Research problem and research questions 5

$\begin{array}{ll}1.3 \text { Theoretical perspectives } & 7\end{array}$

1.3.1 Theory of Social Capital $\quad 7$

1.3.2 Social Economy Theory $\quad 8$

1.3.3 Gender Theories 9

1.3.4 The Concept of Self-reliance $\quad 10$

$\begin{array}{ll}\text { 1.3.5 Circular Economy } & 10\end{array}$

1.3.6 Social Learning Theory 11

1.3.7 Contextual Interaction Theory 11

$\begin{array}{ll}1.3 .8 \text { Theories of bounded rationality } & 12\end{array}$

1.3.9 International Relations Theories $\quad 13$

$\begin{array}{ll}1.3 .10 \text { Critical Consciousness Theory } & 13\end{array}$

1.3.11 Theoretical advances of the self-respect concept 14

$\begin{array}{ll}1.4 \text { Methodological approach } & 14\end{array}$

1.4.1 Qualitative Methodology of Social Research 14

1.4.2 School of thought advocacy/participatory 16

$\begin{array}{ll}1.5 \text { Outline of the thesis } & 17\end{array}$

Chapter 2. Motivations of Mayan women to create microbusiness-cooperatives 21

2.1 Introduction $\quad 22$

2.2 Economic, social and cultural circumstances 23

2.2.1 Economic background: the pressing needs 23

2.2.2 Social background: the concept of social capital 24

2.2.3 Cultural background: the gender relations 25

2.3 Methodology 27

$\begin{array}{ll}\text { 2.3.1 Case selection } & 27\end{array}$

$\begin{array}{ll}\text { 2.3.2 Data gathering } & 27\end{array}$

2.4 Empirical results 28

2.5 Conclusions $\quad 30$

Chapter 3. Elements of success in cooperatives conformed by Maya women 33 in the Yucatan Peninsula, Mexico

3.1 Introduction 33

3.2 The Theory of Social Economy and Social Capital on elements of 35 integration in cooperatives 
3.3 Case Selection and Methodology $\quad 36$

3.4 Case Study Results 38

3.4.1 Case 1: Illustration of the importance of social capital 38

3.4.2 Case 2: Social Capital and Monitoring $\quad 39$

3.4.3 Case 3: Ethical leadership as an additional factor of success 40 and sustainability

3.5 Discussion: Elements of success could be also constraints inside the cooperative 43

3.6 Conclusions $\quad 45$

Chapter 4. Analysis of the federal Mexican program POPMI which supported $\quad 47$ female entrepreneurship initiatives in the Yucatan Peninsula, Mexico

4.1 Introduction 48

4.2 The Program of Productive Organization for Indigenous Women (POPMI) 50

4.3 Case Selection and Methodology 52

4.3.1 Case selection $\quad 52$

4.3.2 Data gathering 53

4.3.3 Data analysis: Contextual Interaction Theory 53

4.4 Empirical Results $\quad 54$

4.4.1 Backgrounds of the actor characteristics of the women in the cooperatives 54

4.4.2 The Implementation Process of the POPMI Program in the Mayan Region 55

4.4.3 Organizational Aspects of Microbusiness Cooperatives participants in $\quad 58$ this research

4.5 Discussion

61

4.6 Conclusions $\quad 62$

Chapter 5. Analysis of Canada Fund for Local Initiatives (CFLI) supporting $\quad 65$ economic development of Maya women in Mexico's Yucatan Peninsula

5.1 Introduction 66

$\begin{array}{ll}5.2 \text { International Aid } & 67\end{array}$

5.3 Mexico-Canada Bilateral Relations $\quad 69$

5.4 International Relations as Theoretical Framework $\quad 70$

5.5 Case Selection and Methodology 72

$\begin{array}{ll}\text { 5.5.1 Case selection } & 72\end{array}$

$\begin{array}{ll}\text { 5.5.2 Data gathering } & 72\end{array}$

5.5.3 Contextual Interaction Theory (CIT) 73

5.6 Empirical Results $\quad 74$

5.6.1 Backgrounds of the actors involved 74

5.6.1.1 The Canadian International Development Agency (CIDA) 74

5.6.1.2 The National NGO 76

5.6.1.3 The Female Cooperative 77

5.6.2 The submission of the project for approval, its granting and follow-up $\quad 78$

5.6.3 The internal organization of the cooperative and its development $\quad 79$

5.6.4 Analysis of the process using CIT $\quad 81$

5.7 Discussion $\quad 84$

$\begin{array}{ll}5.8 \text { Conclusions } & 85\end{array}$ 
Chapter 6. Promoting Food Sovereignty through a Cooperative Model in the

6.2 Social Movements and the emergence of Food Sovereignty 89

6.3 Customs of the Maya population living in the Yucatan Peninsula 92

$\begin{array}{ll}\text { 6.3.1 Agriculture } & 92\end{array}$

$\begin{array}{ll}\text { 6.3.2 Migration } & 93\end{array}$

6.3.3 Diet and physical activity 94

6.3.4 Cooperation as part of the culture $\quad 95$

6.3.5 Women participating in cooperatives $\quad 95$

6.4 Theoretical Framework 96

6.4.1 Critical Consciousness Theory 96

6.4.2 The concept of self-respect and its contribution to personal 98 autonomy and self-reliance

6.4.3 Indigenous Perspectives associated with social economy 98

6.5 Methodology and Case Selection 99

$\begin{array}{lr}\text { 6.5.1 Case selection } & 99\end{array}$

$\begin{array}{lr}\text { 6.5.2 Data gathering and analysis } & 100\end{array}$

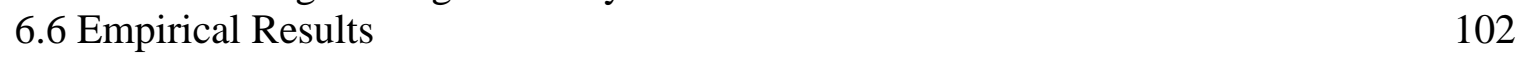

$\begin{array}{ll}\text { 6.6.1 Category 1. Food Sovereignty } & 102\end{array}$

6.6.2 Category 2. Economic aspects 105

6.6.3 Category 3. Environment 105

6.6.4 Category 4. Self-esteem 106

6.7 Discussion on the information obtained 108

$\begin{array}{ll}6.8 \text { Conclusions } & 110\end{array}$

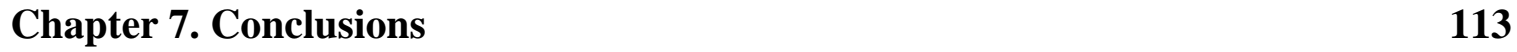

$\begin{array}{ll}7.1 \text { Introduction } & 113\end{array}$

7.2 Summary and answering of the research questions 113

7.3 Implications for the debate on the role of cooperatives 120

$\begin{array}{lr}7.4 \text { Policy implications } & 122\end{array}$

$\begin{array}{ll}\text { References } & 127\end{array}$

Annex 1 Food sovereignty questionnaires $\quad 153$

$\begin{array}{lr}\text { Summary } & 161\end{array}$

Samenvatting $\quad 163$

$\begin{array}{ll}\text { About the author } & 165\end{array}$ 


\section{List of Figures}

Figure 1.1 Structure of the dissertation 6

Figure 1.2 Layered contexts for interaction processes $\quad 12$

Figure 4.1 Dynamic interaction between the key actor-characteristics that drive social 54 interaction processes and in turn are reshaped by the process

Figure 5.1 Dynamic interaction between the key actor-characteristics that drive social 74 interaction processes and in turn are reshaped by the process

\section{List of Tables}

Table 3.1 Elements of success found in three cases of cooperatives

Conformed by Maya women in the Yucatan Peninsula

Table 4.1 Overview of motivations, resources and cognitions of main actors 60

Table 5.1 Overview of motivations, resources and cognitions of main actors 82

Table 6.1 Get help when nothing to eat $\quad 103$

$\begin{array}{ll}\text { Table 6.2 Appreciation of relatives } & 107\end{array}$ 


\title{
List of Abbreviations
}

\author{
CDI National Commission for the Development of Indigenous Peoples \\ CECS Center for Evaluation and Monitoring Quality Professional Services \\ CFLI Canada Fund for Local Initiatives \\ CGD Center for Global Development \\ CGEIB General Coordination of Intercultural and Bilingual Education \\ CIDA Canadian International Development Agency \\ CIT Contextual Interaction Theory \\ CONAFE National Council for Educational Development \\ CONEVAL National Council for the Evaluation of Social Development Policy \\ CSTM Department of Governance and Technology for Sustainability \\ DAC Development Assistance Committee \\ DFAIT Department of Foreign Affairs and International Trade Canada \\ DFATD Department of Foreign Affairs, Trade and Development \\ DGEI General Directorate of Indigenous Education \\ ECLAC Economic Commission for Latin America and the Caribbean \\ FAO Food and Agricultural Organization of the United Nations \\ FIA Inter-American Foundation \\ FIRCO Shared Risk Trust \\ GNI Gross National Income \\ HDI Human Development Index \\ INE Mexican Credential to vote \\ ICA International Cooperative Alliance \\ ICESR International Covenant on Economic, Social, and Cultural Rights \\ IDB Inter-American Development Bank \\ ILO International Labor Organization \\ INAES National Institute of the Social Economy \\ INAI National Institute of Transparency, Access to Information and Protection of \\ Personal Data \\ INCA National Institute for Training and Development or Rural Sector \\ INEGI National Institute of Statistics and Geography \\ INEA National Institute for Adult Education \\ INI National Indigenous Institute \\ INMUJERES National Institute of Women Issues \\ MDG Millennium Development Goals \\ NAFTA North American Free Trade Agreement \\ NGO Non-Governmental Organization \\ ODA Official Development Assistance \\ ODAAA Official Development Assistance Accountability Act \\ OECD Organization for Economic Cooperation and Development \\ PADF Pan American Development Foundation \\ PND National Development Plan \\ POPMI Program of Productive Organization for Indigenous Women \\ PROCAMPO Program of Direct Support to Rural Areas \\ PROIN Program for the Production Improvement for Indigenous Peoples
}


PROMAF Support for Productive Chain of Producers of Corn and Bean

SAGARPA Secretariat of Agriculture, Livestock, Rural Development, Fisheries and Food

SDG Sustainable Development Goals

SEDARI Secretariat of Rural and Indigenous Development

SEDESOL Secretariat of Social Development

SEP Secretariat of Public Education

SFP Secretariat of Public Function

SPSS Statistical Package for the Social Sciences

UNDP United Nations Development Program

UN United Nations

UNICEF United Nations International Children's Emergency Fund

UN Women United Nations Entity for Gender Equality and the Empowerment of Women

WB World Bank

WFFS World Forum on Food Sovereignty

WHO World Health Organization

WTO World Trade Organization 


\section{Acknowledgments}

To my Heavenly Father and my Lord Jesus Christ for Thy constant presence in my life and in the course of this research. Whenever I felt discouraged, through prayer I found the motivation and inspiration to move forward with firmness of purpose.

To my parents for their support and protection, for making me believe that I could achieve everything I proposed because I have the capacity to do it.

To Professor Dr. Hans Th.A. Bressers, his guidance and constant support made possible this study. Without his participation as my thesis director, this project would not have been successfully completed. To his wife Mieke, who welcomed me warmly.

To Dr. María Laura Franco García, who provided me with literature, food, warm clothes and a bicycle, which facilitated my transportation in the region of Twente.

To the Mayan women of the Yucatan Peninsula's countryside, who received me in their homes and inspired me through their spirit of entrepreneurship and love towards their families.

To María Francisca Poot Cahún, Rudy Rubén Chan Tuz, Nelsy Rubí Cituk Poot and Gilberto Kú Mukul, talented Mayan youth, and their mothers, who welcomed me into their homes and provided me with shelter and food while I was doing the field work related to this study.

To Sister Aurora Del Rivero Heredia and the team of Ayuda para Ayudar Foundation (APA), who inspired this research through their honest work for the benefit of Mayan women.

To my grandmothers, independent and strong women who served as rural professors, educating generation after generation of Mayan youth in the states of Yucatan and Quintana Roo in southeastern Mexico.

To my favorite uncle, Francisco Osorio Centeno, who inspired me through his work in rural areas and his fraternal relationship with the Mayan farmers.

To the Nestle Foundation, who supported me financially to develop this research, particularly to Dr. Paolo Suter.

To the University of Twente and the National Education System in Holland whose members receive and constantly support young Mexicans.

To Dr. Francisco Rosado May, indigenous leader who believed in me and gave me the opportunity to be part of his team at the Universidad Intercultural Maya de Quintana Roo.

To the Initiative 100,000 Strong in the Americas, particularly to Lee Tablewski who believed in me and supported me.

To my dear friends who gave me their love, support and company, which has been very important to me.

To the Universidad Anáhuac Mayab, an institution that gives me the academic freedom that I value so much and provided me with security in times of change, especially to my friend José Antonio Silveira Bolio, for his constant support in my professional career.

To Ms. Sandy Rae, who patiently works improving my English grammar. 
To Dr. Carlos Macias Richard whom I respect and admire, who encouraged me to continue in the academic path when I was an undergraduate student.

To Dr. Jonathan Seglow, who influenced me positively with his example of altruism, generosity and kindness.

To Dr. Cheryl De Boer who, at a time when it was difficult for me to concentrate, listened to me and helped me to move on.

To Dr. Roland Ebel, who recommended me to send my project proposal to CSTM, the Department of Governance and Technology for Sustainability at the University of Twente, for the dynamic and purposeful research developed in this graduate center, known beyond its borders.

To my students, source of joy, challenges and constant affection. Generation after generation, I hope they succeed and achieve worthy goals in their lives, it has been an honor to have served you as your teacher.

To Laika, who was by my side while I was writing this dissertation. 


\section{Chapter 1. Introduction}

\subsection{Background}

A number of Mayan women from the Yucatan Peninsula work in cooperative microbusinesses in order to provide extra family income, and in doing so, they are also promoting the development of social capital in the rural environment in which they live. This social capital helps them to confront the difficulties they must face in relation to poverty, the migration of their husbands and sons due to labor reasons and the gender inequalities that still persist in these indigenous communities.

Through their participation in cooperatives, Mayan women improve themselves not only economically, but also as human beings, as they discover their skills and capacities in the process, which are reinforced by community and family recognition when the cooperative is sustainable over time.

The context in which this research was carried out will be explained as follows. The Yucatan Peninsula is located in southeast Mexico, formed by the three states of Yucatan, Campeche and Quintana Roo. Mexico is a country with indigenous roots and traditions, in which more than 68 linguistic groups coexist (CDI, 2015, INEGI, 2015, UNDP, 2015), with the Yucatecan Maya being the predominant indigenous group in the region.

The main economic activities are related to the third sector ${ }^{1}$. The state of Quintana Roo is the most representative case, where a massive tourism industry has been developed with little care taken to preserve the environment for future generations and where the presence of Mayan culture is limited to the archaeological sites and to the recruitment of workers from nearby Mayan communities to perform poorly remunerated labor with strenuous workdays.

Agriculture, a traditional activity of the Mayan people, provides them with basic food; however, the application of pesticides, herbicides and fertilizers to forcefully increase the productivity of the land, has reduced the harvest over the years due to impoverishment of the soil (Altieri, 2009).

The low levels of education in these indigenous rural communities do not allow them to compete fairly in the labor market, especially for adult women, most of whom have not completed primary education. Due to this situation, the Mexican government has implemented several governmental programs for the promotion of education through the National Institute for Adult Education (INEA), the National Council for Educational Development (CONAFE) and various actions of the Secretariat of Public Education (SEP) through the General Directorate of Indigenous Education (DGEI) and the General Coordination of Intercultural and Bilingual Education (CGEIB), among others.

\footnotetext{
${ }^{1}$ The third sector of the economy in Mexico is associated to services and businesses.
} 
Due to the aspects described above, job opportunities in rural communities are almost nonexistent, forcing the inhabitants to move to urban centers, which leads to the gradual loss of their rites, customs and traditions, mostly practiced in groups in their communities (González, 2008, Collí, 2014, Mijangos-Noh, Cardos-Dzul, 2011).

Mayan women, if they choose to move to the cities, are usually hired as domestic servants (Burgos \& Osorio, 2017), which offers only low wages, low expectations of professional advancement and the consequential separation from their family.

In this context, cooperatives are one way to supplement family income without abandoning their homes and traditions. In Mexico, 32.2\% of indigenous women work independently (INEGI, 2016), giving them flexibility in the workplace, since these activities are carried out in their communities with schedules that allow them to be close to their families.

According to the National Council for the Evaluation of Social Development Policy (CONEVAL), seven out of ten indigenous language speakers are living in poverty (CONEVAL, 2015), taking into account that indigenous identity in Mexico is related to the use of indigenous language (CDI, 2017). In view of this, cooperatives are an alternative in the fight against poverty and have been promoted and supported at international meetings, such as the Economic Commission for Latin America and the Caribbean (ECLAC), the InterAmerican Development Bank (IDB), and the International Labor Organization (ILO) (Dureyttere, 2003, Lerner, 1996, Díaz, 2006).

In Mexico, the National Development Plan 2013-2018, a document that serves as a guideline from the federal government, promotes greater profitability of microenterprises and the participation of women in economic activities in the country (PND, 2013).

These initiatives have been promoted in the southeastern region of Mexico with the support of the Mexican government through various secretariats and institutions, such as the National Commission for the Development of Indigenous Peoples (CDI), National Institute of Social Economy (INAES), Secretariat of Social Development (SEDESOL), Secretariat of Agriculture, Livestock, Rural Development, Fisheries and Food (SAGARPA) among others, with the support of religious and community leaders and international organizations.

Due to the importance of cooperatives in this study, as an organization with characteristics of social innovation ${ }^{2}$ that promotes the development of women living in indigenous communities, a historical review of the cooperative movement is presented as follows.

\footnotetext{
${ }^{2}$ Social innovation is defined as processes of social change and the transformation of society as a whole. This includes the extensive literature on the role of civil society in social change and the role of the social economy and social entrepreneurs in delivering economic growth and social inclusion (Caulier-Grice, Davies, Patrick, \& Norman, 2012).
} 


\subsubsection{Historical Antecedents of Cooperativism}

Although indigenous Maya populations are traditionally organized in a communal way, following their ancestral customs to provide for the general welfare (Coque, 2005), firstly an historical review will be made in reference to European cooperative movements and their influence in Latin America and subsequently in the Mayan region.

In Europe, the Industrial Revolution brought great advances to humanity, but also meant an increase in working hours because this new system of production raised the levels of wellbeing and comfort for the privileged classes, often at the expense of the working classes.

As a response, in Western Europe, a movement emerged that privileged the human being over capital, where the surplus of production was fairly distributed among the participants and did not allow accumulation on the basis of exploitation. The main authors associated with these values are known as social utopians and among them were Robert Owen (17711858), William King (1786-1865), Charles Fourier (1772-1837), Philippe Buchez (17961865 and Louis Blanc (1812-1882). They proposed an alternative system to the liberalism of the time, where the human being was perfected through collective work, which was carried out in a participatory and democratic way to meet the specific needs and interests of workers.

Examples of these early associative models were developed in England in the year 1760 with workers who administered cereal mills on a cooperative basis, in 1769, with the Fenwick spinners' cooperative and in 1795, with the Oldham Cooperative Supply Company (Culti, 2002).

The most representative example of this movement was the cooperative formed in 1844 in England by Rochdale spinners in Manchester, also known as the Rochdale Pioneers, who associated themselves not only in response to the environment of industrial exploitation, but also in relation to moral principles relating to work behavior.

The cooperative movement transcended in the rest of Europe, with the creation of labor cooperatives in France and credit cooperatives in Germany and Italy, subsequently influencing Latin American thinkers, where cooperative experiences had been present since 1610, promoted by the Jesuit order or Company of Jesus of the Catholic Church, with the purpose of fostering a collective spirit, a better quality of life and general well-being through the formation of people according to Christian principles (Teixeira \& Soler, 2002).

Later, the International Cooperative Alliance (ICA) was founded in 1895 in London. This organization was created based on the cooperative principles and the experience of the Rochdale Pioneers of 1844, which include solidarity, equality, participation, democratic administration, honesty, the primacy of work against capital, among the most outstanding principles (ICA, 2017).

In the historical review of cooperatives, the presence of cooperatives in Spain during the Republic was next to ideology-driven also a way to foster social utility. The creation of cooperatives was an expression of the culture, beliefs and values of social groups and their necessities as community (Alonso, 1991, Reventos, 1960). 
Even the United States has experience with cooperatives. For instance, Alabama's 23 rural electric cooperatives deliver power to more than one million people, or one-fourth of the state's population. The examples given above are thus by no means exhaustive.

The benefits of cooperativism have been the subject of many debates among thinkers, philosophers and economists. From the economists' perspective, John Stuart Mill, Marshall, Pareto and Walras emphasize economic efficiency and increased productivity through cooperative work. Other economists instead focused on the implications for distributive justice. Their claim was that cooperation, by supporting the economic and moral progress of the socially disadvantaged, contributes to the progress of society as a whole, not just the advancement of the social groups concerned (Mori, 2014: 332).

There has also been experiences with cooperatives in many developing countries. For example in Latin America, after the First and Second World War, cooperativism had two main influences, on the one hand, socialist ideology related to cooperativism with trade unionism and workers' associations as a means of resistance to the authoritarian governments present in the region, movements which were mainly driven by the working class.

On the other hand, cooperativism was also propagated by the US government through international programs as a mean of counteracting socialist movements, examples of which are the actions of the Alliance for Progress and the Inter-American Foundation (FIA), whose programs have been present in Latin America for several decades (Teixieira \& Soler, 2002, Díaz, 2006).

At the present time, in countries such as Denmark, the Netherlands, Germany and Sweden, cooperatives occupy an important place in the production of energy, agriculture and commerce in the European community, creating networks of cooperatives also known as cooperatives of second degree, which makes them more competitive in the international market (Gómez, 2004). Latin America has benefited from this, given that it has received support from European governments and NGO's from Germany, Switzerland, Italy and the Netherlands, who finance projects to transfer knowledge in the cooperative field (Gemelli, 2008).

\subsubsection{The cooperative as an innovative organization}

According to the guidelines established by the International Cooperative Alliance (ICA), these are the principles and values of the cooperatives established in 1995:

- Democratic control of members

- Economic participation of members

- Autonomy and independence

- Education, training and information

- Cooperation between cooperatives

- Commitment to the community 
The figure of the cooperative is defined as an autonomous association of persons who have been united voluntarily to meet their common economic, social and cultural goals in the figure of a democratically controlled company (ICA, 2016).

In addition, cooperatives are organizations that promote the economic development of the participants, the local development of communities and the social development of the human being, promoting social inclusion, acquisition of new knowledge and creation of contact networks (Da Silva \& Salanek, 2009).

The importance of cooperatives in relation to social innovation is their contribution to the regional development of communities and to the social development of participants by the organizational structure.

Innovation aspects of the organization are present in the flexibility of schedules, in the horizontal communication between the participants, favoring a consensual decision-making. This organization encourages the participation of rural society in economic processes as it offers the availability of an honest income which is not easily accessible by other means in these communities, using the resources available to them, which in turn favors resilience.

Given the neoliberal economic model established in Mexico, which fosters the concentration of income in a few people belonging to privileged classes, as well as inequality and social exclusion (Espadas, 2015), cooperatives are a real alternative for the development of these communities using commercial practices based on cooperation rather than competition (Culti, 2002).

These commercial practices are related to traditions present in the Maya culture of these communities, strengthening community social ties, taking into account that unfulfilled needs favor social organization. Although other forms of social organizations exist, in this dissertation only the forms of associative organization that were actually found during field research will be discussed.

\subsection{Research problem and research questions}

As we have described in the previous sections, cooperatives are seen by several authors as a potential means to answer the social problems that must be faced in these rural communities; however, there is still insufficient information regarding when and under what circumstances cooperatives can fulfil that function. The existence of numerous local, national, and international support programs shows that there are resources available for the target population; however, according to the national average, the operational period of a microbusiness in Mexico is only 5.9 years (INEGI, 2015).

What happens then? International commitments exist, national and local governments have made resources available to the population through productive programs; nonetheless, microbusiness cooperatives are not always sustainable in the market. 
The overarching research problem can be formulated in the following main question for this research: What factors support or restrict the contribution of cooperatives to the improvement of the development of Maya women on the Yucatan peninsula and their families? This question leads the attention not only to the mere capacity of the cooperatives to endure, even though this is a necessary condition for further beneficial effects, but also to the factors that support the cooperatives to increase aspects like food sovereignty, economic security, responsible environmental behaviour and self-esteem.

For the functioning of the cooperatives we discern various relevant levels: the individual participants, the organization of the cooperative, the national support schemes, and the international support schemes. Lastly, we will compare the contribution of cooperatives to food sovereignty and other assets with women that are equally economically active, but not within the framework of a cooperative.

A figure has been developed to show the following chapters of the dissertation: motivation of the participants, elements of success that favour the sustainability of cooperatives over time, analysis of the implementation of a Mexican and a Canadian program, the contribution of women's participation in cooperatives to their food sovereignty and the interrelation in the personal level of the participants, organizational level and community level.

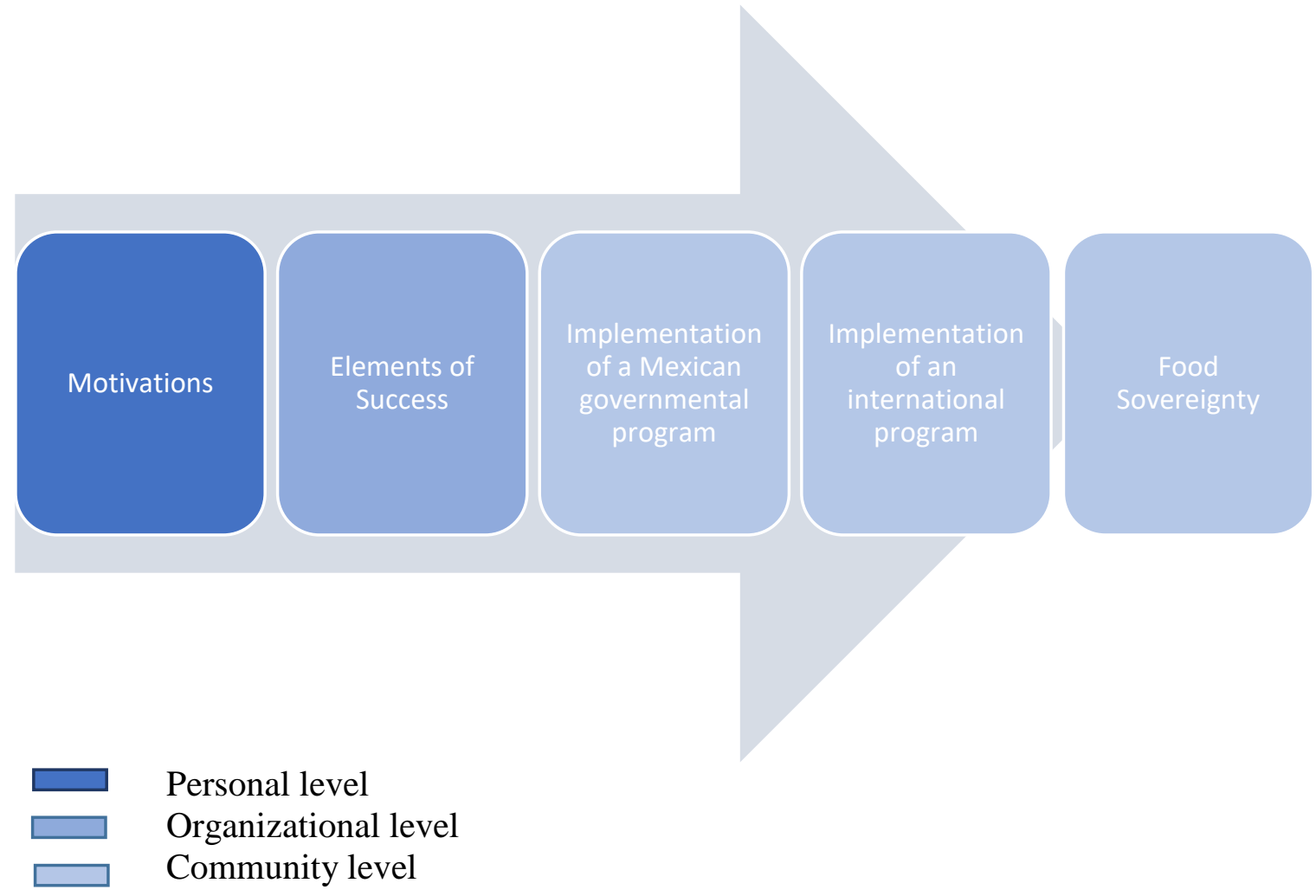

Figure 1.1 Structure of the dissertation. Source: Main author, 2017. 
Each of the chapters is geared towards answering a question that can be regarded as subquestions of our main research question. These will be explained in the last section of the chapter.

\subsection{Theoretical perspectives}

This study draws from many bodies of literature. While each of the chapters has an own edge to study the subject of the thesis, there is not one single or composed theoretical framework that has guided all studies. This section gives an overview of all the strands of theory that played a role in this research. Some are mostly sources of inspiration at the basis of this research, for instance influencing the choice of factors that one or more of the studies focuses on. Others are put into use in a more instrumental way, for instance as a model of explanation in one or more of the chapters. In each case, we will not only briefly explain the theory or approach, but also where and how we used it in our studies.

During this research it was observed that the cooperatives are dependent on complex interactions between governmental representatives, organizations and local agents. Because of that it was necessary to look at different theoretical approaches to find alternative routes to understand better their context and thus, possible solutions. The literature reviewed related to organizational development, economics, gender and even psychology, which applied to different stages and aspects of the microbusiness cooperatives. In the rest of the section this results in a discussion of complementary concepts and theories that have inspired the studies in this dissertation and their contribution to the development of this investigation.

\subsubsection{Theory of Social Capital}

In this research, Bourdieu's concept of social capital was used as a departure point to explain the social interactions observed in the Mayan communities. Bourdieu defined social capital as a network of people who contribute to inclusive social development (1997). Additionally, because of the characteristics found among the inhabitants, contributions of other authors were integrated. Putnam defines social capital as networks, norms of social trust, which facilitate coordination and cooperation to create reciprocal advantage (2000). Coleman, in turn, establishes that social capital is an important resource mainly for non-elites and classifies social capital as productive, making it possible to reach goals that would be unattainable if social capital did not exist (1988).

Accordingly, Ostrom and Ahn establish social capital as norms of reciprocity, networks and forms of civil participation and rules or institutions both formal and informal (2003). Rojas complements by stating that social capital can generate economic benefits by acquiring social skills and responsibilities through the connections and networks of people (2013).

Social capital promotes the socioeconomic development of the regions (Gelauff, 2003), through the formation of networks of people who interact socially to satisfy common needs for the participants. 
This capacity for social organization allows the resolution of present difficulties in these Mayan communities arising from their remote location, the lack of available services, and the poverty in which they live. For example, it can be of help in the transportation of the sick to health facilities and in the procurement of food and basic goods in times of natural disasters, such as droughts, forest fires and hurricanes, common in the region.

These networks of people are supported by values such as trust, collaboration and solidarity, which can become an important competitive advantage within organizations (Bakaikoa, Begiristain, Errasti \& Goikoetxea, 2004).

An additional factor for creating such feelings of union is sharing characteristics and a common background, which in this case are the Mayan culture, mainly the language, the rural environment, the socioeconomic level and the needs shared by the inhabitants.

These characteristics reinforce social capital, since the needs strengthen the reliance on support systems which favors in turn the creation of groups, associations and cooperatives. The organizational experiences that emerge from the excluded or the poorest constitute a real initiative in development with the available resources in the unfavorable conditions in which they live (Culti, 2002).

The influence of this theory is further elaborated throughout this dissertation as a way to explain how social capital works in favor of the women who participate in these entrepreneurial initiatives which beneficial effects were deployed, not only among them but also within their community, the urban centers and in some cases abroad.

\subsubsection{Social Economy Theory}

Social Economy was used as the main theoretical framework in this research and it was applied in the following chapters to explain economic alternatives to vulnerable sectors of society, such as indigenous people, women, people with different capacities, the elderly, etc. (Lavilla, 2004). Social Economy and Social Capital are interrelated. Both demonstrate the importance of alternative forms of organizations in marginalized populations. Social Economy recognizes the figure of cooperatives as the most representative form of social organization, not based on excessive profit but on satisfying the needs of the participants through the formation of networks and working groups (Villegas, Ortubia \& Lillo, 2011). In addition, social capital recognizes the networks of support created as a result of common needs which are reinforced when women spend additional time together sharing the workload in a cooperative.

Social Economy studies the relationship between economy and social behavior. It analyzes how the human being is influenced by morals, ethics, and other humanitarian philosophies. Social Economy promotes the creation of a strong, sustainable, prosperous, and inclusive society (Sampedro, 2009, Felber, 2012). It also investigates the economic viability of cooperatives and the value of non-profit organizations (Monzon 2003, Monzon \& Defourny, 1993, Bastidas \& Richer, 2001). 
Social economy is a critique of utilitarianism and unlimited consumerism of the population which will destroy the planet's natural resources. It is known as Social Economy in Europe or Solidarity Economy in Latin America (Coque, 2005). This theory became more popular through the support of nongovernmental organizations as a response to the neoliberal opening of markets in the 1980s. Social Economy, through cooperativism, promoted community solidarity and networks of support defined as social capital in response to the advances of the capitalist system in the region, which led to a crisis of unemployment, widening disparities in income and deepening poverty.

Good Living (Buen Vivir in Spanish), is an indigenous perspective that influenced social economy and includes environmental and spiritual aspects in the economy. It is known as Good Living in Ecuador, Living Well or Suma Qamaña in Aymara language in Bolivia, or Sumak Kawsay in the Kichwa language of Ecuador and means living fully (Langlois, 2016). Buen Vivir emphasizes how the economy needs to be inclusive and consistent with community values (Leon, 2009, Guillen \& Phelan, 2012, Acosta \& Martinez, 2009, Cienfuegos \& Sanahja, 2010, Correa, 2005). Buen Vivir is an indigenous notion of life based on ethical and spiritual codes of conduct between human beings and nature, maintaining a vision for the welfare of future generations.

Both in Ecuador (2008) and in Bolivia (2009) indigenous knowledge has been taken as the basis of development in its constitutions, contradicting the model of economic growth that is based on the excessive exploitation of natural resources, proposing instead cooperation among workers.

Because of its components, this theory was inspiring to pay attention to the practices of sharing, bartering and cooperation over competition, behaviors found in indigenous groups to overcome poverty and rural isolation.

\subsubsection{Gender Theories}

The gender perspective of this research was based on the role congruity theory proposed by Eagly and Karau (2002) as a reflection of the affirmation that both men and women have preestablished roles in society and therefore economic activities in which they should be involved. This theory was used to demonstrate the barriers Maya women had to overcome in order to be successful in their microbusiness cooperatives.

Elements of feminist economics were also taken in consideration, where capitalism is related to the feminization of poverty, taking into account variables such as the amount of work carried out by women at home - in the private sphere - and their relation to the patriarchal system understood as the social system based on relationships of domination of men over women (Perea, 2014).

Therefore, gender theories were used to understand the power relations between men and women in this region, specific those living in indigenous communities, where patriarchal structures are strongly rooted and the will of the woman has been generationally subject to the will of a male figure. References to gender concepts are mentioned in the following 
chapters to understand the social context in which these women develop their microbusinesscooperatives.

\subsubsection{The Concept of Self-reliance}

This research work mentions the concept of self-reliance, highlighting the importance that every human being should strive to be self-reliant in all aspects of life. This applies to Maya women, since if a woman provides for herself, she is more likely to help those around her and also influence her children in this behavior. When a woman has not reached this level of development as a human being, her vulnerability can produce dependence. This concept was applied throughout in this dissertation as an aspirational goal that these women are achieving through entrepreneurship to gain a certain degree of independence within their households and communities.

This is shown theoretically with the contributions of Abraham Maslow (1943) in his hierarchy of needs related to the theory of human motivation. He mentioned the development of the human being in five different stages, ranging from the physiological needs where food is included, the safety needs where income and employment are present, belonging needs including friendship and fellowship, esteem needs, including self-recognition, trust, respect and success, and self-actualization needs.

In addition, self-reliance also moves into the scope of public programs. In Mexico, there is a predisposition to create dependence on public programs among the population, thereby creating a weak and impoverished society, especially in rural areas (López-Torres, VargasHernández, 2005). This dependent attitude affects the freedom and creativity of the human being. An alternative is to evolve into solidarity societies promoted by cooperatives since these organizations promote economic growth with solidarity among the participants (Pavia, 2013).

\subsubsection{Circular Economy}

Another theoretical approach that forms a background for this research is Circular Economy which involves sustainability elements (World Economic Forum, 2014). The theory of circular economy implies a new way of producing goods and a way of doing business with innovative organizations as cooperatives as discussed in chapter two.

The characteristic of this approach is that it seeks the growth of the economy based on environmental sustainability, reducing the use of resources and the production of waste, while limiting the consumption of energy.

It includes organizations belonging to the social economy and promotes the creation of innovative businesses such as cooperatives, mainly because of their orientation based on ownership, where the payment structure is determined by contribution to the work rather than profit maximization for owners (Ellen MacArthur Foundation, 2013). 


\subsubsection{Social Learning Theory}

The theory of social learning is mentioned in relation to the figure of ethical leadership and the positive influence it may have on an organization. Mexico, as a country, faces serious problems of corruption in society, which has permeated in business, this investigation demonstrates that alternative approaches to this situation are not only possible, but greatly needed.

Through the Social Learning Theory proposed by Bandura (1977) it is shown that the behavior of the human being can be molded by observations of good examples and can also be self-regulating in order to adapt socially to his or her reference group. In the case of cooperatives, having an ethical leadership, conducted with honesty, has a positive influence on the organization and can even improve the economic performance of the micro-business. This theory was utilized in chapter three to discuss the influence of positive role models to enhance honest behaviors among the participants.

\subsubsection{Contextual Interaction Theory}

At the beginning of this research, it was necessary to define a frame of reference to analyze the process of the implementation of national and international funds that support Maya women's cooperatives in the Yucatan Peninsula. Contextual Interaction Theory (CIT) was chosen, since it emphasizes that implementing public policies and programs is a process of social interactions, an important factor to take into account in order to determinate the degree of success. CIT explains these interactions using the motivations, cognitions and resources of the participating actors.

In Contextual Interaction Theory, motivations drive the actors' actions; cognitions represent the subjective knowledge held to be true and resources provide the actors with the capacity to act and with power over other actors (Bressers, 2004).

This model also considers the economic, political, cultural and technological environment where social interactions are taking place. For a graphic explanation of the above mentioned, the following figure is presented: 


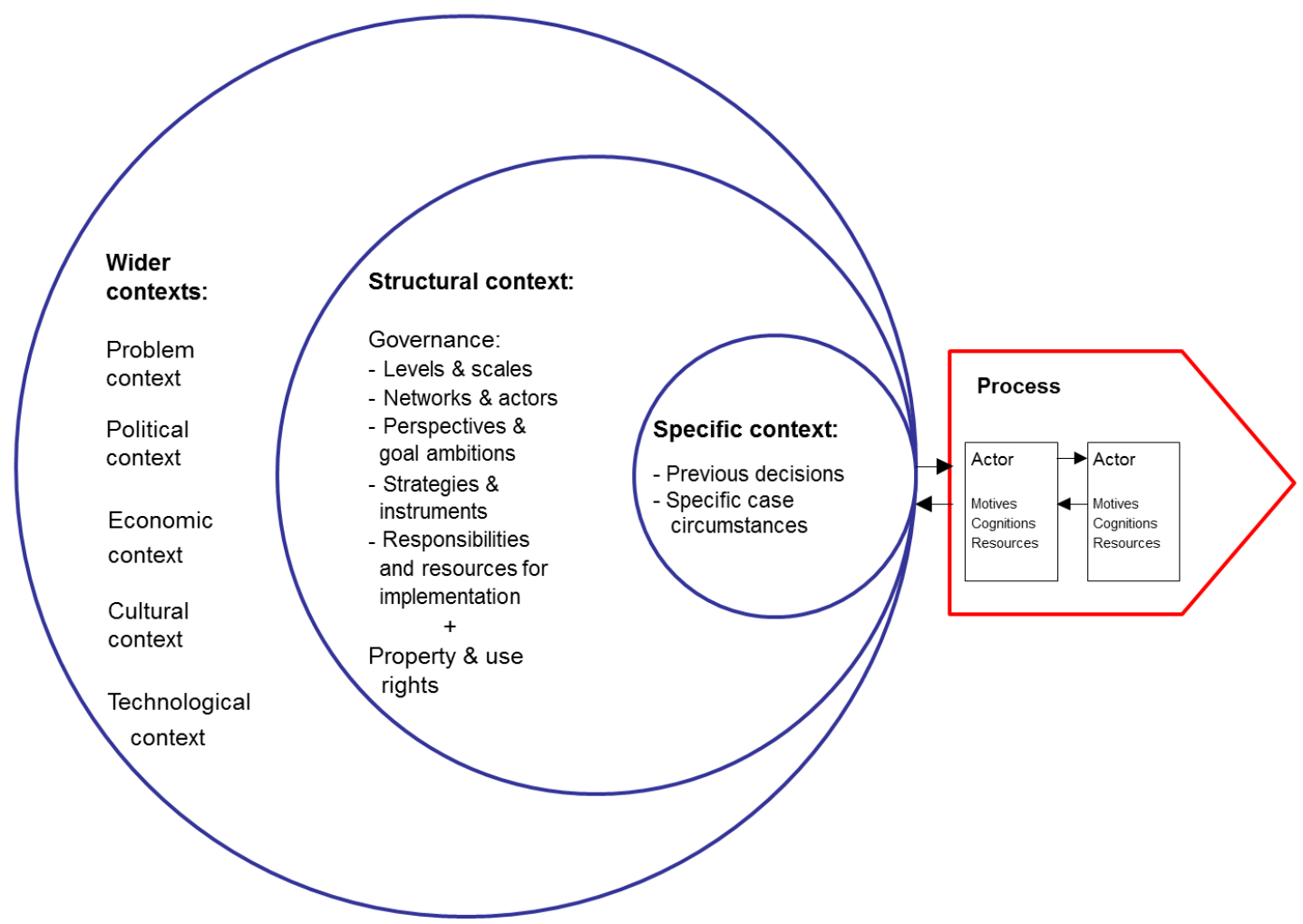

Figure 1.2 Layered contexts for interaction processes.

Source: Bressers, 2004.

Because this study has predominantly social characteristics, CIT facilitated the interpretation of the results specifically in chapter four and five related to the implementation of support programs in the region. It is in these social interactions where it could be explained why certain people or institutions favor cooperation, obstruction or opposition in the implementation process.

\subsubsection{Theories of bounded rationality}

Theories of bounded rationality (Simon, 1979) were related in this research to the available information Maya women have in their decision-making process. Simon, in his contributions to organizational theory, explained decision-making and problem-solving processes and their implications for social organizations.

Classic economic theories state that human beings make decisions to maximize their utility. Simon in his theory of bounded rationality mentions that the human being only possesses information within limited boundaries. This leads to a rational choice given the information that is available, which reaches certain levels of rational satisfaction.

This theory was applied in chapter four to explain the barriers Maya women face to make decisions in their economic activities based in the uneven distribution of information among the population combined with language barriers in these Maya communities. 


\subsubsection{International Relations Theories}

Approaches to international relations have had different theoretical frameworks to explain international events, which are formulated in relation to the historical context of the development of ideas regarding the relationship between international affairs and humanity. In this study three main currents of thoughts are mentioned: idealism, realism and the theory of interdependence.

The idealistic stage of humanity inspired the creation of the League of Nations in 1919. It was based on diplomacy as a means of conflict resolution to ensure international order and peace. It was in favor of the eradication of war as an instrument of state policy and of establishing a global system of collective security capable of avoiding future strife (Wilson, 1918). The aim of international relations under this ideology was the pursuit of peace and prosperity as a common interest of all countries (Del Arenal, 1984).

The outbreak of the world wars prompted the rise of political realism to the detriment of idealism. Realism defines the national interest in terms of power which is related to state security. Countries are in constant competition and their main instruments to retain peace are militia, armament and fear (Morgenthau, 1948). The Cold War illustrated this form of peace by mutual deterrence.

The theory of interdependence proposed by Keahone \& Nye (1988) seeks a middle ground and defines international relations as contacts, coalitions and interactions beyond nation states. It recognizes the role of independent actors such as non-governmental organizations, civil society and grassroots groups.

Furthermore, it establishes symmetrical and asymmetric relations between international powers, the latter being the most frequent in the global sphere. This theory favors cooperative relations and the idea of the community of interests considering existing inequalities in international relations (Del Arenal, 1984). The relevance of these theories for this research is related to the international support program that is studied in Chapter five. Because of the nature of this research, Official Development Assistance (ODA) is mentioned in reference to international relations theories but with emphasis on the theory of interdependence in Chapter five. There is serves as a way to understand the use of foreign aid to foster women empowerment in Maya communities from the donor country's perspective.

\subsubsection{Critical Consciousness Theory}

Critical Consciousness Theory, from the educator Paulo Freire (1974), formulated his contributions on the basis of his experience in the literacy process of marginalized populations in Brazil. Freire describes the process in which the human being is valued as a person, which promotes his or her development.

Freire, in his theoretical approach, affirms that sometimes the intervention of progressive leaders is necessary, in this study manifested in the form of ethical leadership. These inspirational leaders give impulse to the rediscovery of the value of the human being (Freire, 
1993). In this process, marginalized populations recognize themselves as productive members of society, envisioning a better future, which sustains hope for a better life, encouraging their personal improvement when living in difficult conditions.

These community leaders, who support this process, are characterized by their commitment and attitude towards overcoming social injustices. The process of human development that occurs in women who undertake their micro-businesses is explained by Critical Consciousness Theory. This theory was of particular importance in chapter six, to understand the dialogue with other women where the recognition of their own value emerges and extends from the internal to the external aspects of their lives, from the person to the organization and the community.

\subsubsection{Theoretical advances of the self-respect concept}

Similarly, the theoretical contributions of Dr. Jonathan Seglow on the concept of self-respect (2016) mentioned in chapter six, are also considered, based on thinkers such as John Rawls (1999), Axel Honneth (1995), Robin Dillon (1997) regarding social justice and human rights. This approach contributes to the alleviation of the social and economic disadvantages suffered by minorities, which in this case would be Maya women.

The concept of self-respect is understood as the dignity that all human beings have inherently. Based on moral reasons, Professor Seglow explains why it is necessary to respect oneself as this in turn influences how we relate to others.

Among Maya women there are still injustices, mistreatment and disrespect, associated with the discrimination they suffer outside their communities due to their ethnic origin and social class, and also as women in their homes. Sexism and misogyny exist inside their families due to the patriarchal system present in these rural communities. These abusive behaviors diminish when the women find themselves as income producers in their micro-businesses, which fosters self-respect and women's empowerment (Abu Jaber, 2014). These aspects will be broadly discussed throughout the dissertation.

\subsection{Methodological approach}

In the following section, the methodological approach used and the research tools applied in this dissertation will be explained.

\subsubsection{Qualitative Methodology of Social Research}

The various forms of qualitative methodology can be used in research on people's lives, lived experiences, behaviors, emotions and feelings, as well as to understand organizational functioning, social movements, cultural phenomena and interaction between nations (Strauss \& Corbin, 1998: 20).

Due to the characteristics of the population as subject of our research, it was decided to use the qualitative methodology of social research with a participatory approach, since it was essential that the development of this study be based on the experience of the women who 
initiate their micro-businesses in order to analyze its context, rural communities, indigenous' population, national and international productive programs, of which they have been beneficiaries, as well as family structure and gender relations from an inductive perspective. The authors of reference of this methodology as used in this study are Tarrés (2014) Creswell (1998), Denzin \& Lincoln (2000) and Hernández, Fernández \& Baptista (2007).

The research activities were carried out with the participation of nine cooperatives located in Mayan communities where access to internet and telephone services was limited, since these conditions favor the preservation of their language and traditions; however, these conditions also have an impact on the level of information available to the population for their decisionmaking processes.

The use of translators was essential for this study, since the women mostly speak the Mayan language. The translators who participated have strong bonds with the communities. Before the interview process a brief meeting was held with the translators, where the design and application of the questionnaires was explained. Generally, the interview process was carried out at home while the interviewees were working, which allowed the author to observe the context while conducting semi-structured and in-depth interviews with the participants.

The qualitative methodology of social research with a participatory approach allowed a rapprochement with the community as it favored a dialogue to understand the problems faced by rural populations, which has a decisive role in working with communities in the subsequent development of self-esteem, systematizing and re-evaluating the local experience and knowledge of the participants (Geilfus, 2002: 4).

Taking into account that a population or universe is all the cases that agree with a series of specifications, the sample is usually defined as a subgroup of the population (Hernández et al., 2007). In this research, the sample selection procedure to investigate the motivations of the participants, the elements of success in cooperatives of Mayan women and the analysis of the productive program of Mexican origin (POPMI) was based on a list of cooperatives, from which the elements of the population were randomly selected. The procedure of case selection is explained in each of these chapters.

The implementation of international support programs was analyzed through a single case study. In this support scheme of Canadian origin (CFLI) only one cooperative had participated. The single case study, as part of the qualitative methodology of social research, still allowed us to identify important elements that could contribute to the advances of research in specific subjects.

The implementation process of the Mexican program (POPMI) and the Canadian program (CFLI), was analyzed using the Contextual Interaction Theory (CIT). CIT was applied in order to understand the background of actor characteristics, the interaction between policy implementers and participants and the interaction among the participants themselves, all the processes contribute to the analysis of both productive programs.

As regards to food sovereignty, quantitative methodology complemented the qualitative approach using a questionnaire with a Likert scale, which was applied to measure levels of 
food sovereignty. The questionnaire was applied to 24 women who work in cooperatives and was also used with 24 women who work alone and are not associated in cooperatives. The sample was drawn from a population classified as economically active female population from a list provided by the National Institute of Statistics and Geography (INEGI), an institute that provides data and indicators of the Mexican population for official and academic use.

The women were interviewed as voluntary participants, usually in the afternoon in their homes or at their point of sale. This information was complemented with information from in-depth interviews and observations relating to the economic and social effects that Maya women experienced in relation to starting their own business through associative work.

This part of the research provided an understanding of the additional benefits that cooperativism gives to entrepreneurship and food sovereignty, creating support systems which are consolidated when working with other Maya women.

Various sources of information, including interviews, observations and documentary review, were identified as primary sources of information in qualitative methodology (Patton, 2002). The interviews were open and semi-structured, dealing with the participants' experience, their perceptions, opinions, feelings and knowledge. The information consisted of statements or quotations. Observations consisted in describing activities, behaviors, actions, conversations, interpersonal and organizational interactions, community processes, traditions, or any other observable aspect of their way of life during fieldwork.

Bibliographic review and desk research were carried out on national and international programs working in favor of indigenous populations in Mexico, mainly involving women. In addition, an analysis of economic indicators, education, religion, entrepreneurship, marital status and migration was carried out.

The qualitative methodology of social research allowed the interviewees to share their experiences on a personal, family and organizational level within the cooperatives and in the community before and after their involvement in entrepreneurship activities.

Additionally, biographical and ethnographic methods were used as tools that strengthen the qualitative methodology of social research (Creswell, 1998: 79). Ethnography allowed the analysis of the particularities of the human groups by means of observation and recording of daily activities (Alvarez \& Gálvez, 2014). Moreover, this method which is mostly used in anthropological studies (Patton, 2002), allows the researcher to interact with indigenous populations to collect information about their way of life through observation and, together with the life history of the individuals, can help to understand the community context in a more integrated way.

\subsubsection{School of thought advocacy/participatory}

This research is part of the school of thought on advocacy / participatory research described by Creswell (2003), which is characterized by its collaborative, political, empowerment and 
social change-making orientation, which mostly uses qualitative methodology (Patton, 2002).

The school of thought for advocacy/participatory research initiated between 1980 and 1990 given that the social environment and the theories developed until then did not have a proposal to work in favor of social justice. Among its main exponents, Freire can be found with his Critical Consciousness Theory, as explained before. Other exponents are Fay (1987), Heron and Reason (1997), and Kemmis and Wilkinson (1998), who proposed the participation of grassroots groups in research, not as spectators but as protagonists.

Empowerment, inequality, oppression, domination, suppression, and alienation are the subjects related to this current of thought. It recommends working with the target population in a participatory way, from the perspective of the marginalized classes. It integrates feminist perspectives and critical theories that help the human being to transcend the constraints placed on them by race, class, and gender.

The school of thought on advocacy / participatory research is focused on research that serves to create a social change which helps human beings to have better living conditions, to overcome personal limitations and norms of society in order to attain their self-development and self-determination. Consequently, the information from this research will be made available to the organizations who contribute to the welfare of indigenous women.

\subsection{Outline of the thesis}

The following chapters were developed with the support of farmer women, educators, indigenous students, representatives of national and international organizations, with the participation of the public and private sector. It is organized in chapters, the contents of which are summarized as follows:

Chapter two will address the motivations of Mayan women to start a micro-business cooperative with the following research question: What are the actual motivations of Maya women in the Yucatan Peninsula to participate in the development and exploitation of cooperative micro-businesses? Although the reasons motivating them could be related to material needs such as obtaining an alternative source of income, as this chapter will show, their motivations go beyond the economic reasons and are more related to the well-being of their family. This illustrates a natural tendency of Maya women towards the protection of their children and dependents.

From the beginning, most of the women were receptive to the research visits and our interest in their motivations, their family and community context. The interviews were held in their homes mostly while they were working, with their family around listening to the conversation with interest. This part of the study was important to determine the thematic and sequence of the subsequent chapters, developed in a sequence from a personal and intrinsic level such as the motivations to start their microbusinesses, to an organizational level and thereafter a community level.

Chapter three will analyze the elements of success that lead to the sustainability of Mayan cooperatives in rural communities in the Yucatan Peninsula with the following research 
question: Which are the key elements found in the cooperatives selected as subjects of this study that promote success? This research was carried out through three case studies. The objective in the development of this chapter of the dissertation was to identify elements that could be replicated in other cooperatives formed by Maya women in similar contexts to ensure their sustainability in the market.

Visiting several Mayan communities to determine which microbusiness cooperatives should be selected for the development of this research, helped to verify the presence of key elements in cooperatives that were sustainable over time. Based on empirical evidence it was found that the concept of success in these initiatives is not only related to the necessary condition of endurance, but also to its contribution to food sovereignty, environmental responsibility and gender empowerment.

In the final stage of this investigation, it was confirmed that the three cases mentioned in this chapter were still operating despite having experienced various difficulties over the years.

In Chapter four, the implementation of the Program of Productive Organization for Indigenous Women (POPMI) was evaluated in cooperatives formed by rural Mayan women through the following research question: What aspects in the implementation process of the Program of Productive Organization for Indigenous Women (POPMI) for the Mayan population of the Yucatan Peninsula hampered its contribution to its stated goal, which was to encourage self-sufficiency among the population?

POPMI was a federal program implemented by the National Commission for the Development of Indigenous Peoples (CDI) which promoted, until 2014, female entrepreneurship initiatives in the Yucatan Peninsula. The results of this research stage were developed with the help of Contextual Interaction Theory (CIT) to analyze data, emphasizing the motivations, cognitions, and resources of the women who benefited from the program.

This was perhaps the most challenging chapter for the author, some of the women talked openly about the relation between local politics and the opportunity to be beneficiary of these support programs. Most of them expressed concern that they would one day be charged for the economic support they received from the government, even though it was classified as a non-refundable fund. This part of the study was carried out during the election period of the governor in the state of Quintana Roo, which significantly agitated the social structures in the communities in which this research was conducted.

In Chapter five, using the Contextual Interaction Theory (CIT), an evaluation of the implementation of the Canada Fund for Local Initiatives (CFLI) program was developed to answer the following research question: What aspects in the implementation process of the Canada Fund for Local Initiatives for the Maya population of the Yucatan Peninsula helped or hampered its contribution to its stated goal, which was to promote sustainable economic growth and advance gender equality among the beneficiaries?

The Canadian International Development Agency (CIDA) was a Canadian federal agency which promoted, until 2013, female entrepreneurship initiatives among Maya women in the Yucatan Peninsula. One reason to carry out this analysis was to have a frame of reference to 
compare the implementation of the programs of the Mexican government with the experience of the international programs in the same region of study, developed through a program of Canadian origin.

The collection of information and the creation of networks of contacts that supported this part of the investigation were possible due to the realization of a research stay in Lakehead University, a university whose purpose is to support the educational development of First Nations in the province of Ontario in Canada. This stay broadened the understanding of the Canadian government's way of working with indigenous population, coupled with a series of visits and interviews carried out in different non-governmental organizations working in the area in favor of indigenous women.

Chapter six is an analysis of the levels of food sovereignty, including economic aspects, environmental stewardship, and self-esteem, comparing between women working in cooperatives and women who start their micro-businesses in the same context of the Mayan communities with the following research question: Does the participation in cooperatives contribute to food sovereignty among Maya women in the Yucatan Peninsula?

As it will be discussed in the chapter, the term of food sovereignty was utilized rather than food security because it includes attention for the contribution of women to economic activities, indigenous beliefs and human rights that is barely present in the concept of food security.

A comparative study was carried out between groups of 24 women who work in cooperatives and 24 women who started their own micro-business, and the contribution of these initiatives to food sovereignty ${ }^{3}$. It is important to mention the value of both efforts, as it is even more challenging to start a microbusiness alone, since it is not common in the cultural environment in which these women live. Thus, the research in this dissertation is divided into five chapters in the form of research articles, with a concluding Chapter seven, where the findings found and lessons learned during the development of this thesis will be compiled.

\footnotetext{
${ }^{3}$ Food sovereignty is understood to be the right of the people to define their own policies and sustainable strategies for food production, distribution, and consumption which guarantee the right to food access for all the population, based on small and medium-scale production, respecting their own cultures and the diversity of farming, fishing and indigenous modes in agricultural production, commercialization and management of rural areas, in which women play a fundamental role (World Forum on Food Sovereignty, 2001).
} 


\title{
Chapter 2. Motivations of Mayan women to create microbusiness-cooperatives ${ }^{4}$
}

\author{
María Cristina Osorio Vázquez ${ }^{5}$, Hans Th.A. Bressers ${ }^{6}$, María Laura Franco García \\ Cheryl De Boer \& Oscar Iván Reyes Maya ${ }^{7}$
}

\begin{abstract}
Purpose - The micro-businesses integrated by indigenous Maya women in the Yucatan Peninsula, Mexico, are an alternative source of family income which alleviates the social and economic circumstances in which they live. With a high rate of migration to the north of the Peninsula characterized by mass tourism and further north to the United States with the objective of crossing the border illegally, rural communities are inhabited by vulnerable populations: women, children and the elderly. Initially, in order to contribute to the family income, integrated by fledgling agricultural production and remittances, these women undertake micro-businesses with the main motivation of providing food and educational opportunities for their children.

Design/methodology/approach - Employing the qualitative method of social research, this paper shows their motivations to initiate these cooperatives, which generally go beyond just earning money.

Findings - The empirical evidence proved that part of their motivation is rooted in a deep system of values and traditions, rather than in a classical economic way of thinking. In the Yucatan Peninsula, most of Maya women who live in rural areas, work together in cooperatives for the preservation of customs, family integration, and sense of community in order to cope with poverty.

Originality/value - With elements of innovation in their organizations, these cooperatives follow circular economy paths as bottom-up initiatives. Networking, mutual support and trust in each other provide the social capital in these populations to make this possible. This conclusion is relevant for both (1) the design and implementation of support schemes and (2) for the internal management of the cooperatives.
\end{abstract}

Keywords Motivation-Rural-Maya-Women-Micro-businesses-Cooperatives-Social Capital Type of paper - Research paper

\footnotetext{
4 This paper has been presented at the 4th International Symposium held in EGADE Business School of Tecnologico de Monterrey (Mexico), November 11-13, 2015 and has after peer review been accepted for publication in the Management Research Review Journal.

${ }^{5}$ M.C. Osorio

School of Economics and Business

Universidad Anáhuac Mayab

e-mail: maria.osoriov@anahuac.mx

${ }^{6}$ H. Bressers, L. Franco \& Ch. De Boer

Twente Centre for Studies of Technology and Sustainable Development (CSTM)

University of Twente, The Netherlands

e-mail: j.t.a.bressers@utwente.nl

e-mail: m.l.francogarcia@utwente.nl

e-mail: c.deboer@utwente.nl

${ }^{7}$ O. Reyes

Department of Sustainable Development

Universidad Intercultural Maya de Quintana Roo, Mexico

e-mail: oscar.reyes@uimqroo.edu.mx
} 


\subsection{Introduction}

This paper is the result of a research conducted in Maya communities inhabiting the Yucatan Peninsula, Mexico. The main objective of this research is to describe the motivations of rural women to initiate rural micro-businesses formed mainly by women; for the purposes of this study these will be called "cooperatives". Cooperatives integrated by women represent a way to increase the family income; but, is this the only reason why they are choosing to participate in the cooperatives studied herein? Our study departs from the assumption that often the motives to participate are too easily restricted to the economic. Thus, this research will use an analytical approach focusing on the characteristics of women, such as their values and traditions that permeate their entrepreneurial behavior.

It is worthy of note that the women who participated in this study carry out entrepreneurial activities in their micro-businesses while continuing to perform small-scale agricultural activities. The latter represent strenuous work and very little financial compensation. Keeping in mind the unbalanced and poorly valued traditional roles within their families, "Women are the world's primary food producers, yet cultural traditions and social structures often mean women are much more affected by hunger and poverty than men" (WFP, 2015). Therefore, investigating their personal motivations is even more relevant for analysis, given the complexity of their daily life.

One of the reasons why government programs promote micro-businesses formed by women is related to the reported low productivity of the agricultural activities. Yunez-Naude and Taylor noted in 2004 that a key feature of rural households is the diversification of income. This situation is observed in rural households producing staple crops for home consumption. The development of non-agricultural activities allows them to supplement the family income. This last part has been quantified and represented as "incomes of rural households from nonagricultural activities are now a major component in the Mexican countryside, which also contribute to reducing poverty" (Ceron and Yunez, 2004: 20).

While the generation of income is undoubtedly an important part of the motivation to participate, by focusing support programs mainly on the assumption that the motives are purely economic, one runs the risk of creating ineffective incentives or even disturbing promising developments of cooperatives. In consequence, it is warranted to study the motivations in order to participate from a much wider angle, allowing for a richness of possible drivers. This is also important for a second reason: although the source of motivation is often explicitly or even implicitly assumed to be such or so, it is much rarer to allow the people to speak for themselves. In this study we tried to combine literature on factors that form a background and possible source of motivation for Maya women to engage in cooperative micro-business. With an empirical study based on interviews and meetings with the women themselves, we seek to answer the research question: "What are the actual motivations of Maya women in the Yucatan Peninsula to participate in the development and exploitation of cooperative micro-business?".

In the next section we present literature giving some insights into the economic, social and cultural circumstances that could be sources of motivations. These circumstances are often, in turn, influenced by others, such as geographical factors which may influence each other. 
This wide scope of possible sources of motivations was not used to suggest a variety of motivations in the empirical study. In fact, amid many other straightforward questions, the motivation to participate was asked as an open question. However, in the interpretation of the answers, due attention was paid to the variety of answers, rather than just seeking their (economic) common ground. The third section will further explain the methodology used. The fourth section will present the results of the empirical study and lastly, a conclusion section will answer the research question.

\subsection{Economic, social and cultural circumstances}

Some of the most relevant regional conditions where the shareholders of cooperatives live and operate their micro-businesses are in this section and are presented in order to understand their influence on the cooperative success/failure.

\subsubsection{Economic background: the pressing needs}

On average, more than half of the income of these households (rural) comes from activities outside the venue. In these activities, non-agricultural wages, income from self-employment and remittances are generally more important sources of income than the agricultural wages. (De Janvry and Sadoulet, 2004:125). The main source of income of rural Mexican households no longer comes from agricultural activities, but rather from the participation of its members in wage labor markets (Ceron and Yunez; 2004: 20). In the case of rural households, although income is determined by remuneration for regular employment $(52 \%)$, the second most important source of income are transfers $(21 \%)$ and in third place, additional income from self-employment (18.2\%). (INEGI, 2013: 11). This last statistic refers to the importance of non-agricultural work within the Mexican rural sector.

Studies on the income of rural households in the Maya region make clear the vulnerability of these families regarding their income structure since public transfers represent up to $37 \%$ of total household income. The product revenue from the sale of agricultural products is only the third most important source of income, contributing only 19\% of total revenue (Reyes and Barrera, 2014: 129). Another component that drives the creation of micro-businesses as an alternative to family income is the geographical location of these communities; a major part of the Yucatan Peninsula participates in the economic activity of tourism and with the employment generated by the hotel industry, the young generation can participate in this economic activity, which generates jobs with low qualifications, but also increases the pressure of overexploitation of natural resources (Balam, 2010). Thus, the rural communities consist primarily of women, children and the elderly, many of them without formal education (Pech, 2012). It is only logical therefore that a population with low educational levels will have difficulties in obtaining a decent income. The high cost of living and, more recently, the economic recession has increased the need for women to contribute to the household income. This situation is exacerbated in single-parent families or those with an absent father (Nwagbara and Babatunde, 2012: 39).

In this regard, the precarious situation and the feeling of being abandoned explain the accentuation of collective strategies to confront difficulties (Bastidas and Richer, 2001:16). These micro-businesses have the basic elements of social economy theory which consist of 
autonomous organizations, free of any direct control of the state or a private company; which receive public funding or funding from private companies and have management autonomy (Bastidas and Richer, 2001:9). Embarking on a micro-business means an income option for women and, when the financial support comes from government programs, this represents a low, financial risk since, in the case of failure of the venture, the resource is considered lost, without the possibility or obligation for repayment.

Many women are involved in income generating activities outside the home; these include selling products at local markets or in urban markets, if they are sufficiently close to urban areas or if there is transportation available. (Fonchingong, 1999: 75). Jarosz (2011) found that the women involved in agricultural production mentioned, among their motivations, to be able to supply for themselves and others. However, the author also mentions: "It is clear that for these women, social relationships are more important than making money through their farming practices" (Jarosz, 2011: 307). Moreover, as Pinheiro (1985) mentioned, the involvement in productive activities produces in women new sources of self-esteem. They develop positively by the achievements they attain in search of success, as opposed to passivity, no longer as a mere spectator, they become protagonists. These women are also breaking with ancestral cultural responsibilities that, since pre-hispanic times, determine the role of women in subordination to the head of household (Ruz, 2011). In the aforementioned study, therefore, it is not the money as such that motivates women entrepreneurs in the rural areas studied, but rather being able to supplement the family income which is linked to their own welfare. This brings us to other sources of motivation that we have gathered under the aspects of social and cultural backgrounds.

\subsubsection{Social background: the concept of social capital}

As a further alternative to family income, people in the community, usually linked by family ties, integrate micro-businesses. The concept of "social capital" has been taken as an explanatory basis for the functioning of these cooperatives, as we can recognize in this an element which not only reduces poverty, but also improves living standards and even contributes to regional development, despite this globalized world context that could propel society to forget their ties to their community. The concept of "social capital" was applied to deepen the organizational aspects, especially in explaining support networks formed between the cooperatives themselves.

Although the concept of social capital was no stranger to sociology in the nineteenth century, it was not until the early 80's of the twentieth century when Pierre Bourdieu associated this concept to economy (Westlund, 2006). Using the definition provided by Bourdieu, the social capital is created in relation to individual participants in a defined social context, to generate economic benefits that are due to the way in which skills are acquired and social responsibilities are met, through connections and networks (Bourdieu, 1997) (Rojas, 2013: 191). The concept of social capital emphasizes several factors that are not new, but were generally overlooked during the rise of neoclassical economics and theories of rational choice: trust and norms of reciprocity, networks and forms of civic participation and rules of both formal and informal institutions (Ostrom and Ahn, 2003: 156). Networking, cooperation and community organization is the way to achieve endogenous development "always decentralized, with bottom-up initiatives" (Boisier, 2005: 51). So, for the purpose of this 
study, social capital can be considered as the set of norms of trust, reciprocity, and cooperation when they are related to "norms and values of communities. While the emphasis is on interpersonal relationships when it is connoted in terms of networks" (Cazeres and Ríos, 1999: 524).

While the Maya communities are low on many resources, they have a good starting position in terms of social capital. This concept has worked empirically in the Maya community whose rules existed long before the scientific concept was created. From colonial times, Maya communities were identified with a culture of mutual support within their organizations, "Landa refers to this when he says that the Indians have the good habit of helping each other in all their activities" (Rosado, 2001: 50). The elders have the habit of thinking in the community as a whole (Colli, 2014), they deny any form of individualism, which is contextualized in their religious traditions, in the offerings, in the harvest and in the justice system, among others. "Strong organization is accompanied by a sense of group responsibility" (Rosado, 2001: 76). The community is defined as "a group of people who interact directly, frequently and in a multifaceted way" (Rojas, 2013: 193).

As these rules of human behavior favor the creation of new income opportunities, this can promote the union of indigenous women in order to achieve goals of cooperation through micro-businesses. In addition, the sustainability of these initiatives is enhanced through the social capital, in which trust is a "social asset" which brings people together (Rojas, 2013:197) and leads societies to prosperity (Fukuyama, 1995). In research conducted by Pech in the Maya population, he proved the importance of involving community participation in new business projects. If community participation is achieved, the effectiveness, efficiency, autonomy, local coverage and sustainability of the area where the project is conducted will be ensured (Pech, 2012:49). This may result from the implementation of the principles awarded to the term "social capital", which implies, in our study, the formation of support networks that promote the creation of micro-businesses formed by Maya women.

\subsubsection{Cultural background: the gender relations}

As part of the contextual analysis of this research, it is important to mention the dimension of the organizational culture of the Maya people, their traditions and the role of indigenous women based on a "patriarchal" system (Colli, 2014), where the will of the woman has been generationally subject to the will of a male figure, such as the father, husband, and sons. Women in the developing world (and perhaps even in some so-called developed countries) have workloads linked to their families' financial needs, which include the rural production of agricultural products, implying that their working hours exceed those of men given the tendency of women to fulfill responsibilities at home and in productive activities outside the household (Fonchingong, 1999: 75).

It is important to note that the support networks for mutual help and taking care of family needs have favored the creation of new micro-businesses where women generate family income, because they have been "forced" to take on the management of the cooperatives due to the illegal migration of the husband to the United States or his absence resulting from alcohol problems, among other reasons. The contribution of indigenous women in the home is now more visible. While men had previously been regarded as breadwinners, now both 
sexes share this role, although the women are rarely recognized for their efforts. According to studies by Sali and Al-Ghazali (2012), some of the factors for women to start their own businesses include practicing their traditions, aligned with their values; these efforts also promote leadership, self-esteem, and self-reliance. On the other hand, society has reinforced the role of women to take care of family members as their responsibility, which drives them to seek new sources of income to support their families.

Research around the world has reported that more women are establishing a greater number of micro-businesses in comparison with those generated by men. The women's microenterprises also report lower failure rates. Other scientific studies found that women have innate gender skills that help them to be more successful in a business participatory organization. It has been reported that women have a leadership style that is particularly more effective in contemporary organizations. On the other hand, women have social characteristics of kindness, support, consideration and awareness of the needs of others, known as community characteristics (Rosette and Plunkett, 2010: 222). Women are characterized by being more customer-focused than men are. "Women tend to operate ethically and make social contributions, in addition to economic stimulus" (Sadi and AlGhazali, 2012: 100). Women have a more interpersonal style of work. "Women are more democratic than men, using a more participatory style of work" (Denmark, 1993: 347). Gender research also mentions women leadership as the only way to "introduce sustainable change" (Aerden, 2012: 23) in organizations, it is essential to examine how they organize to change their socio-economic environment.

Another theoretical approach presented in this research is the Circular Economy which involves sustainable elements implemented in several countries and companies (World Economic Forum, 2014). The advantages of its application have been discussed recently with measurable impacts in terms of economic growth and with environmental improvements towards a more sustainable production trend (Lett, 2015: 2).

The theory of circular economy implies a new way of producing goods, doing business by means of innovative organizations such as the cooperatives, the object of this study.

The development of circular economy should help to reduce the use of resources, reduce waste production and limit energy consumption. It should also participate in productive reorientation of countries. In addition to environmental benefits, this emerging activity is the creator of wealth and employment (including the scope of the social economy) throughout the territory and its development should be allowed to obtain a competitive advantage in the context of globalization (OEC, 2015).

This section showed a wide array of economic, social and cultural sources of motivation to be analyzed. They include the need to improve the household income and the opportunity to carry out these projects which can be translated into better living conditions for those who actually strive to work and show the benefits of honest work. As was previously discussed, these practices correspond to the social capital given that they not only improve the income of families, but also have the "capacity to improve the lives of the people" (Uphodd, 2003: 143). Furthermore, they preserve and socially manage community resources (De Boer, 2012). 


\subsection{Methodology}

The following section will explain the methodological approach used in this research to analyze the evidence discovered in conversations with the indigenous women, based on a semi-structured interview which allowed them to give a broader explanation regarding their motivations rooted in a traditional way of thinking and their concerns for the well-being of their dependents

\subsubsection{Case selection}

The cooperatives included in this study were selected from a list of 90 cooperatives provided by the Centre for Evaluation and Monitoring Quality Professional Services (CECS), an academic department within the Universidad Intercultural Maya de Quintana Roo, supported by governmental funds to evaluate entrepreneurial activities in rural communities. From this list of 90 cooperatives, 19 had female presence; however, only 10 had the predetermined characteristics for this research which were to be integrated mostly by women -more than $80 \%$ of female participation. In order to obtain the financial support from the Mexican government to start their micro-businesses, the participant must have an indigenous background and dependents, such as children under 18 years old, elderly members of the family or relatives with chronic illnesses; in all cases living within the household. During the fieldwork, one of these associations refused to participate in this study. Another had no women involved, although it was recorded that women were included; therefore, it was eliminated from this research which includes a gender perspective. These eight cooperatives are located in seven Maya communities in the Yucatan Peninsula in the south of Mexico.

The process of interviewing the members of the cooperatives was carried out between March and May 2014. Of the surveyed groups, we worked with three associations of agricultural production, a production of honey, one dedicated to the marketing of plastic and glassware, one that serves traditional medicines and traditional food, a veterinary and one that sells typical clothes. The average age of the women participants was 44, with elementary education, indigenous Maya background and married with dependents.

\subsubsection{Data gathering}

For this research, the qualitative method of social research (Tarrés, 2001) was used to collect information which would identify the motivations of Maya women who decide to start their own businesses. This methodology prioritizes the narrative of the members' experiences in their cooperatives in order to interpret them theoretically, establishing the social dynamics and roles developed in the internal organization of agricultural associations. This methodology allows us to understand the internal organization of agricultural cooperatives, from the perspective of the members, on a daily basis and in a context which goes beyond the profit obtained from the administration of production, taking the experiences of the members and the aspects relating to their interest in participating in this organization. The data gathering methods used were literature review, participant observation and interviews based on semi-structured questionnaires (Tarrés, 2001, Creswell, 1998; Denzin and Lincoln, 1994) applied to members of eight cooperatives in seven Maya communities located in the Yucatan Peninsula. 


\subsection{Empirical results}

This section presents the results obtained in the field work after their systematization and interpretation under the approach of social capital theoretical framework of business organization integrated by Maya women who use their culture and identity as social capital in order to cope with the economic and social needs in which they are immersed.

As part of the information gathered, the women indicated that their work in agricultural production has increased considerably in recent years. In rural areas, most women work with basic tools and have no access to agricultural support, as offered by the Secretariat of Rural and Indigenous Development (SEDARI - for its acronym in Spanish). Additionally, they are engaged in livestock activities.

All the leaders of the organizations included in the study confirmed that their first motivation was economic necessity, since the economic structure of the region does not offer employment alternatives that allow them to provide a decent standard of living for their family. They also declared their willingness to help their husbands in supporting their families, in order to have enough economical resources to send their children to school and give them more opportunities in life (G6, G7, G8, interviews 2014).

While members of organizations are self-employed, two organizations are engaged in vegetable production and also generate temporary work. They hire workers at the time of harvest and planting, offering fifty five direct jobs, almost all of which are given to women because they "work more carefully, without haste, they handle the product very gently, not looking to earn a lot of money, just enough, they are more honest and are harder workers, more responsible, and command respect within the unit of work" (G5, interview 2014).

In this sense, the employment of women as labor in farming activities performs two functions, on the one hand they help their husbands in the traditional production of the milpa that allows the consumption of basic grains and on the other, they provide cheap labor in organizations that require their work, which allows these organizations to increase their profit margin by having an available workforce with wages below the market price.

While the salary given to women for collaborating in organizations that produce vegetables is lower than that of the market, this salary allows them to maintain a family nucleus since the men "no longer have to leave their families; before, the husband travelled to Cancun, Playa del Carmen or the United States, now they work here in the morning and after a while they are already in their houses ... " (G1, interview 2014).

In general, all the organizations argue that the incorporation of women into productive activities via the micro-businesses, serves not only as a complement to the sustenance of the family, which cannot be achieved only with the work of their husbands in agricultural activities, but also empowers the women within the community and in decision-making in their homes. 
In addition, all the organizations sell their products in local markets and, although their products are sold in regional markets, this process is conducted via intermediaries who come to the site to buy the production. This marketing channel is limited since it reduces potential buyers and limits flow of sales; however, the profit margin rises to $40 \%$ (in the production of traditional medicines and traditional clothing).

Regarding the beginning of the organizations, the role of the Secretariat of Rural and Indigenous Development (CDI - for the acronym in Spanish) is crucial as a source of financing for producer groups, since the eight groups studied herein all had the support of this federal institution in providing financial support to micro-businesses. Although all the organizations have received support from the government, the members of cooperatives participants in this research denied any government support when they were asked, possibly for fear of being charged for the support.

It is important to mention that while the government agencies provide the funds for the implementation of these initiatives, these instances lack appropriate follow-up programs that could lead to a higher level of profitability and sustainability of these women's microbusinesses.

All the participants in the interviews are Mayan speakers; a characteristic which may not be the only requirement to qualify as a member of the culture, but it is a good indication of belonging. The average age of members is 44 , the youngest member is 34 years old and the oldest is 56 .

In the organizations included in this study, trust plays a key role since "it allows the person who trusts to perform an action that involves the risk of loss if the person that you trust does not perform the expected action" (Ostrom and Ahn, 2003: 182), as occurs in economic terms, since beyond the monetary benefits that produce the organization, there are other interests that hold them together.

In the Yucatan Peninsula, most of the Maya women who live in rural areas, work together in cooperatives whose characteristic elements are the preservation of customs, family integration, and sense of community to cope with poverty. Networking, mutual support and trust in each other provide the social capital in these populations. Although the profitability of most of these cooperatives is low, the desire to preserve their customs and sense of community provides the necessary conditions for these companies to be sustainable over time.

The Mexican government, through governmental programs that encourage alternatives to agricultural activities in order to have a complementary income, provides the funding, they work together with local governments, but these cooperatives work according to their own organizational culture of the Mayan people, their market is the local consumer and their business model is based on social capital (G7, interview 2014).

This research found that if an organization wants to run a community project, it should take into account the social participation of the inhabitants in the project. Community involvement 
can achieve effectiveness, efficiency, autonomy, local coverage and sustainability of the area where the project will take place (Pech, 2012).

The women say that the most important requirements for participating in the cooperative are to be honest, hardworking and Maya. However, members of these organizations indicate that their main interest in joining the group is to improve the family income on order to provide nutritional food and educational opportunities for their children, help their husbands economically, reduce migration through these sources of income and preserve the culture, language and Mayan traditions. These were identified as the reasons that motivate and empower rural women of the Maya communities in the Yucatan Peninsula.

\subsection{Conclusions}

The low profitability of agricultural activities has led the inhabitants of rural areas to seek employment at the poles of tourism development existing in the northern part of the Yucatan Peninsula. Additionally, the reality of the indigenous Maya women is commonly related to marginalization and poverty, their main tasks are directly associated with the needs of their children, elderly family members and household activities. They try to provide their children with access to education in order to break the cycle of poverty in rural areas such as the Maya region of the Yucatan Peninsula.

In response to this phenomenon, the cooperatives have served as an alternative in family income which has prevented the disintegration of the family caused by migration. The role of government support such as the funds provided by CDI has been crucial to boosting the efforts of these organizations, because, although women have indicated economic need as the main reason to get organized and stay united around a micro-enterprise, it is these government agencies who provide the financial support for those efforts.

With little or no commitment to return such economic support, Maya women undertake these micro-businesses with little technical assistance, which represents one of the major constraints for the sustainability of these initiatives over the years.

In spite of the low educational level of the majority of these women entrepreneurs, they themselves acknowledge the importance of sending their children to school and providing healthy, nutritious food for the well-being of their families.

With elements of innovation in their organization, these cooperatives also follow circular economy paths as bottom-up initiatives which function as a natural response of the volatility in the economy. This kind of entrepreneurship should be welcomed and supported (Ellen MacArthur Foundation, 2013: 80).

For the purposes of this research, the importance of working on self-esteem from an early age in Maya women has been established. With appropriate support from childhood, the women will grow up believing they are able to achieve their goals. It is important to give them confidence given that the achievements of women are crucial for the economic productivity and prosperity of any country and for the welfare of the women themselves and their families (Shibley and Hyde, 2001). 
This can have an impact on future generations, given their clear responsibility for the future of their children. The behavior of these women denotes social responsibility, and more importantly, responsibility to themselves and their direct dependents. This is supported by research in which women are taking a higher percentage of successful businesses to a global level (Sadi and Al-Ghazali, 2012).

It is in such organizations that social capital is more present, as an integrating element, with the members recognizing their culture as the most valuable asset and making their Maya cultural heritage a common denominator where they share not only the Maya language, but also a conception of what is valuable as a community to preserve and promote. However, it is essential that public agencies and society in general, recognize the work these organizations exert to preserve and protect the cultural heritage involving the Mayan traditions.

Our study also highlights the important role of government institutions in the provision of seed funds and training programs with the aim of increasing the capacity of the women participants. It is also important to involve members of civil society and non-governmental organizations in this effort, which would foment the valuation of the women's work beyond the economic and allow the legitimization of the different roles assumed by women in society.

In the fight against poverty, marginalization and ignorance, with little or no formal education, the Maya women of the Yucatan Peninsula represent an example of courage and entrepreneurship, undertaking their micro-businesses with little preparation in the field and working long hours to make them profitable, these additional revenues represent the difference between marginalization and aspirations for a better life.

\section{Acknowledgments}

This research project was funded by the Nestlé Foundation, for the study of problems of nutrition in the world.

The authors wish to recognize the work of María Francisca Poot Cahun and Rudy Rubén Chan Tuz who were Mayan translators to the Spanish language during and after the interviews carried out as part of this research paper. 


\title{
Chapter 3. Elements of success in cooperatives conformed by Maya women in the Yucatan Peninsula, Mexico ${ }^{8}$
}

\begin{abstract}
María Cristina Osorio Vázquez ${ }^{9}$, Hans Th.A. Bressers ${ }^{10}$, María Laura Franco García Cheryl De Boer \& Oscar Iván Reyes Maya ${ }^{11}$

Abstract

This paper describes different elements leading to the success of cooperatives formed by indigenous Maya women of the Yucatan Peninsula in Mexico. These elements have shown to facilitate the sustainability (permanence over time) of the cooperatives and their presence in the market, while improving the work environment and enhancing the practice of honesty. All these elements have generated an increase in the number of clients and beneficiaries due to their trustable relationships. As can be appreciated in this study, indigenous Maya women living in the Yucatan Peninsula are demonstrating an innovative way to do business, which has resulted in greater social benefits and profitability through social capital, ethical leadership and monitoring of actions.
\end{abstract}

Keywords: Success-Women-Cooperatives-Trust

\subsection{Introduction}

Ethical business behavior in Mexico is an important issue that must be addressed given the lack of confidence shown by Mexican society as to whether honest entrepreneurial behavior is a possible way to earn enough income to ensure long-term welfare for their families. This is a reflection of the strong fissures in Mexican societal values and affects the economic development of this country (González, Molina, Padrón, De la Rosa, Segovia, Huitrón, 2013).

In Mexico, corruption is one of the main factors affecting the credibility of the government from the perspective of the citizens. This underlying belief permeates the attitudes and behavior of societal actors, and, in some cases, gives rise to the attitude that acting dishonestly is required to create the conditions for a stable income and to have access to services such as health, education and work (Morris, Klesner, 2010, Rose-Ackerman, 1999).

\footnotetext{
${ }^{8}$ This paper has been presented at the International Conference for Business and Economics held in Harvard University (US), May 26, 2015 and has been published in the International Journal of Research and Education (IJRE).

${ }^{9}$ M.C. Osorio

School of Economics and Business

Universidad Anáhuac Mayab

e-mail: maria.osoriov@anahuac.mx

${ }^{10}$ H. Bressers, L. Franco \& C. De Boer

Department of Governance and Technology for Sustainability (CSTM)

University of Twente

e-mail: j.t.a.bressers@utwente.nl

e-mail: m.1.francogarcia@utwente.nl

e-mail: c.deboer@utwente.nl

${ }^{11}$ O. Reyes

Department of Sustainable Development

Universidad Intercultural Maya de Quintana Roo

e-mail: oscar.reyes@uimqroo.edu.mx
} 
In contrast, cooperatives are based on values such as trust, honesty, networking and mutual support. In this study of cooperatives formed by indigenous Maya women in the Yucatan Peninsula we found elements that contribute to the sustainability (timewise) of these micro businesses. What is particularly notable in light of the prevailing attitude supporting the economic benefits of unethical and corrupt behavior, is that social capital, ethical leadership and monitoring of actions are found to be important elements of success in these cooperatives. Hence, it is relevant to provide some background on these concepts and approaches applied in this study.

Given that the focus of this paper is on success, it is important to define success in small businesses in order to explain the approach used in this research. For the purpose of this research, a "successful small business" is an association which promotes sustainable economic growth and an increase in food security, while ensuring stability and creating opportunities for society (Canada Fund for Local Initiatives, 2014). This definition provides the basis for measuring the elements of success of these cooperatives conformed by Maya women.

Social capital is understood as the norms and values that enable cooperation of civil society formed in groups where the trust level determines its prosperity, degree of development and competitiveness (Fukuyama, 1995). Social capital integrates the participants based on their traditions and culture, and ethical leadership, involves the practices of honesty and social justice between the members of the organization (Bandura, 1977). Both elements are based on - and strengthen - this trust, a difficult value to observe when the Mexican government, the main provider of funds for productive projects in rural areas of Mexico, sometimes uses public programs to benefit political parties instead of supporting the development of vulnerable classes of society. The third element is monitoring of the first stages of the micro business developments that are located in rural areas.

To illustrate the "monitoring of actions" success element applied to the Maya women cooperatives, it is relevant to mention some international initiatives that have an important impact in the Yucatan Peninsula. One of them is through the Canadian International Development Agency (CIDA). CIDA is an institution that promotes sustainable development in developing countries like Mexico to reduce poverty through government programs such as the Canada Fund for Local Initiatives, promoting local development and supporting rural communities since 1985 (FCIL, 2014). This program not only provides funding for the start of the cooperatives, but also provides technical training to benefit indigenous Maya women and conducts regular visits to ensure business permanence. Another international program that provides technical training and supports cooperatives in the south of Mexico is the United Nations Development Program (UNDP). In this international program "the innovation factor" is incorporated as an important element. This program promotes training diversification in production for Maya women to ensure market presence and increase the sustainability of their businesses.

With respect to the purpose of this study, the research question was formulated as follows: Which are the key elements found in the cooperatives selected as subjects of this study that promote success? Based on literature review and an understanding of the context in which the research is being undertaken, we found the key elements of social capital, monitoring 
and the presence of ethical leadership. This paper is structured as follows: theoretical framework based on social economy and the concept of social capital, case selection and methodology, description of three different successful cooperatives, discussion of the empirical results and conclusions.

\subsection{The Theory of Social Economy and Social Capital on elements of integration in cooperatives}

Cooperation is the fundamental basis of human cultures and is part of their essence, making it a transforming factor in dialectical terms, between the actions of the individual and the collective. The fundamental value of the cooperative is cooperation in terms of the principles of integration, solidarity and social democracy. A cooperative's purpose is based within these values, which are to ennoble, liberate, emancipate and integrate society (Monje, 2011). The purposes and values of the cooperatives overlap with those promoted by social economy. Hence, some of the theories relating to Social Economy drew the researchers' attention and is further explained in this section.

The theory of social economy is based on the solidarity of workers as an alternative model of society and enhances the representation of marginalized classes in order to improve their living conditions (Mateo, Méndez, Solveira, 2011). Social economy has various legal forms of associations such as foundations, nonprofit organizations and cooperatives. These organizations provide values such as service to members, service to the community, autonomous management, democratic decision-making process, the primacy of people and work over capital and the distribution of profits (Levesque and Mendell, 2003) (Mateo, Méndez, Solveira, 2011).

For the utopian socialists, cooperation and cooperatives arise as products of the disagreement of capitalism with the interests of the broad masses of the population and their ideals of good and justice. Socialists are aware of the dissatisfaction that capitalism provides, its irrationality, and its economic and social injustices (Monje, 2011).

An approach known as Economy of the Common Good has been derived from Social Economy. The author, Austrian researcher Christian Felber, offers a number of points upon which cooperative work is based: trust, cooperation, appreciation, democracy and solidarity (Felber, 2012), all features found in the cooperatives that are the subject of this study.

In this theoretical approach, the economic success of enterprises is not measured solely by monetary value or profitability, other factors are also involved. The more social, ecological, democratic and united the productive activity is, the better the results of the balance of the common good achieved. We can relate this statement with the organizations studied here and formed by Maya women in the south of Mexico, where the women are not only driven by economic benefits, but also by ensuring food sovereignty, respect for the environment and promoting cultural traditions that are often forgotten (Maathai, 2006). These are proposed as being key elements for the long-term presence of these companies in the market.

In Latin America the social economy has led to the theory of Buen Vivir (Good living) developed mainly in Ecuador and Bolivia, where collective and communal forms of 
production are promoted with respect for the individual and the environment. It is characterized by the construction of a collective identity, whose main subject is the community. Collective work is in balance and harmony with nature, and with respect for human beings. At present, social economy based on this theoretical approach aims to move towards a democratic, productive society, promoting the comprehensive development and self-determination of indigenous communities (Chiroque, Mutuberría, 2009).

In Latin American countries, as in the case of Ecuador for example, indigenous communities have supportive behaviors; in other words, its economy is governed by practices of solidarity, reciprocity and redistribution (Martínez, 2009). Such behavior is also observed in Maya communities.

Due to the difficult working conditions that must be faced in the Mexican economy, such as unemployment and job insecurity, indigenous people establish a set of strategies that combine work in the cities located close to their communities, selling agricultural products and seasonal employment in agribusiness farms. The difficulty of their inclusion in the labor market is due to the fact that the mentality of these societies is not compatible with western oriented mentalities that are also present in the region studied. Another problem they must face is the relatively short period of formal education they have received, which also leads to conditions of precarious and informal work (Bello, 2002).

The practices of social economy, through the integration of rural and indigenous communities into cooperatives have allowed the survival of rural populations. In countries like Bolivia, Colombia, Peru, Chile, Guatemala and Mexico, there are complex indigenous commercial networks linking distant and different communities, based on fair trade and with the support of international organizations. Through these networks the production of cooperatives is sold in international markets. One of the limitations of this form of production is the organizational capacity of indigenous populations to confront the interests of the government and the market, which affects their interests and the development of their productive organizations (Chiroque, Mutuberría, 2009). Cooperatives, as a way of organizing production and property, are essential to build a new society with democratic, egalitarian and social justice character, an advanced society with democratic bases (Monje, 2011).

\subsection{Case Selection and Methodology}

The cooperatives studied herein were selected from a list of 90 cooperatives provided by the Centre for Evaluation and Monitoring Quality Professional Services (CECS), an academic department within the Universidad Intercultural Maya de Quintana Roo, supported by governmental funds to evaluate entrepreneurial activities in rural communities.

Of this list of 90 cooperatives, 19 had female presence. However, only 3 had the predetermined characteristics for this research, which were to be integrated mostly by women -more than $80 \%$ of female participation-, to have received financial support from the Mexican government to start their micro-business, the participant should have an indigenous background, with dependents such as children under 18 years old, elderly family members or relatives with a chronic illness, all living within the household. The characteristics must also be consistent with the definition of success provided by the Canada Fund for Local Initiatives, as was explained before. Each of the cases classify as successful given that they 
promote sustainable economic growth, increase the food security stability, and create opportunities for societal development of vulnerable Maya women.

The preselection of only successful cases might raise questions, as standard methodology tends to indicate that selecting and comparing both successful and unsuccessful cases would be the best way to identify success and fail factors. However, in order to justify this research design, one must assume that the success and failure factors mirror each other, given that the failure factors are just the absence of success factors, and vice versa (compare Dente \& Fareri, 1998: 5). This assumption does not seem to be warranted however in this population of cases in which the variety of reasons for failure is very large, while just a narrow path seems to lead to success. Therefore, an explorative study to draw lessons from these success stories makes sense, at least as a starting point.

This study was conducted in 2014 with three cooperatives located in three different Maya communities in the Yucatan Peninsula in southeastern Mexico. The rural communities, which were the subject of this study, are located in municipalities where poverty ${ }^{12}$ is common, with at least $70 \%$ of the population living in marginal conditions, and where more than $25 \%$ of the population cannot meet their food needs (CONEVAL, 2014). In terms of Human Development, these municipalities share similar levels observed in other Central American countries that are considered underdeveloped. They are comparable to the case of El Salvador, where the Human Development Index ${ }^{13}$ (HDI) measured by gender indicators was lower in the case of women, who also have fewer opportunities for development given that the majority of the women have not completed elementary education (UNDP, 2014). Therefore, although the Gini coefficient ${ }^{14}$ is relatively low, poverty in the population is evident in those municipalities where the population has few opportunities of employment and development. In this context, rural cooperatives play a fundamental role in providing employment opportunities and generating income to the population of rural communities, where the precarious economic situation interferes with their human development.

This research employed qualitative methodology (Hernández, Fernández \& Baptista, 2010) with a semi-structured questionnaire combined with participant observation and systematization of data. The questionnaire was applied in the Maya language with the support of translators to Spanish, since some of the members of the cooperatives do not speak Spanish. The content of the interviews was written in Spanish by the first author, who is a native Spanish speaker, in order to interpret the results and understand and register which are the elements mentioned that led them to success.

\footnotetext{
${ }^{12}$ Poverty in Mexico is officially measured by the National Council for the Evaluation of Social Development Policy (CONEVAL). A person in poverty is defined when he or she has at least one social deprivation and the income is insufficient to purchase goods and services required to meet food and non-food needs. For more information on measurement methodology see: http://www.coneval.gob.mx/Medicion/Paginas/Glosario.aspx

${ }^{13}$ The Human Development Index is an attempt to quantify the welfare of people that includes health, education and income, where 0 is the lowest and 1 is the highest. Nationally, Mexico is considered to have high Human Development with an HDI of 0.775 in 2012. For more information on national terms see: www.mx.undp.org 14 Gini coefficient measures economic inequality in a society, by exploring the level of concentration that exists in the distribution of income among the population. It takes values between 0 and 1; a value which tends to 1 reflects greater inequality in income distribution. Conversely, if the value goes to zero, there are better conditions of equity in income distribution. For more information see: http://www.coneval.gob.mx/Medicion/Paginas/Cohesion_Social.aspx
} 
In the case of the cooperatives participating in this research, all three of them demonstrate high levels of social capital among the members, measured as the trust among them; the second case also presents monitoring activities in their processes, and the third case has, in addition to social capital, monitoring and ethical leadership as main characteristics. In order to protect the anonymity of the interviewees, we identify the cooperatives participating in this research by using numbers instead of names.

\subsection{Case Study Results}

In this section, the three cases analyzed herein are briefly described according to their inner characteristics, using the three success factors mentioned in the theoretical framework of this paper.

\subsubsection{Case 1: Illustration of the importance of social capital}

Cooperative 1 is a cooperative dedicated to the sale of livestock food and is formed entirely by Maya indigenous women, without knowledge of the Spanish language, and with incomplete elementary education. In an interview with members of the cooperative, the reasons mentioned for the success were trust and responsibility in their work (C1 I2, 2014).

The initial funds of this cooperative were provided by the National Commission for the Development of Indigenous Peoples (CDI). This is a decentralized agency of the federal government in Mexico, autonomous in its administration and use of its budget. The purpose of this institution is the deployment of public programs focused on improving the quality of life and the preservation of traditions and languages of the indigenous population in Mexico.

These funds have a very flexible repayment engagement or no repayment at all. This is related to the history of bankruptcy in microbusinesses; however, this cooperative has been successful. It has stayed in business for more than four years, selling products in the community. The participants mentioned that the Mexican government gave them economic resources to initiate the business but did not send a person to check how the resources have been used or to help them develop the new project. The interviewers were able to confirm that the Mexican government did not in fact monitor or follow up on the activities of this cooperative.

Cooperative 1 operates in local markets, but has not yet expanded the business further into the region. The business is profitable despite the hard work and the multiple barriers they have to confront. The women involved in the business must carry heavy food packages since no men are involved in the cooperative and they have to deal with intermediaries with little knowledge of the Spanish language.

The women who work in Cooperative 1 are married and their husbands work in agricultural activities. During the interviews they repeatedly mentioned responsibility in the workplace and honesty, to which they attribute the increase in trust between the members, which in turn has led to the success of the organization. The elements which encourage social capital were evident and included the Mayan language they share, their indigenous background and the 
fact that they are women with dependents and therefore have a responsible attitude towards work.

A number of factors have limited the growth of the cooperative. Language barriers existed for all of the women involved; all of whom speak only the Maya language. With none of them communicating effectively in Spanish, this limits their ability to submit requests for funds to promote business growth. Their limited education prevents them from filling out forms, which are often requested when applying for free technical training to the national governmental institutions, non-profit institutions and international aid agencies.

It is important to mention that the main asset of Cooperative 1 is the social capital represented by these women. This social capital evolved because they share a responsible attitude towards work and recognize this is as an important factor related to the cooperative's success. While this is reinforced by the Mayan language, traditions and family situation, this asset seems to be their main barrier, as well, since their inability to speak Spanish prevents the growth of the business. Although they have a profitable and stable business, it will be a challenge to face regional markets without an interpreter and it is imperative that such interpreters should be trustworthy as they will need to negotiate for them.

\subsubsection{Case 2: Social Capital and Monitoring}

Cooperative 2 demonstrated a high degree of trust among the members. With ten years of presence in the region, this cooperative is engaged in the marketing of honey and derivatives. In this cooperative, it was also observed that the elements promoting high cohesion and trust between the members are related to the Mayan language and their indigenous background. They understand that work is the way to make an honest life, but language barriers prevent them from selling their production directly. The cooperative leader, who speaks Maya and Spanish, is in charge of this part of the business.

In the terminology of social economy theory, Cooperative 2 integrates the disadvantaged classes of society, in this case older women, with those of indigenous backgrounds who live in rural areas in poverty conditions. They work at home, transforming honey into products such as soaps, candles, syrups, cosmetics, food supplements and medicinal products. The women members of this cooperative dislike leaving their community because of their advanced age and Maya background. The leader of the cooperative goes to their homes to collect the products and represents them in sales activities in local, regional and international markets.

These honey products are currently sold regionally in the Yucatan Peninsula and, on a national level, in the states of Sonora and Michoacan in Mexico. They have also had international presence in international fairs held in Belize and Spain; these initiatives were promoted by the state and federal Mexican government.

Initial funding for the business came from the Mexican government through the National Commission for the Development of Indigenous Peoples (CDI), the Secretariat of Agriculture, Livestock, Rural Development, Fisheries and Food (SAGARPA) and technical training through workshops supported by the National Institute for Training and 
Development or Rural Sector (INCA Rural). Similarly, they have received international funds from the United Nations Development Program (UNDP) for technical training, specifically to diversify the production of honey. Staff of this specific program did followup visits and diverse monitoring activities, even years after the economic support was received. As the leader assured the interviewers during the field research, this was an important element that led to the success of the business (C2 I2, 2014).

Another characteristic worthy of mention is the importance that the leader of the cooperative gives to innovation. Two specific examples of innovation have been observed in this cooperative; the concern to diversify the production in order to impact a broader market and their interest in applying for technical training received from the Mexican governmental institutions and international organizations like the United Nations.

Another strategy related to innovation has been the use of the Internet in sale activities. In an interview with the leader of the cooperative, she mentioned that, initially, she had no knowledge of how to use a computer. However, due to the profitability of the business she asked her son to teach her how to use it to promote their products on a larger scale (C2 I3 2014). Today, among its marketing tools, Cooperative 2 has a website and a facebook page for business.

\subsubsection{Case 3: Ethical leadership as an additional factor of success and sustainability}

One of the most outstanding cases found in the region of study in terms of ethical leadership is Cooperative 3. Ethical leadership is defined as "the demonstration of normatively appropriate conduct through personal actions and interpersonal relationships, and the promotion of such conduct to followers through two-way communication, reinforcement, and decision-making” (Brown, Treviño, \& Harrison, 2005:120; Brown, Treviño, 2006:596).

This nonprofit organization has a nun as a leader, a religious women who organized Maya women of the region in cooperatives to promote self-sufficiency and food sovereignty among the beneficiaries.

This cooperative began because of the consequences of hurricane Wilma in the Yucatan Peninsula in 2005, which left farmers with flooded lands and homes in poor conditions. With no alternatives, and without sufficient financial support to cover their needs, this desperate situation encouraged producers to work in cooperative associations.

The leader, founder and president of Cooperative 3, shared some of the comments the farmers of the region expressed during those difficult moments of need and hunger: "we appreciate the governmental support, but we need to learn how to provide for ourselves and our families", "we are thankful for the food supplies but we want seeds and fertilizers to recover our land" or "don't give me alms, teach me how to be self-reliant" (C3 I1, 2010). These affirmations show the spirit of the Maya communities.

The statements mentioned above are related to the lack of support from government authorities to promote the economic and labor stability of farmers in the south of Mexico, since most government programs are designed to meet short-term needs, generating 
dependency of the population on governmental programs. Also, this support is subject to political interests which have little to do with the interests and development of Maya communities.

In this scenario the leader, with an unusual entrepreneurial perspective as a catholic nun, organized the farmers in the region. Through her international contacts in the United States and Spain, she received financial support through donations, to acquire machinery and infrastructure. Through these efforts, this initiative emerged as an organization that has helped more than 4,500 families, most of them with single women as head of households.

Among the objectives of this organization we found the promotion of food sovereignty practices among other Maya women, motivating them to exchange fruits and vegetables in order to have variety in their diet. Cooperative 3 also helps them with the sale of their agricultural production in local, national and international markets and to process the surplus production in sauces and jams.

Other activities of the cooperative include the equipment of drip irrigation systems, and the provision of seeds and fertilizers that Cooperative 3 receives from municipal, state and federal governments for the farmers of the region. Among the achievements are 1) the acquisition of tractors through the Productive Options Program of the Secretariat of Agriculture, Livestock, Rural Development, Fisheries and Food (SAGARPA); 2) maize granted to producers through the program Support for Productive Chain of Producers of Corn and Bean (PROMAF) from the same institution; 3) technical training through workshops given by the National Institute for Training and Development of the Rural Sector (INCA Rural); 4) economic resources of Shared Risk Trust (FIRCO) from the state government and; 5) seed grants and training provided by the National Commission for the Development of Indigenous Peoples (CDI).

Amongst the beneficiaries of Cooperative 3 we found more than twenty rural communities. Cooperative 3 is generating income for rural producers, finding alternative markets for the crops that are not sold in traditional markets, promoting the participation and leadership of women and increasing the production of habanero pepper and other crops in the region through technical training for the associates supported by donations, NGO's and governmental funds.

Cooperative 3 creates awareness among rural women regarding the importance of changing a culture of paternalism -that makes farmers dependent on government programs promoted by the same Mexican government- to a culture of work and responsibility (APA, 2014). Receiving government support without proper monitoring as in the Program of Direct Support to rural areas (Procampo) from SAGARPA, creates dependency among the farmers of the region, while the lack of appropriate support limits their growth and the opportunity to have a life with more dignity.

The work done by Cooperative 3 promotes monitoring the productive activities of these cooperatives for a period of three years, during which they are supported with free technical training. The selection of women beneficiaries is carried out by means of an interview conducted by the nun, with selection criteria based on the person's attitude towards work and 
the belief that the only way out of poverty is through effort and education. Moreover, the beneficiaries are encouraged to diversify their agricultural production and promote supplementary activities to increase family income with other productive options, such as beekeeping activities, which is a common practice among agricultural producers in the south of Mexico.

During the interviews, members of Cooperative 3 commented that the main problems Maya women have when they receive economical support from the Mexican government through public programs are the low levels of production, low quality products, lack of monitoring activities and training and lack of agricultural machinery and equipment. To resolve these issues, Cooperative 3 works with women to provide technical advice for growing corn, tomatoes, habanero pepper, sweet pepper, xcatic pepper (a local variety of pepper), watermelon, cantaloupe, squash, beans, radish and others vegetables. It also tries to establish a culture of forest conservation and promotes the mechanization of fieldwork to increase the productivity of the land.

In addition, Cooperative 3 works with social problems such as alcoholism, drug addiction, and migration, and creates awareness on gender equality through free workshops and gives technical training to increase the profitability of small business, promoting education as a development alternative.

Among the achievements of this cooperative are the openings of national and international markets through the processing of habanero pepper in sauces which are currently exported to the United States, specifically to the states of California and Texas.

Another activity that has been successful is the provision of micro-credits for women to start small businesses. This cooperative gives them ideas about what business could be profitable, it also promotes a culture of savings and responsibility with flexible repayment plans with no penalties charged if they fall behind in their payments or if they cannot return the money, or perhaps if the business does not work.

To support the women beneficiaries, the cooperative, through its representatives, collects the loans without interest from the homes of the women who borrowed money to start their business. This means that they do not have to spend money on transportation to meet their payments, considering that most beneficiaries are living in remote areas of the Yucatan Peninsula. The loan is for sixteen weeks and in order for the loan to be granted the cooperative asks them only for an ID, to identify themselves. They are not asked for endorsement or securities of any property. In the words of the leader: "It's about helping women; not to do business with women" (C3 I1, 2010).

With respect to the reasons for working mostly with women, as was mentioned before, this cooperative supports women because they are the center of the family and as such, they are very hardworking and responsible. They organize their own work schedule and administrate the resources well for the benefit of their families. Microcredits help them to feel that they are valued as a woman and also help them to become self-sufficient. 
Although the leader of this cooperative is a nun, the provision of support is performed on the basis of equality, irrespective of creed. Among the newest projects of this cooperative are alternative productive activities in greenhouses and raising chickens for sale.

The main weakness of this cooperative is that, in the last year the leader has been sick because of her advanced age. Members of the cooperative have commented that the future of the organization is at risk, since her ethical leadership supports the cooperative (C3 I3, 2014). The precautionary measures taken so far only include the formation and training of employees to replace her if she is absent, however they mentioned emphatically that it is the leader, through her catholic religious figure, who obtains resources and donations. They do not know what will happen if she can no longer participate in the cooperative. This is the main organizational strength contained in the presence of an ethical leadership, which turns against the cooperative itself as its greatest weakness, since the present risk of losing her could change the course of the organization and the loss of her efforts to benefit Maya women.

By definition, ethical leaders are altruistically motivated, caring, and concerned about their followers and others in society (Brown, Treviño, 2006:603). However, what happens when ethical leadership disappears in the organization? This is probably the question that the cooperative 3 members will have to answer when the nun can no longer lead the group. One alternative is the emergence of new ethical leaderships, based on the premise of social learning theory where people learn appropriate behavior by observing others (role modeling). The manager as a role model is in a direct position to influence the behavior of employees who learn to behave ethically or unethically by observing the behavior of the manager and other employees (Treviño, Hartman, \& Brown, 2000).

Studies conducted in organizations with ethical leadership indicated that having had an ethical mentor in one's career was positively related to ethical leadership (Trevino, Butterfield \& McCabe, 1998). The influence of the leader permeates the organization to ensure ethical behavior in their practices and procedures, even if he or she is no longer involved and, with time, new leaders are expected to emerge and sustain ethical behavior in order to increase the number of families involved in cooperative partnerships through this nonprofit organization.

\subsection{Discussion: Elements of success could be also constraints inside the cooperative}

The main purpose of this study was to demonstrate which elements lead to success in cooperatives conformed by Maya women in rural communities in the south of Mexico. Although honest behavior is rarely observed in businesses where economic needs are not fulfilled, these women have demonstrated an innovative model of organization and several key elements that should be replicated in similar communities located in rural areas in order to increase the sustainability (timewise) of these organizations in the market and obtain a greater income for the women participants in microbusiness-cooperatives (Table 3.1). 


\begin{tabular}{|l|c|c|c|}
\hline $\begin{array}{l}\text { Case Selection/ } \\
\text { Element of Success }\end{array}$ & Social Capital & Monitoring Activities & Ethical Leadership \\
\hline Cooperative 1 & $\checkmark$ & x & $\checkmark$ \\
\hline Cooperative 2 & $\checkmark$ & $\checkmark$ & x \\
\hline Cooperative 3 & $\checkmark$ & $\checkmark$ & $\checkmark$ \\
\hline
\end{tabular}

Table 3.1 Elements of success found in three cases of cooperatives conformed by Maya women in the Yucatan Peninsula.

Source: Main author, based on field work data 2014.

The common base found in this research was the importance of trust among business partners, not only in the financial aspects of the microbusiness, but also in the attitude towards responsible behavior and equal distribution of work between the members, one of the characteristics of cooperative organizations. These practices enhance trust between the members, which is also social capital, reinforced by a common language such as the Maya language, an element which made them feel part of the same community and with a full understanding of the instructions and activities to be performed inside the organization. In this sense, the use of Spanish is for the visitors, the outsiders, the customers, the intermediaries, the Maya language is between the members.

This trust was an element also found in Cooperative 3 with ethical leadership, related to a religious figure, enhancing trust among the members because of their catholic beliefs, but also creating trust outside the organization, which facilitated support in the form of funds and donations. This practice has created a network of support which has helped Cooperative 3 to grow considerably compared to other cooperatives.

The monitoring process has also been an element of success. Monitoring creates engagement between the cooperative members and the agencies that gave them the economic support. The regular visits by their sponsors guided the members, primarily in the first stages of business, gave them confidence and reinforced cohesion between the participants.

Nevertheless, an important finding was that two key features mentioned as elements of success could also cause the failure of the cooperative. The Maya language as a cultural factor which helps the members to be understood and to be part of the group can also be considered a constraint in the market. In Cooperative 1 it was observed that the women have difficulties in negotiating the prices of their products. Thus cooperative growth occurred only inside the community, where the Mayan language is commonly used and the Spanish language is rare. In this way the Mayan language makes them feel safe, "at home", but it seems that choosing to stay at this stage might limit cooperative growth.

In cooperative 3 , with its strong ethical leadership, the concern of its members is about the uncertain presence of the catholic nun as the head of the organization. If this leadership behavioral style has successfully permeated through the organization, the prognosis for sustainability of this cooperative can rank high. However, if an ethical leadership does not 
emerge when the present leader leaves, the future of the cooperative and its success in obtaining funds could be seriously affected.

\subsection{Conclusions}

Considering the difficulty of permanency in the market for small businesses and the considerably high probability of extinction in the early years (INEGI, 2015: 9), the cooperatives studied have managed to be sustainable based on human values such as trust, honesty and responsibility, which have been displaced by the mentality of greed and exploitation of vulnerable human beings that is characteristic of unbounded capitalism.

The cohesiveness of cooperatives formed by Maya women located in the Yucatan Peninsula is strongly related to social capital that is present in all three of these rural organizations. In two of the organizations (Cooperatives 2 and 3), monitoring activities were seen to play a strong role in maintaining the stability of the organization and providing key assistance for addressing problems that often occur following the initial development of the initiatives. In Cooperative 3 , there was a presence of strong ethical leadership that acts as a guidepost and sense of common trust for those involved in the initiatives.

As such, the three key elements of success - social capital, monitoring and ethical leadership - were indeed observed to be present in the cases studied here. While this is not in any way considered to be proof of a causal relationship, it does provide support for these three elements as being important for the success of rural activities aimed at improving the quality of life of rural Maya women.

In a context of poverty and marginalization it is common for indigenous people to work together to make their own local development initiatives (Martínez, 2009). Ethical leadership and social capital are innovative practices that promote social integration, both based on the intangible value of trust, which is formed over time through observation of the behavior of human beings.

Although Maya rural populations have high rates of poverty, it is through these networks of trust and the promotion of work responsibility among women that some of these cooperatives have been successful in promoting sustainable economic development in the region, increasing food sovereignty and creating opportunities for social and economic development for the people of the region.

\section{Acknowledgment}

This research project was funded by the Nestle Foundation, for the study of problems of nutrition in the world.

The authors wish to recognize the work done by María Francisca Poot Cahun and Rudy Rubén Chan Tuz who were Mayan translators to Spanish language during and after the interviews carried out as part of this research paper. 


\title{
Chapter 4. Analysis of the federal Mexican program POPMI which supported female entrepreneurship initiatives in the Yucatan Peninsula, Mexico ${ }^{15}$
}

\author{
María Cristina Osorio Vázquez ${ }^{16}$, Hans Th.A. Bressers ${ }^{17}$, María Laura Franco García
}

\begin{abstract}
Purpose -This paper analyses the implementation process of the Program of Productive Organization for Indigenous Women/Programa de Organización Productiva para Mujeres Indígenas (POPMI) in the Mayan region of southeastern Mexico. This is a federal program implemented by the National Commission for the Development of Indigenous People (CDI) which promoted, until 2014, female entrepreneurship initiatives in the Yucatan Peninsula.

Design/methodology/approach - This evaluation study uses qualitative methodology of social research to collect information and Contextual Interaction Theory (CIT) to analyze data, emphasizing the motivations, cognitions and resources of the women who benefited from the program.

Findings - Although POPMI supported the creation of micro businesses among women, mostly associated in cooperatives, the research demonstrates some serious deficiencies in the implementation and effectiveness of this governmental program, occurring in the process of granting financial support, the execution of the business project, and in the selection of beneficiaries. These deficiencies are related to political reasons and should be seen against a background of structural problems in Mexican society such as dishonesty, lack of trust in Mexican authorities and dominant family relations under patriarchal systems. However, this program not only offered participation in businesses but also served to promote self-esteem among the women and community recognition, resulting in the empowerment of the participants.

Originality/value - This study demonstrates the importance of increasing the level of dialogue between Mexican governmental representatives and society in an attempt to create public programs that fully benefit the population according to their culture and traditions regardless of their political affiliation.
\end{abstract}

\section{Key words:}

Women-Maya-Empowerment-POPMI-Contextual Interaction Theory

\footnotetext{
15 This paper has been presented at the 3rd Congress of Economic History held in Universidad de Santiago de Chile (Chile), August 11-12, 2016 and has been submitted to peer review procedure as a book chapter in a publication dedicated to indigenous population in Latin America organized by The Johannes Gutenberg University of Mainz.

${ }^{16}$ M.C. Osorio

School of Economics and Business

Universidad Anáhuac Mayab

e-mail : maria.osoriov@anahuac.mx

${ }^{17}$ H. Bressers \& L. Franco-Garcia

Department of Governance and Technology for Sustainability (CSTM)

University of Twente

e-mail: j.t.a.bressers@utwente.nl

e-mail: m.l.francogarcia@utwente.nl
} 


\subsection{Introduction}

The case studied in this paper is part of a comprehensive governmental initiative involving social, economic, political and cultural aspects which, until 2014, supported indigenous female entrepreneurship initiatives in Mexico. According to their size, most of the cooperatives that evolved remain in the micro-business category. The federal program used as a case in point for this paper is the POPMI, an abbreviation that stands for "Programa de Organización Productiva para Mujeres Indígenas ${ }^{18}$. POPMI was created in 2002 with the purpose of offering opportunities for indigenous women in highly marginalized areas to start their own businesses and thus support their family income without abandoning their communities. This latter goal relates to the high rates of migration in areas where employment opportunities are scarce and most work does not provide sufficient economical compensation.

These governmental initiatives are part of social programs which provide financial support to indigenous women throughout Mexico. Training and financial support to start their own micro-businesses form a part of such programs. However, some scholars have reported that the allocation of these resources are often conditioned by the political affiliation of the beneficiaries and election periods. In this way, such governmental support seems to be used to ensure the maintenance of a political party in power, promoting a culture of paternalism ${ }^{19}$ and a population dependent on State decisions; situations in which micro-businesses cannot sustainably grow (Ceceña, 2009: 85).

In the official discourse, the POPMI program declares the intention to (1) encourage selfsufficiency; (2) promote social inclusion of indigenous women living in poverty who have low educational levels; (3) guarantee their access to fundamental human rights, in particular that of no-discrimination; to enable a life free of violence; and 4) aspire to opportunities of development. Thus "on paper" the POPMI program is quite progressive and shows awareness of some of the pitfalls mentioned above. In the implementation phase of this program, a number of indications were observed which have motivated the authors of this paper to analyze both the positive and negative perceptions of their impact.

Because the target group of POPMI consists of indigenous women, this research integrates the gender perspective and how women interact with their contextual conditions. This context is important in order to understand their environment, their family context and the challenges they face as indigenous women living in rural communities.

Cultural values, particularly those of indigenous people, are described here as a background given that, traditionally, women are expected to be subordinate to the male societal structures that create unequal life standards for women. In order to illustrate the last statement, it can be said that indigenous women have to multi-task because they must simultaneously take care of their household chores, children and elderly family members, help in agricultural

\footnotetext{
${ }^{18}$ Program administered by the National Commission for the Development of Indigenous People (CDI), an agency of the Mexican federal government through their state delegations.

${ }^{19}$ Paternalism is the tendency to apply the rules of authority or protection traditionally assigned to the parent to other areas of social relations such as politics and the work field (Alemany, 2005).
} 
activities and perform any productive work to contribute to the family income. In many occasions, the woman is the head of the household, in which case their economic contribution is the main income.

Often, they suffer physical, psychological and sexual violence, and their levels of health and education are precarious. In addition, their homes are generally inadequate for the needs of a large family. Indigenous women in Mexico are more vulnerable than other women, not only because of unequal treatment within the family and community, but also because paradoxically, in Mexico, with its deep indigenous roots, there remains a high degree of discrimination against ethnic groups (Montaño, 2001, Quezada, 2008).

Under such circumstances, it is logical to assume that gender and ethnic discrimination relates to poverty conditions. It is estimated that in Mexico there are 6.4 million indigenous women, of which $80 \%$ live in extreme poverty (INEGI, 2010).

The increasing number of female-headed households, which are among the poorest households, is associated with the phenomenon of the "feminization of poverty". According to some scholars, the feminization of poverty has served to justify governmental programs such as POPMI. However, in some cases, these have been perceived as a way to legitimize public spending, with very little effect on the eradication of poverty but with a strong impact on public opinion during election times (Klisksberg, 2003, Leon, 2000, Montaño, 2001).

The entrepreneurial activities of the female indigenous groups are mostly organized in the form of cooperatives. This is mainly because this type of organization offers them the possibility to choose alternative rhythms and allocation of work. Reasons that are vitally important when there are children and other dependents to consider, as well as household chores, which is the case of the participants in this study. Another important characteristic of developing microbusinesses under cooperative principles is accounted in terms of collaborative attitudes based on trust, promoting solidarity and other social and ethical values (Calderon, 2011, Tomassini, 1992).

These cooperatives are alternative ways to overcome a capitalist and patriarchal legacy that has condemned rural women to poverty. This can be illustrated with land tenure. In these Mayan communities, the ownership of land is traditionally given to men, even if women work the land, which contributes to the marginalization and poverty of women (León, 2009).

Consequently, the research question to be answered in this paper is formulated as follows: What aspects in the implementation process of the Program of Productive Organization for Indigenous Women (POPMI) for the Mayan population of the Yucatan Peninsula hampered its contribution to its stated goal, which was to encourage self-sufficiency among the population? To answer this research question the POPMI Program will be analyzed from the beneficiaries' perspective, departing from their experiences at different levels/components of the POPMI implementation process and analyzing these through Contextual Interaction Theory (CIT). This form of analysis concentrates on their motivations, cognitions and resources: (a) looking at the backgrounds of the target population as sketched above; (b) the submission of the project for approval, its granting and follow up; and (c) the internal organization of the cooperatives and their development. 
In the second section we present background information on the context and purpose of creation of the POPMI Program, the governmental institutions involved in the process and the changes this program has gone through over time. The third section will provide a more detailed explanation of the methodology used. In the fourth section, the implementation of the POPMI program will be analyzed using the Contextual Interaction Theory from the backgrounds and experiences of the beneficiaries; in the fifth section, the results will be discussed and lastly, a conclusion section will answer the research question.

\subsection{The Program of Productive Organization for Indigenous Women (POPMI)}

The POPMI program was created in 2002 with the purpose of integrating women in the workforce, in particular those who require alternative support in replacement of the unpaid work, especially related to the care of others ${ }^{20}$ : children, elderly and sick people living in the same household (Inmujeres, 2012:64). These tasks are performed simultaneously with their economic activities. Most women engaged in agricultural activities are recognized only as unpaid family workers, since they do not have ownership of the land; therefore, their participation in microbusinesses in their communities is a viable income alternative conditioned to their available time.

POPMI was administered by the Secretary of Social Development/Secretaría de Desarrollo Social (SEDESOL). At that time, its main objective was to improve the living conditions and social position of indigenous women living in areas of high marginalization. Its purpose was to encourage and empower them to be organized and to participate in any possible decisionmaking processes. Female indigenous people were stimulated to generate their own productive project, not only for the purpose of improving the income of the women and their families, but also to provide them with opportunities for personal development. POPMI was part of what became known as the Indigenous Fund.

In 2003, POPMI was transferred to the National Indigenous Institute/Instituto Nacional Indigenista (INI), an institute created in 1948 that mainly addressed the issues related to indigenous people. That same year, 2003, the INI became the National Commission for the Development of Indigenous People (CDI).

The National Commission for the Development of Indigenous People (CDI) is a decentralized institution of the Federal Public Administration with an autonomous budget and administration. CDI works through state delegations, which means that decision-making and management are transferred from the federal government to local agencies that have some autonomy. Delegation is the weakest form of decentralization but it means at least a degree of decentralization in a highly centralized country such as Mexico. These state delegations of CDI do not depend on the decisions of the offices located in Mexico City. However, they do not have complete management of the budget either, as there are guidelines that commit them to the instructions of central administration.

\footnotetext{
${ }^{20}$ Caring for others. Cultural values that promote the idea that women should take care of their husbands, daughters and sons, mothers, fathers, grandmothers, grandfathers, sick aunts or the elderly and in general, everything that requires care. This is unrecognized, unpaid work and is not only a disproportionate burden on women but also, in practice, an invisible subsidy to the economic system (Lavalle, 2010: 54).
} 
CDI, through the POPMI Program, provided support for indigenous women above the age of 18, who formed groups of, at least, eight women. Furthermore, indigenous women were beneficiaries under the age of 18 if they were married or living with a partner or as a single parent, with the responsibilities of maintaining the home. The program granted up to $\$ 150,000$ pesos $^{21}$ for productive projects of which $20 \%$ of the support was designated for training and technical assistance for installation and start up of the project. The remaining $80 \%$ was destined to the purchase of inputs or raw materials for production, tools, machinery, equipment and costs associated with the installation of the micro-business, and adjustments to the physical space for the allocation of the production project which was generally the living room of the cooperative leader.

POPMI was developed in localities with $40 \%$ and over of indigenous population, with high rates of marginalization, preferably outside the municipalities. In those indigenous populations the Mayan language is the dominant language. Because of that, the women received the support of bilingual female promoters hired by the CDI, who were native people from the community with a certain educational level (secondary school). The paper work relating to the request for support to finance their productive project was a service which, according to the POPMI's guidelines, was free of charge for all women who met the characteristics required by the program.

CDI promoters were the main actors of rapprochement and liaison between the institution and the beneficiaries, especially monolingual beneficiaries. Their function was to spread information about the program and accompany the group of women. This facilitates the follow-up process and reduces obstacles in the beginning of the project. The promoters, in addition to speaking the Mayan language and being part of the community, also deepen the knowledge of the situation of the women involved in the productive project, creating responsible leadership in the community (Quezada, 2008: 54).

For the application process the women had to show that they had no debts from any other governmental programs and that they had never been a beneficiary of other similar federal programs (DOF, 2013). All amounts received should be used for expenses authorized by CDI, and all invoices, receipts and notes should be endorsed by the local authority and the signature of each member of the cooperative to ensure transparency in the use of the resources.

POPMI's guidelines indicated that all productive projects should have post allocation support (follow-up), which must be conducted during and after the project installation through regular visits by representatives of the CDI. For instance, in the first year of the project, if the female group is inactive for more than three months, or has disintegrated leaving a minimum of four beneficiaries, its assets should be transferred to another similar group also participating in the POPMI Program.

In 2014, POPMI changed to Program for the Production Improvement for Indigenous People/Programa para el Mejoramiento de la Producción y Productividad Indígena (PROIN). The PROIN is the fusion of several production programs which had been operated separately

${ }^{21} \$ 8,350$ USD dlls. 
until 2013 (CDI, 2014: 5).

Currently, PROIN projects are intended to support indigenous women, eco-tourism and community production projects. Although this paper describes specifically the POPMI Program implementation process, one of the differences found between the POPMI Program and the PROIN Program is the reduction of the needed number of participants from eight women required by POPMI to five women in the PROIN Program. Another important difference is the amount approved per project which was increased from $\$ 150,000$ to $\$$ $250,000^{22}$ pesos. Participants did not have to show prior organizational experience in business and the percentage for training increased from $20 \%$ to $30 \%$ of the approved budget.

\subsection{Case Selection and Methodology}

In this section the methodological approach used in this research is explained. After the case selection, the data gathering process will be explained. Thereafter data analysis will be dealt with and the framework used for this purpose.

\subsubsection{Case selection}

The cooperatives included in this research were chosen from a list of 90 cooperatives which was provided by the Center for Evaluation and Monitoring Quality Professional Services (CECS). This is an academic department within the Universidad Intercultural Maya de Quintana Roo, supported by governmental funds to evaluate entrepreneurial activities in rural communities.

Case selection was not geared towards systematic case comparisons, but rather towards providing the most complete picture possible of the kind of cases that fit our research. Therefore, we preselected 19 cooperatives out of the total of 90 which had female presence. However, only 10 had all the predetermined characteristics for this research: (a) the cooperatives should have more than $80 \%$ of female participation; (b) they should have received financial support from the Mexican federal government through POPMI (seed money to start their micro-business); (c) the participants should have an indigenous background; (e) they should have dependents (either children under 18 years old or elderly family members or relatives with a chronic illness) living in the same household. During the fieldwork, one of these 10 cooperatives refused to be part of this study. Another cooperative did not have women involved although it was officially registered that women were included as part of the cooperative organization. Hence, the members of 8 cooperatives were interviewed, all of which were located in seven Maya communities of the Yucatan Peninsula in southeastern Mexico. Of these 8, 3 are agricultural, producing low-tech products. The other cooperatives are dedicated to: honey production, the marketing of plastic and glassware, traditional medicines and traditional food, a veterinary and a traditional clothing shop.

\footnotetext{
${ }^{22}$ From $\$ 8,350$ USD dlls. to $\$ 13,900$ USD dlls.
} 


\subsubsection{Data gathering}

This study employed the qualitative methodology approach for social research of Hernández, Fernandez \& Baptista (2010). This methodology prioritizes the narrative of the experiences of the members of cooperatives in order to interpret them theoretically thereafter, and also establishes the social dynamics and roles developed in the internal organization of the cooperatives. It allows the determination of the real scope of the program, the process of formation of the groups, the follow up process, and also the disagreements between group members and the challenges they had to face during the implementation process, the experiences of the members and their interest in participating in this organization.

Aside research desk using as much documentation as could be gathered provided by the Mexican federal government through official documents and information concerning POPMI available on their websites, 8 group interviews were held as well, based on a semi structured questionnaire, which were carried out to gather empirical information. The location for the interviews was arranged in accordance with the participants' availability; 6 interviews were held while they were performing their productive activities on cooperative premises and 2 in the homes of the participants.

The participants that were interviewed presented an average age of 44 years, with elementary education, indigenous Maya background, married and with dependents. The questionnaire was applied in the Mayan language with the support of translators to Spanish, since some of the members of the cooperatives do not speak Spanish. The content of the interviews was written in Spanish by the first author, who is a native Spanish speaker, in order to interpret the results and understand and register which of the elements mentioned led them to success. The process of interviewing the members of the cooperatives took place during the year 2015 . The interview format allowed the female interviewees to describe their experiences participating in POPMI and creating the micro-business in the cooperatives. The questionnaires were centered on understanding which aspects hampered the contribution of POPMI in its intention to encourage self-sufficiency among the female Mayan population. In addition to desk research and interviews, a direct observation method was also applied during the field work.

\subsubsection{Data analysis: Contextual Interaction Theory}

Data was systematically organized under the elements of the Contextual Interaction Theory (CIT) (Bressers, 2004:290) emphasizing the motivations, cognitions and resources of the actors involved in the cooperatives. According to the authors, motivations drive the actors' actions, cognitions represent the subjective knowledge held to be true and resources provide the actors with the capacity to act with power over other actors. This theory was chosen because it has shown to be applicable in the assessment of policy implementation, which is the case of the project in hand. Policy implementation is not a unilateral act of government, but rather a multi-actor interaction process (De Boer \& Bressers, 2011:57). The CIT was applied in order to understand the background of actor characteristics, the interaction between policy implementers and participants and the interaction among the participants themselves, as both processes contribute to the degree of success of the POMI program. Figure 4.1 
illustrates the relationships between actor motivations, cognitions and resources and their impact on the ongoing processes.

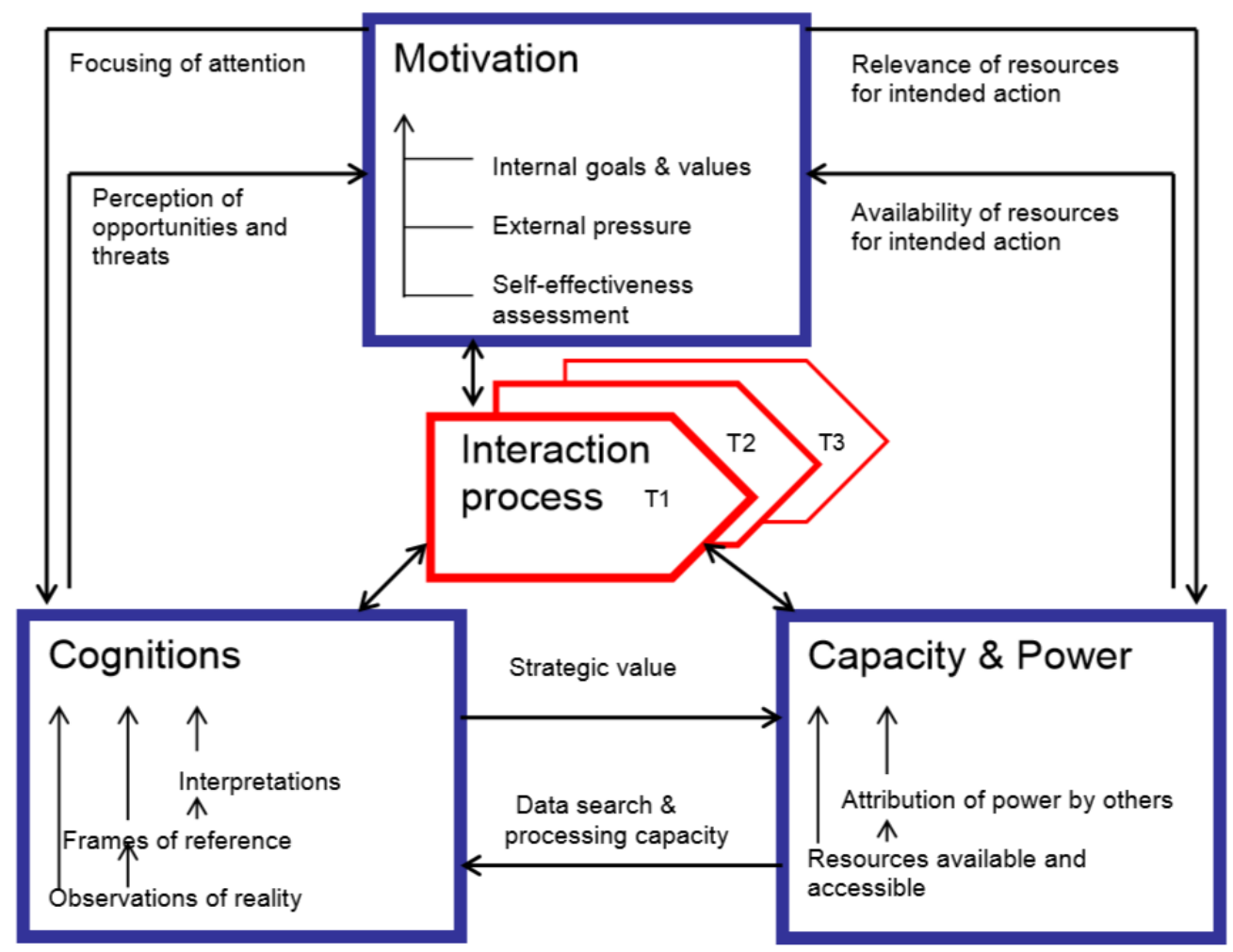

Figure 4.1 Dynamic interaction between the key actor-characteristics that drive social-interaction processes and in turn are reshaped by the process.

Source: Bressers, 2009.

\subsection{Empirical Results}

The results of this study are presented in three sub-sections. The first part uses the elements of the Contextual Interaction Theory to clarify the background of actor characteristics of the Maya women participants. This is important as a context since the implementation of POPMI did not enter a "blank" situation, given that its new elements contacted actors that already have a lot of characteristics that stem from their general situation. This part is mostly based on desk research and direct observation. The second sub-section describes some aspects of the POPMI implementation which was undertaken by CDI government representatives and cooperatives formed by women participants. Subsequently, the organizational aspects of the cooperatives, object of this research, were analyzed to further understand the aspects hampering POPMI implementation in the Yucatan Peninsula.

\subsubsection{Backgrounds of the actor characteristics of the women in the cooperatives}

The motivations which drive the actions of the women are rooted in a strong association between internal goals and family values related to their Maya heritage, in which a patriarchal 
family structure prevails, where men make the decisions and women obey. Among the relevant external pressures, we can find a predominant culture where the women in the community can relate only to other women living in the community. Their actions must be developed only in the private sphere, inside the house. However, the motivation to provide better opportunities for their children through education and adequate food are sometimes stronger than external pressure, which drives them to break down these social barriers and leave their homes to work with other women in cooperatives. In this way they provide an alternative income to meet household expenses, help their husbands, educate and nourish their children, and to support elderly and sick family members living in the household.

For the purpose of this research the term cognitions was defined as information held to be true, as observations are filtered by frames of reference through which the situation is interpreted (Bressers, 2009). The interpretation of reality that these women have is limited by the remote geographical location of their communities, in some cases without access to communication services such as telephony or internet and with frequent electric power failures. Their frames of reference are often just their culture and home situation and the information provided is mostly given by their spouses and children studying outside the community. As mentioned by Simon (1979) in his contribution to organizational theory; in this case the process of decision making is limited to information provided by family and community members. This "bounded rationality" affects their expectations of POPMI and its implementation.

The resources, understood as assets providing capacity and power, are not only the technical capabilities of the participants in this research, based on traditional knowledge applied to productive activities, but also the cultural aspects such as community and family as an organizational base, with their practices and customs which provide them with the frame of reference for their behavior, while providing social capital as a support network among community members. Many other resource bases are lacking, as was mentioned above.

Of course, the general situation in one box influences the other. One relationship demonstrated by the theory is that of resources and cognitions: data search and processing capacity (which would provide cognition of POPMI for example), is partially dependent on initial resource position. Also, according to the theory, cognitions present the world as a combination of opportunities and threats to the motivation; however, when cognitions are lacking, e.g. because information about POPMI does not reach the women, then such opportunities will not be able to motivate. This means that unsupportive patterns of resources, cognitions and motivations might even deepen or stabilize on unsupportive levels. Programs like POPMI have stated goals to break through such stalemates.

\subsubsection{The Implementation Process of the POPMI Program in the Mayan Region}

As was mentioned in the introduction of this paper, in general, the POPMI program and its implementation have contributed to positive changes in the personal lives of the beneficiaries. The description of the program in section 2 also showed that it has many "progressive" features that are geared towards avoiding some of the pitfalls of paternalism that are not uncommon in support programs all over the world. However, that does not imply that the 
implementation and effectiveness of the program were flawless. Some inadequacies reported during the interviews in relationship to POPMI implementation were:

- No public consultation was considered during the preparation of the implementation program, resulting in insufficient overview of potential beneficiaries and their situation and customs.

- Insufficient communication to reach all potential beneficiaries creating relatively coincidental inclusions and over-representing those with better contacts.

- Soliciting payments for support with proposal writing.

- Using the granting of support for political benefit.

- Conduction of follow-up visits in a rather superficial way.

Many of these points are actually in contrast with the program guidelines. These points are illustrated below with some of the experiences of the participants:

In a conversation carried out with the women beneficiaries from the eight cooperatives, during field research, it was recorded that there had been no process of public consultation in the communities regarding the implementation of the program. This has had a negative effect on its affinity with the customs of the region of the Yucatan Peninsula. This lack of public consultation for the development of public policies and programs involving the indigenous population is quite typical since any dialogue with governmental authorities in these kind of initiatives is not at all usual. None of the participants in this research reported having been invited to meetings with CDI or government officials prior to the call for participation in the POPMI Program.

In the same way the management of information related to the financial supports was among people who were close to the political sphere of these communities, and who were familiar with the procedures for submitting a productive project through a relative or acquaintance in a position of popular representation: "My husband told me they were offering support for projects because at that time he worked as secretary to the mayor" $(\mathrm{C4}, 2015)$.

In the process of developing the productive project, free support was given by CDI representatives according to the program's guidelines; however, it was quite common to find that the beneficiaries received external support from relatives and other representative figures of the community such as rural professors or museum directors: "I found out about the support and asked my daughter who is studying her bachelor degree to help me to prepare the project and she submitted it to the CDI located in the municipality of José María Morelos. We gave them our documents and they asked us if the group was formed by women" (C6, 2015).

Another discrepancy found refers to the fact that the guidelines established for the POPMI program cannot be used in the development of electoral processes of federal, state and municipal elections, nor be related to political purposes; however, a strong relationship was found between the delivery of approved resources and political interests, e.g.: "When we received the support it was election period" (C7, 2015), thus we can observe that it was not a systematic support, but was given according to election times in some of the cases; also as a form of self-promotion by the authorities in turn: "The mayor came in person to our houses with other state and local government officials and when we were handed the check they took photos with us" $(\mathrm{C} 1,2015)$. 
Follow up activities and accompaniment were carried out by governmental officials, but the aim of these visits was more focused on finding out if the cooperatives continued working, instead of promoting their further development: "We regularly had visits from the CDI promoters and other government officials to check if we still ran the cooperative and when they came they took pictures" $(C 1,2015)$. "We received visits from the government to see where we would be working and after receiving the support" $(C 2,2015)$. "We received visits from representatives of the government to check our work and the place where we were working. Later we received other visits and they took pictures as evidence. They visited us every 15 days during the first year and also after that they visited us, but not too often " (C6, 2015).

This could also result in advice that was not really appropriate for the situation of the cooperative: "CDI officials asked us to change the label and put a barcode on it to help us to distribute our products in supermarkets, but if we do that the product will ferment. We use traditional methods. We cannot sell it after one week of preparation anyhow" (C2, 2015).

As for the training, in all cases the actions were according to the those established in the guidelines; the participants in this research mentioned that they took courses and participated in workshops as part of the support, they did not have to pay for training and the instructors were assigned by the CDI, in some cases the training was in their communities and in other cases the training was carried out in the municipality: "The training we received lasted for a month. The CDI sent the instructor to us and he came to teach us. We did not pay him; he was paid with the support already approved" $(\mathrm{C} 1,2015)$.

One other element that was well aligned with the purpose of the program was the presence of indigenous promoters in all of the cases, who were of great help to the beneficiaries. Like the women from the community, they spoke the Mayan language and gave their support in starting up the business and consolidating the cooperative.

Despite the two positive points mentioned above, and acknowledging that both the implementers and the beneficiaries are not homogeneous groups, but have individual differences, is seems that the motivation of at least some of the implementers has been quite shallow, more orientated towards applying the program at face value than to using it maximally to improve the situation of the cooperatives, as in the stated goal of the program. This also restricted the eagerness with which they have been building up their cognitions, the "focusing of attention" in the theory. Without sufficient overview of the cooperatives and their circumstances, optimal allocation of support is difficult. Furthermore, the option of using follow-up visits for additional information gathering and guidance was also used quite superficially. It was not possible to ascertain to what extent this was due to lack of resources, for instance woman/manpower, creating insufficient capacity for implementation. The mere fact that the implementers had the power of decision over the granting of financial support created an asymmetrical resource dependency, and thus power.

With respect to the beneficiaries in the process, there was certainly positive motivation to receive the support; however, in order to experience this motivation at least some cognition is needed regarding the existence and conditions of the program and, as we have seen, these were unevenly disseminated. The low resources of the beneficiaries made it just a matter of 
coincidence for them to become aware of the program and to receive support in the elaboration of proposals. Their weak power position also implies that it is not easy for the beneficiaries to demand a more adequate application of the program by the implementers.

Given the dependent position of the beneficiaries, the manner in which they themselves are organized within the cooperatives is of particular importance. Therefore, in the next subsection, we will delve somewhat deeper into the internal interaction in the cooperatives in an attempt to explain the degree of success of the POPMI program for the 8 cooperatives analyzed in this research.

\subsubsection{Organizational Aspects of Microbusiness Cooperatives participants in this research}

Regarding the organizational aspects of the micro-business, it was observed that:

- In cooperatives already formed within the community there is a different process compared to those formed with CDI intervention. The latter are more vulnerable to internal conflict and disruption. For existing cooperatives, motivation is stronger and therefore more stable as it is not just about obtaining POPMI support. Moreover, their cognitions on how to collaborate are more developed, building social capital as a resource.

- Having to work together in situations of conflicting interests can be demanding. Positive experiences can result in an upward feedback cycle, strengthening motivation, cognitions and resources; however, the opposite is also possible (compare the feedback between the process over time and the actor characteristics in figure 1). When a positive cycle occurs, this could involve more people than just the women participants.

The cooperatives already existing in the community were formed by women who have known each other for a long time. In most cases they are linked by family ties and trust, which increases the existing social capital and has a positive effect on the sustainability of the cooperative. Examples are cooperative 6 and cooperative 7. The participants in these two cooperatives had already met and started working together before receiving the support, and being a part of the POPMI Program allowed them to develop further the existing businesses.

Both cooperatives are still working and both are profitable because the ties that bind them are stronger than merely economic interest, whereas cooperative 3 , for example, disintegrated in the first year of operation. We can compare the testimonies of the participants of Cooperative 7 and Cooperative 3 as follows: "We acquired our knowledge of traditional medicines from our grandparents and we gathered together to work in the museum. We went voluntarily because we wanted to. Over time, the number of people increased, and then the cooperative was formed" $(C 7,2015)$. In contrast, the participants of Cooperative 3 declared that they were not consulted about who they wanted to work with. During a meeting with CDI representatives about the benefits of POPMI Program, they divided them into groups with women they did not know, which led to the failure of the productive project: "A woman from the community invited us to a meeting to get support from the POPMI Program, we were 21 people and we were divided into subgroups of 7 women. I did not know them, the CDI grouped us. I think it was one of the reasons why the cooperative did not work. All they wanted was to distribute the money among everybody" $(\mathrm{C} 3,2015)$. 
As for the internal organization of the groups, problems among the members of the cooperatives were mentioned repeatedly, for various reasons. Some of these related to the distribution of profits, family problems that affect business, and even lack of interest:

"We had internal conflicts within the cooperative. We were eight at first, but gradually some of the women were discouraged. They didn't come every day to work as they promised in the beginning, and then they showed no responsibility for the expenses made. We had many discussions that even turned to insults. We had to have a meeting to discuss the problems and invited CDI representatives to let them know the situation and we asked them to intervene and to give us a solution. In the end we divided the cooperative into two groups, some come in the morning and others come in the afternoon" (C1, 2015).

"Some of the women left the cooperative, after the first year. We decided to give them each $\$ 5,000$ pesos (about $\$ 300$ USD dl.) to get full control of the business" (C4, 2015).

"From the beginning to the present day only five women stayed. This is because many are discouraged and do not come to work. But I keep working because I like it and also because I have to help my children with their school expenses" (C6, 2015).

Among the benefits mentioned by the participants was the fact that the business eventually becomes a family business, where the sons, nephews and sometimes their spouses participate. This fact was confirmed during the interviews, when some male relatives were observed working with the women. This was not mentioned to CDI since the support was only for women. Furthermore, they feel recognized in the community as successful women because they have their own business and can help their families, especially the children who are still studying (C3, C4, C7, 2015), all of which helps to strengthen their self-esteem and sense of self-sufficiency, which is the ultimate goal of this program.

The two main observations in this subsection illustrate the importance of the development of motivation, cognitions and resources over time for the successful absorption of the POPMI support. In that sense therefore, it was an implementation mistake to try to develop new cooperatives during the process of providing financial support.

To better understand the interactions between the Mexican government and the indigenous Maya population, a chart has been created to explain the implementation process using CIT: 


\begin{tabular}{|c|c|c|c|}
\hline & Motivations & Resources & Cognitions \\
\hline $\begin{array}{l}\text { Mexican } \\
\text { Government }\end{array}$ & $\begin{array}{l}\text {-Encourage self-sufficiency } \\
\text {-Promote social inclusion of } \\
\text { indigenous women living in poverty } \\
\text { who have low educational levels } \\
\text {-Guarantee their access to } \\
\text { fundamental human rights, in } \\
\text { particular that of no-discrimination } \\
\text {-To enable a life free of violence } \\
\text {-Give the opportunity to the women } \\
\text { living in marginalized conditions to } \\
\text { aspire to opportunities of } \\
\text { development } \\
\text {-To improve the social position of } \\
\text { indigenous women living in areas of } \\
\text { high marginalization } \\
\text {-To encourage women to be } \\
\text { organized and to participate in any } \\
\text { possible decision-making processes } \\
\text {-To encourage personal and } \\
\text { economic development } \\
\text {-Enhance the skills of the Maya } \\
\text { population } \\
\text {-Promote gender equality in rural } \\
\text { communities } \\
\text {-To influence the rural population in } \\
\text { election times to vote for political } \\
\text { parties (undeclared) }\end{array}$ & $\begin{array}{l}\text {-Financial resources to } \\
\text { support } \\
\text { entrepreneurship } \\
\text { initiatives } \\
\text {-Power of decision over } \\
\text { the granting of financial } \\
\text { support } \\
\text {-Bilingual } \\
\text { (Maya/Spanish) female } \\
\text { promoters hired by the } \\
\text { CDI } \\
\text {-Training and technical } \\
\text { assistance for } \\
\text { installation and start up } \\
\text { of the project } \\
\text { - Post allocation support } \\
\text { (follow-up) during and } \\
\text { after the project }\end{array}$ & $\begin{array}{l}\text {-Use of Maya language } \\
\text { with target population } \\
\text {-Experience in the } \\
\text { application of } \\
\text { development programs in } \\
\text { indigenous populations } \\
\text {-Political networks inside } \\
\text { the communities }\end{array}$ \\
\hline Coop & $\begin{array}{l}\text {-Alternative source of family } \\
\text { income } \\
\text {-Provide better opportunities for } \\
\text { their children through education } \\
\text {-Provide adequate food for their } \\
\text { children } \\
\text { - Support economically the elderly } \\
\text { and sick family members living in } \\
\text { the household } \\
\text {-To acquire new skills and abilities } \\
\text {-To spend time with other women } \\
\text { living in the community and share } \\
\text { time and life experiences (the more } \\
\text { so when these women are already } \\
\text { acquainted with each other) } \\
\text {-To avoid physical, psychological } \\
\text { and sexual violence occurring inside } \\
\text { the family }\end{array}$ & $\begin{array}{l}\text {-Traditional knowledge } \\
\text { applied to productive } \\
\text { activities } \\
\text {-Community and family } \\
\text { as an organizational } \\
\text { base } \\
\text {-Social capital as a } \\
\text { support network among } \\
\text { community members } \\
\text {-Occasional knowledge } \\
\text { on the existence and } \\
\text { conditions of the } \\
\text { POPMI program }\end{array}$ & $\begin{array}{l}\text {-Limited interpretation of } \\
\text { reality due to the remote } \\
\text { geographical location of } \\
\text { their communities } \\
\text {-Incomplete information } \\
\text { about the program in the } \\
\text { community }\end{array}$ \\
\hline
\end{tabular}

Table 4.1 Overview of motivations, resources and cognitions of main actors. Source: Main author, 2017. 


\subsection{Discussion}

Programs such as POPMI are necessary to provide economic and social alternatives for indigenous women. Despite the deficiencies in the implementation of this program, this research found intangible benefits which go far beyond economic profit among the participants, such as promotion of their self-esteem. This is one of the values most needed among this population because of the history of abuse they have experienced in relation to cultural aspects of their society. It also provided an increased sense of self-sufficiency, respect from their spouses and support from their children in their new productive activities.

However, during the implementation process of the Program of Productive Organization for Indigenous Women (POPMI), we also perceived some indications of an inadequate involvement of CDI officials in the grouping of women in cooperatives, a paternalistic attitude of the government related to political interests, internal problems between the women, and traditional production methods which were found to be an asset that united them, but were also a limiting factor in the commercialization of the production in local markets.

One of the most important deficiencies relating to governmental actions was the lack of consultation with the indigenous population and alignment with their uses and customs prior to the implementation process. When working with indigenous communities it is essential to involve them in the formulation and implementation of public policies, in particular the social and productive programs that benefit them. Their input, based on local values, aspirations and social organization, makes their culture an asset rather than an impediment to development (Dureyttere, 2003, Lerner, 1996).

This observation is in line with Calderon (2009) who mentioned that in Mexico the population living in poverty has a very limited participation in the formulation of public policies and programs to promote their development, and any participation permitted to them is carried out within the parameters imposed by the government in such a way that the population never escapes from vertical state control. The contributions of the population are defined in advance by government officials. Even in the best case scenario their views are taken only to confirm the decisions already made. Most of the time the beneficiaries must simply accept to obey a set of rules in order to receive official support. In the worst case scenario, the support is merely a strategy of politicians and public officials to seek supporters (compare Calderon, 2007: 391). This concurs with the results of this research where the financial support given to indigenous women through POPMI was in some cases related to political interests.

In order to escape from this dependency of the population on the government it is important to enhance civil society participation in the formulation of public policies enabling the people to influence decision-making from a bottom up perspective. While this is formally guaranteed by laws and administrative regulations, promoting cooperation practices and attitudes of trust in practice remains difficult (Aguilar, 2011, Sánchez, 2003, SEGOB, 2006).

It was also found that the grouping of women into cooperatives by the government was a mistake; in this case, a mistake that was made by some of the CDI representatives. These actions caused the dissolution of some of the microbusinesses in the first year of operation 
because the women who were grouped together did not know each other, and thus had no bonds of trust to unite them, much less a history of working together.

On the positive side, the involvement of indigenous promoters who were women of the same indigenous community, with secondary education and who spoke the Mayan language, was of vital support. They supported the participants in the development of the project and after the installation of the business, although their work was limited at this last stage and their visits were related to confirming the existence of the cooperative instead of promoting the consolidation of the microbusiness. Sometimes they were accompanied by government officials to verify the application of the support received rather than to offer further advice and options for business sustainability. This is confirmed by the statements of women who participated in this research who said they received visits from government officials who only "took pictures".

Strangely, although none of the participants in this research claimed to have participated in the process of assessment and feedback of POPMI program, it was found in the literature review process that CDI seems to have conducted an assessment of POPMI program subsidized by the Mexican federal government.

\subsection{Conclusions}

Maya women in the Yucatan Peninsula face unwritten community rules where women commonly work only within the confines of their homes, always under the supervision of their husbands, who often contribute little to the family income. Once the participants start their own businesses with the help of productive programs such as POPMI, women in general along with those working in cooperatives, begin to participate in the public arena, where they have to interact with others in the community beyond the boundaries of their households, seeking support for the start and growth of their microbusiness, developing their management and dialogue skills in their interactions with other community members and government representatives. For the women, this positive feedback represents a major source of appreciation from the people to whom they feel emotionally attached; a respect and support they should have received in the first instance for their activities as mothers and wives supporting their families, prior to their involvement in business activities.

The study reported in this paper started out with the question: What aspects in the implementation process of the Program of Productive Organization for Indigenous Women (POPMI) for the Mayan population of the Yucatan Peninsula hampered its contribution to its stated goal to encourage self-sufficiency among the population? It is concluded that, despite some shortcomings in the way CDI administrated the program (lack of consultation among the community and deficient monitoring) some women have developed selfmanagement skills and have appropriated their projects. Also, others have benefited from training in handling their projects and the knowledge of women's rights, albeit incipiently. 


\section{Acknowledgment}

This research project was funded by the Nestle Foundation for the Study of Problems of Nutrition in the World.

The authors would like to recognize the work carried out by María Francisca Poot Cahun, Rudy Rubén Chan Tuz and Gilberto Ku Mukul who were Mayan translators to the Spanish language during and after the interviews carried out as part of this research paper.

We thank Prof. Dr. Larry O’Toole for helpful comments on an earlier draft of this paper. 


\title{
Chapter 5. Analysis of Canada Fund for Local Initiatives (CFLI) supporting economic development of Maya women in Mexico's Yucatan Peninsula ${ }^{23}$
}

\author{
María Cristina Osorio Vázquez ${ }^{24}$, Hans Th.A. Bressers ${ }^{25}$, María Laura Franco García
}

\begin{abstract}
Purpose - This paper analyzes the implementation process of the Canada Fund for Local Initiatives (CFLI), a program which is part of the Canadian International Development Agency (CIDA). CIDA was a Canadian federal agency which, until 2013, promoted female entrepreneurship initiatives among Maya women in the Yucatan Peninsula.

Design/methodology/approach - This study uses qualitative methods in social research to collect information and Contextual Interaction Theory (CIT) to analyze data, while emphasizing the motivations, cognitions, and resources of the actors involved.

Findings - The analysis of the implementation process demonstrated, from the participant's perspective, that it was possible to achieve the objectives of the program related to promoting sustainable economic growth and advancing gender equality among indigenous populations with an efficient administration of their resources. However, internal difficulties in the organization of the micro-business affected the development of the project. Therefore, the results of the initiative did not achieve the expected sustainability for all the participants. The women with a profile of responsibility and self-reliance were the only ones who endured and benefited from the program in the long-term. This demonstrates that economic development is not possible when only based on external support, but needs to be combined with the capacities, values, and life perspectives of the beneficiaries.

Originality/value - This paper investigates how and to what extent the Canada Fund for Local Initiatives (CFLI) functions as a support program in practice, as well as what factors contribute to and restrict its degree of effectiveness.
\end{abstract}

Keywords:

Women-Canada-Development Aid-Cooperative-Maya

\footnotetext{
${ }^{23}$ This paper has been presented at the 7th Congress of the Belgian Francophone Association of Political Science held in Université Catholique de Louvain (Belgium), April 3-4, 2017 and has been submitted to peer review procedure as a book chapter in a publication dedicated to indigenous population in Latin America organized by The Johannes Gutenberg University of Mainz.

24 M.C. Osorio

School of Economics and Business

Universidad Anáhuac Mayab

e-mail : maria.osoriov@anahuac.mx

${ }^{25}$ H. Bressers \& L. Franco

Department of Governance and Technology for Sustainability (CSTM)

University of Twente

e-mail: j.t.a.bressers@utwente.nl

e-mail: m.l.francogarcia@utwente.nl
} 


\subsection{Introduction}

Development aid is provided by developed countries, through government agencies or special NGO's, to developing countries with the aim of reducing poverty rates and other poverty-related deficits. Unlike other national funds, development aid most often works in the beneficiary country through local NGO's and civil societies in agreement with local governments.

It is undeniable that the existence of social and economic problems in Latin America is related to the high levels of corruption, organized crime, and increasing gaps between social classes (CIDA, 2007). Poverty inevitably leads human beings to frustration. Even when earning the minimum wage, they are unable to reach an acceptable quality of life that would allow their family to enjoy basic health, education, and adequate housing.

This situation is not only the responsibility of the government, who has been blamed for all the troubles of underdevelopment, but also of the people themselves who have elected them. Development aid should be used as a support system for development, not as an alternative solution for poverty. For the development aid to be effective it should be implemented over a period of time with specific objectives that contribute to the self-sufficiency of the inhabitants. When indefinite support continues it only contributes to dependency (Uriarte, 1966).

One of the programs, the focus of this study, is the Canada Fund for Local Initiatives (CFLI). This is a program of the Canadian International Development Agency, a Canadian federal agency that until 2013 administered and implemented different development aid programs to combat poverty in the world. Some of their actions include: working in favor of food security, sustainable economic growth, children and youth, advancing democracy, security and stability. This is done with three crosscutting themes: increasing environmental sustainability, advancing equality between men and women, and helping to strengthen government institutions and practices.

This article will specifically analyze a project financed by the Canada Fund that supported the establishment of a microenterprise created by Mayan women in the Yucatan Peninsula, to promote sustainable economic growth and advance equality between men and women.

For this reason, the following research question is asked: What aspects in the implementation process of the Canada Fund for Local Initiatives for the Maya population of the Yucatan Peninsula helped or hampered its contribution to its stated goal, which was to promote sustainable economic growth and advance gender equality among the beneficiaries?

To answer the previous question, the Canada Fund will be evaluated through the participants' perspective, beginning with their experiences at different levels/components of the Canada Fund implementation process and analyzing them through Contextual Interaction Theory (CIT).

This form of analysis concentrates on the participants' motivations, cognitions and resources: (a) observing the background of the target population; (b) the submission of the project for 
approval, its granting and follow up; and (c) the internal organization and development of the cooperative.

Also, a comparative analysis will be made using qualitative methods of social research between this international program and other national ones that have provided support to the same cooperative of Maya women, to reflect on the lessons learned from their experience.

In the following section, we present a historical review of international aid in the world, its main indicators, and definitions. The third section provides an analysis of the Mexico-Canada bilateral relation followed by the fourth section where mention will be made of the different international relations theories forming the theoretical framework of this study. The fifth section will provide a more detailed explanation of the methodology used, as well as the case selection, while the sixth section will present the empirical results analyzing the implementation process using CIT. In the seventh section the results will be discussed, followed by the conclusion where the research question will be answered.

\subsection{International Aid}

The history of international aid dates back to the perspective of imperialist countries which supported their colonies through the construction of infrastructure such as roads, bridges, schools, and hospitals, as well as by activities that would pay them dividends in their position of colonial power, according to their economic and political interests (Abdel-Malek, 2015).

The political division after the Second World War was one of the causes that encouraged the injection of funds to developing countries with the intention of the dominant countries to win a greater number of allies. The growing division of the world into the socialist and capitalist blocks was the reason why development aid was used as an instrument of foreign policy ${ }^{26}$.

Among the reasons for the existence of international aid for development is the moral imperative $^{27}$, which suggests that developed countries have a duty to support disadvantaged countries in order to accelerate their development processes. On the other hand, a 'realistic' vision of aid views the development in relation to the national interest of donor countries, related to security, political power and commercial progress, sometimes even at the expense of less powerful countries (Morgenthau, 1948, Francis, 1993). From another point of view, it can be seen as a relationship of interdependence and mutual benefit (Keohane, \& Nye, 1988) to open up the market and promote foreign direct investment (Joblin, 1994; Montero, 2002).

In 1961 the Development Assistance Committee (DAC) of the Organization for Economic Cooperation and Development (OECD) was created, of which Canada was one of the founding countries. Its purpose was to make decisions in favor of international assistance to alleviate poverty in developing countries and promote sustainable development so that no

\footnotetext{
${ }^{26} \mathrm{We}$ understand foreign policy in the broad sense as a public policy of the State and the government that is projected to the external sphere (Milani \& Pinheiro, 2013; Llistar, 2016).

${ }^{27}$ Moral Obligation to provide basic needs of the states that have the most to those who have the least. It is a restitution or compensation against poverty; the widening gap of resources and opportunities between rich and poor and unjust historical relations between developed and developing countries (Prado, 2009).
} 
country would remain dependent on external aid. International development assistance is termed here as Official Development Assistance (ODA) and is defined as: "all flows to lessdeveloped countries and multilateral institutions (as defined for this purpose) provided by official agencies, including state and local governments, or by their executive agencies; and each transaction which: a) is administered with the promotion of the economic development and welfare of developing countries as its main objective; and b) is concessional in character and conveys a grant element of at least 25 per cent (calculated at a rate of discount of 10 per cent)" (OECD, 2008).

One of the measures used to assess such assistance is the OECD ranking, defined as the proportion of a country's Gross National Income (GNI) devoted to foreign aid, which determined its contribution towards the developing countries. A $0.7 \%$ aid target has been established as a moral obligation. However, there are few contributing countries that reach the specified amount, such as the United Kingdom, The Netherlands, Denmark, Luxembourg, Norway and Sweden (OECD, 2015). There are other indicators such as the Commitment to Development Index provided by the Center for Global Development (CGD) in Washington, in which additional variables are measured, such as the level of democracy of the recipient countries and the procedure for the distribution of resources.

In 2000, the Millennium Development Goals were promoted by the signatory countries of the United Nations at the Millennium Summit in New York. They functioned as a benchmark for development policies and international cooperation efforts. In 2015, the advances made internationally were evaluated at the United Nations Third International Conference on Financing for Development, held in Addis Ababa. As a result, the Sustainable Development Goals (SDGs) followed the Millennium Development Goals (MDGs), focused on official development assistance (UN, 2015, Ingram et al. 2016).

In addition, there were other international efforts in favor of international aid. To obtain more favorable results, the Paris Declaration on Aid Effectiveness was endorsed in 2005, in which the principle of national ownership was established. While international development assistance should facilitate local development, it was proposed that the recipient countries take responsibility in the process, since developed countries just contribute with economic funds and technical assistance. It is then expected that the developing countries should themselves appropriate this process through their local governments and civil societal groups.

Today's development assistance refers to both official and non-official (private) sources, signaling a growing involvement of the private sector in global development (Ingram et al. 2016, Ocampo, 2015). In recent years, there has been a creation of various foundations and charitable organizations that have contributed to development aid. Foundations, unlike the government, maintain their specific objectives and often the level of bureaucracy is smaller and the decision making is faster.

International aid seeks to solve problems that have no frontiers. Examples range from environmental degradation and migration to drugs and epidemic diseases. The lives of many people have become less secure due to the poverty and misery existing in the world (OECD, 2006). This has led to the need for development agencies which can organize the local groups in order to tackle the problems arising from poverty, at their root. Therefore, if the superior 
goal is to achieve sustainable development - preferably without the presence of external assistance - it is necessary to consider the opinions of the affected inhabitants, while analyzing the local conditions, with the objective of carrying out specific strategies.

\subsection{Mexico-Canada Bilateral Relations}

The relationship between Canada and Mexico can be analyzed from different points of view. Historically, it took off in 1944 during World War II when diplomatic relations with Mexico were established for reasons of national security. Later in the 1970s this relationship was further developed to increase mutual trade relations and reduce their economic dependence on the United States (Deblock \& Benessaieh, 2001).

From a commercial standpoint, the most important advancement in this subject was the Free Trade Agreement between the two countries and the United States, whose official negotiations were carried out in the early 1990s at a time when protectionism in Mexico gave way to the era of economic liberalization that is still in force today. In 1994 this agreement was ratified by the three signatory countries.

While the Free Trade Agreement is likely to be re-evaluated in the upcoming years at the initiative of the United States government which claims US job loss in favor of the Mexican labor market; from the very beginning of the treaty the Canadian posture was more empathic to the interests of Mexicans. This was demonstrated, for example, by the offer of seasonal employment opportunities to agricultural day laborers, indigenous education dialogues (Wesley-Esquimaux, 2015), and a more flexible stance toward Mexican immigration.

The objectives of the North American Free Trade Agreement, as with many other examples of economic integration around the world, go beyond commercial issues, covering political and geostrategic security issues in member countries, with Mexico functioning as a pivotal ${ }^{28}$ country towards Latin America and the Caribbean.

In tourism, Mexico receives more than one million Canadians annually (Klepak, 2012), mainly in beach resort areas, such as those in Cancun and the Riviera Maya located in the state of Quintana Roo. There is a growing number of retired Canadians who are deciding to move to the Yucatan Peninsula, due to the warm climate and low cost of living. This situation has been reported in cities such as Merida and Progreso.

In relation to this study, Mexico and Canada have a meeting discussion point: the fate of indigenous groups. Both countries have indigenous backgrounds, where interracial mixing was the result of the colonization process (Ralston, 2009). However, this has not meant greater respect for the indigenous population, their language, or their traditions.

In Canada, the assimilation and integration policies have promoted the loss of their language, a symbol of belonging; in the same way, they were banned through legislation and policies from wearing traditional clothes and practicing sacred ceremonies, while stripping them of

\footnotetext{
28 Pivotal states are countries which, given their size, geo-strategic position, population, and economic importance have the capacity to affect regional or international stability (Chase, Hill \& Kennedy, 1996).
} 
their disintegrated families and relocating children to residential schools where the loss of their indigenous identity was promoted ${ }^{29}$ (King, 2000). Many of these people were nomadic, so grouping them into reserves ended up producing hunger and disease (Wesley-Esquimaux, 2015), which resulted in a significant reduction in their population. In 2008, the Canadian government apologized to the indigenous populations for these actions and formulated The Truth and Reconciliation Commission, established in 2009, to create awareness in the new generations of what has happened and to encourage them to participate in the reconstitution of their culture and language. In Mexico, this advancement has not yet occurred.

In both countries, indigenous people suffer from poverty and discrimination, and therefore unequal opportunities, in contrast to the mestizo ${ }^{30}$ and immigrant populations. In both Mexico and Canada, the indigenous population faces unemployment, which affects their economic self-sufficiency. Rejection and frustration have favored the abuse of alcohol and harmful substances. These conditions have led to family mistreatment, where most of the victims have been indigenous women and children (Dell \& Lyons, 2007).

In Mexico, with a high degree of discrimination towards indigenous people, the new generations are in the process of losing their language and the use of their traditional clothing to avoid being socially excluded in the work place, or even worse to avoid being fired. The governmental reaction has taken the form of paternalistic ${ }^{31}$ attitudes (both, Mexican and Canadian) towards indigenous populations which has had an unexpected effect, in that it has delayed indigenous development and self-determination (Wesley-Esquimaux, 2015).

Under this bilateral context and in relation to indigenous populations, the implementation of the Canada Fund is carried out for the benefit of Maya women living in the Yucatan Peninsula, granted by the Canadian government through the Canada Fund for Local Initiatives (CFLI) and administered by Canadian International Development Agency (CIDA), currently the Department of Foreign Affairs, Trade and Development (DFATD).

\subsection{International Relations as Theoretical Framework}

In the theory of international relations, development aid can be analyzed from different perspectives; here we will mention three of them, which help explain the behavior of the actors involved.

After the Second World War, in a context of postwar devastation, the realist trend emerged whose most famous author was Hans Morgenthau (1948). He explained that all state actions are aimed at maintaining, increasing, or demonstrating power; which is why every act of foreign policy should be viewed as a representation of national interests, expressed in terms

\footnotetext{
${ }^{29}$ One of the most dramatic forms of discrimination is to deny ethnic groups and minorities the fundamental right to exist as such. This occurs when their suppression or deportation is attempted, or even when they are intended to weaken their ethnic identity until they become unrecognizable (Pontifical Council for Justice and Peace, 2000: 73).

${ }^{30}$ Mestizo refers to a human being with parents of different races and the term is commonly used for the persons with indigenous and European background.

${ }^{31}$ Paternalism is the tendency to apply the rules of authority or protection, traditionally assigned to the parent, to other areas of social relations such as politics and the work field (Alemany, 2005).
} 
of national security. The historical context facilitated the spread of this hard line of international thought, while the countries acted with fear of new attacks and ideologies.

The trend of Idealism, years earlier, promoted peace among nations through agreements and treaties, making use of diplomacy to ensure international order and peace. This thought influenced the creation of the League of Nations (1919), known today as the United Nations, so that disputes could be settled through dialogue and consensus.

The main detractors of this line of thought argued that philanthropy and altruism were characteristics of human beings, not of the Nation-State. The latter should protect its borders and its inhabitants, and any act of goodwill between countries would imply weakness. Idealism declined due to the First and Second World Wars, since peaceful mediums such as treaties, international agreements, and diplomacy were proven not strong enough to prevent war.

As the third ideological current, we present the theory of interdependence, which expresses the growing connection between state and non-state actors, and the need for international cooperation in a world of mutual dependence (Keohane \& Nye, 1988).

According to the idealistic vision, international development aid can be understood as philanthropic actions of the most powerful countries to encourage the development of disadvantaged countries. From a realistic point of view, using foreign policy as a tool to preserve national security and the ultimate goals of the nation-state is often distant from the interests of recipient countries. From the theory of interdependence, a shared interest between donor countries, recipient countries, and other international actors, such as the civil society and private sector is leading. It considers that the poverty and deprivation of the developing countries will end up affecting the developed countries, through migration, diseases and organized crime, among other factors.

The theory of interdependence also analyzes environmental regulation in the process of globalization, since it is the natural resources of developing countries that sustain part of the economic growth of developed countries. International aid could be interpreted as a form of compensation for the unequal relationship between countries. Economic growth, by affecting the forests, seas, rivers, and the ecosystems that inhabit them, including humans, shows that the reciprocal costs of exchanges are not necessarily symmetrical. This inequality should be further seen against the background of the growing influence that the large capitalist countries are having on the population of the developing countries through the media and advertising, where extreme consumerism is stimulated which sustains this circle of abuse towards natural resources and human beings living in material poverty ${ }^{32}$.

Under these theories, development aid is analyzed, given that we can observe realistic, idealistic or interdependent behavior in the donor countries related to the interests that motivated them to act.

\footnotetext{
${ }^{32}$ Non-attainment of the material means indispensable for having a dignified life (González, 2016).
} 


\subsection{Case Selection and Methodology}

This section will describe the case selection process, the methodology that was used, and the analysis of the information using Contextual Interaction Theory (CIT).

\subsubsection{Case selection}

To select our case, the Department of Foreign Affairs, Trade and Development (DFATD) was requested by an electronic format provided by the Access to Information and Privacy Protection Division via its website, to provide a list of the groups that have received funding via the Canada Fund for Local Initiatives (CFLI) for women's productive activities in the Yucatan Peninsula. The requested information included the amount each group received, purpose of the grant, description of the project, and the dates when money was granted. As a result, a letter was received from the Department of Foreign Affairs, Trade and Development with information from a national NGO who was the recipient of the Canadian Fund for a total of $\$ 14,993.70$ Canadian dollars. This funding was handed over in several payments between the years of 2012 and 2013, for the purpose of creating a micro-business through the installation of a grinder and tortilla ${ }^{33}$ maker for the development of a group of indigenous women. This female group came from a Mayan community located in the countryside of the Yucatan Peninsula. For this reason, and with no other groups benefiting, the Canada Fund for Local Initiatives (CFLI) implementation analysis will be addressed as a case study.

The case study allows the sample to be a single unit of analysis through the qualitative methodology of social research (Hernández, Fernández, \& Baptista, 2007), and also allows us to generate new knowledge of some aspects of international aid that have not yet been analyzed. Apart from the unique characteristics, our aim is also to find insights that could be applied in similar contexts. This new knowledge contributed by the case study can be used in turn to analyze causal relationships, in this case the interaction between the Canadian Federal Agency, the national NGO and the Maya women's cooperative.

\subsubsection{Data gathering}

In the case study approach, the characteristics of the participants and the interactions among them are described, using participant observation, biography, ethnography, open and semistructured interviews, both with participants of the cooperative and with representatives of the NGO, to gather empirical information related to the implementation process. This methodology also allows us to establish the motivations, knowledge and resources of the parties involved, to be interpreted through the Contextual Interaction Theory proposed by Bressers (2009).

At the same time as the interaction with the participants, a bibliographical review was carried out on the diplomatic relationship between Canada and Mexico, the role of development aid and a description of the functions of the CIDA federal agency and the Canada Fund program through the Canadian public administration. Also, the commercial, social, and political

\footnotetext{
${ }^{33}$ A tortilla is a portion of cooked maize dough formed into a flat, round shape, served as an accompaniment to food.
} 
context between the two countries was analyzed; these are strongly interrelated and interdependent because of their commercial ties and geographical locations.

In preparation of this study, during the summer of 2015, the first author visited different NGO's and Canadian government agencies to become familiar with the programs and support that this country gives to indigenous women and to observe their way of working with local populations, as part of a research stay at Lakehead University located in Thunder Bay, Ontario province in Canada. The request for information to the Department of Foreign Affairs, Trade and Development (DFATD) was carried out via electronic format in May 2016, obtaining a formal response by letter in July 2016. The subsequent process of conducting the interviews occurred between 2016 and 2017.

\subsubsection{Contextual Interaction Theory (CIT)}

Contextual Interaction Theory is an analysis model of the implementation process of programs and public policies. It conceptualizes implementation processes as social interaction between the actors involved, considering their motivations, cognitions and resources (Bressers, 2004). This model is based on programs that are applied by and to human beings, with their perspectives, capacities, and limitations. Hence, in the social interaction during the implementation of the program it is possible to observe the deficiencies of the program, as well as the degree of its success.

In Contextual Interaction Theory, motivations drive the actors' actions; cognitions represent the subjective knowledge held to be true and resources provide the actors with the capacity

to act and with power over other actors. For a further description of the CIT, the following figure is attached where the elements described are illustrated graphically. 


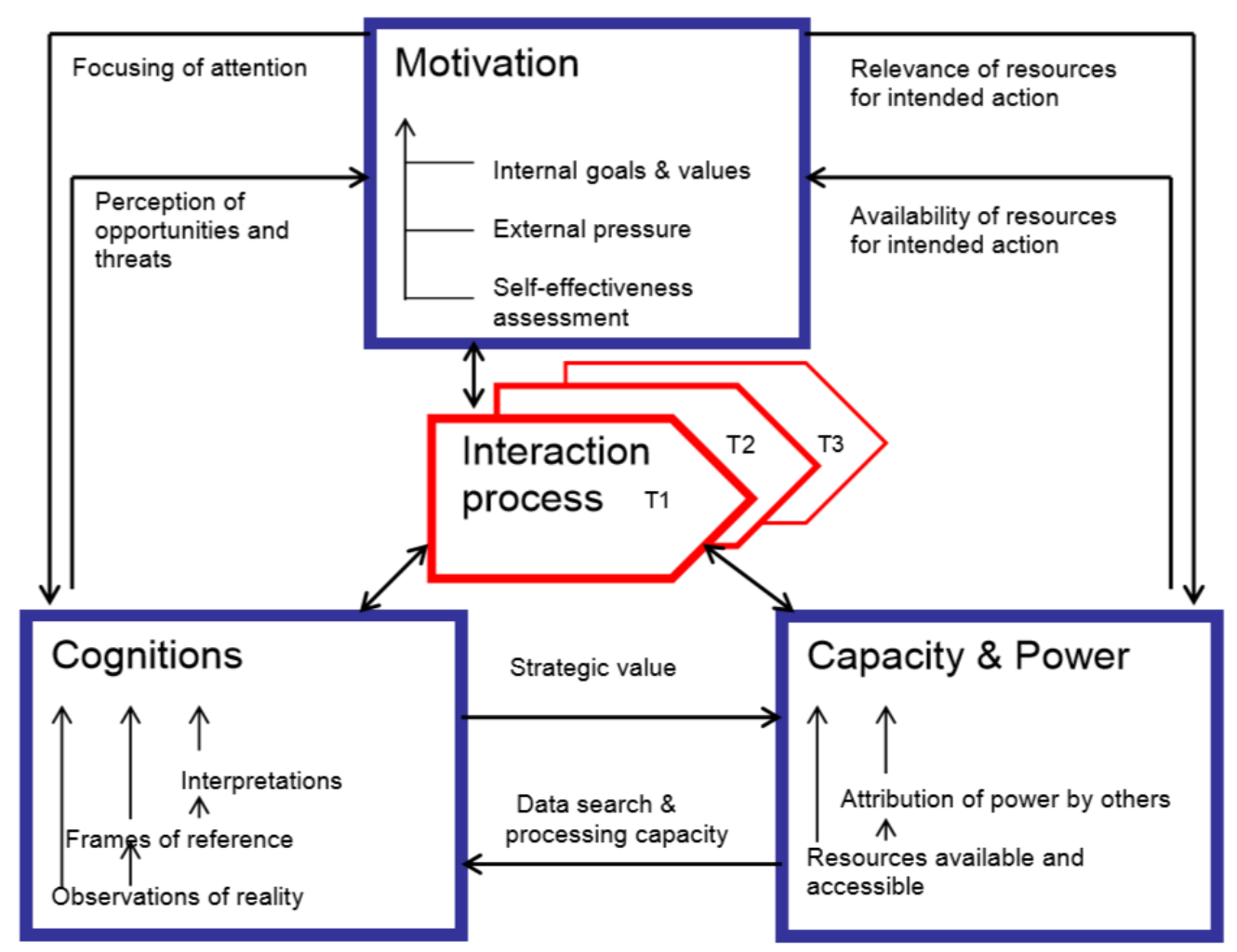

Figure 5.1 Dynamic interaction between the key actor-characteristics that drive social-interaction processes and in turn are reshaped by the process.

Source: Bressers, 2009.

Due to the characteristics of the activities of the Canada Fund for Local Initiatives being a form of implementation process, Contextual Interaction Theory was considered the ideal framework for the analysis of the process.

\subsection{Empirical Results}

The results of this study are presented in four sub-sections. In the first section the characteristics of the actors involved are described. To protect the anonymity of the participants their names are not mentioned. In the second part, the various phases of the implementation are in focus: the submission of the project for approval, its granting and the follow-up. In the third part, organizational aspects of the cooperative micro business are dealt with and in the fourth part; a final analysis of the Canada Fund's implementation is carried out, using CIT.

\subsubsection{Backgrounds of the actors involved}

\subsubsection{The Canadian International Development Agency (CIDA)}

The Canadian International Development Agency (CIDA) was created in 1968 as a federal agency, part of the Canadian Government's Department of Foreign Affairs, but with a degree

of independence in its actions. It administered its own budget and implemented most of the 
international cooperation programs, ${ }^{34}$ with the aim of supporting the sustainable development of developing countries to reduce poverty in the world.

CIDA supported projects in more than 100 countries. Nevertheless, there were between 20 and 25 countries $^{35}$ that received more attention and funds, a priority related to economic and political interests. These funds were transmitted to recipient countries with the intermediation of local non-governmental organizations and in exceptional cases, international NGOs such as UNICEF, the United Nations Development Program, La Francophonie and government institutions. The latter were mostly used for small projects addressing gender equality and women empowerment, democratic governance, climate change and environmental sustainability, security and stability and other issues (Montero, 2002, Fillion-Lauzière, 2008, Pétillon, 2014, CIDA, 2007).

In 2005, the Canadian government issued an approach towards Latin America and the Caribbean with the official statement that it was necessary to reaffirm commitment to Latin American democracies; this was in congruence with the launch of the new "Strategy for the Americas" in 2006, whose goals were to increase economic prosperity, reinforce democratic governance, and advance common security. This meant strengthening the economies of emerging Latin American countries with which Canada had commercial and international security interests $^{36}$ (Macdonald \& Ruckert, 2014, Développement et Paix 2012, Johnston, 2010, Brown, 2016).

Until 2008, the programs it supported were related to health, basic education, private sector development, poverty reduction, democratic governance, gender equality, and environmental sustainability. Later, in 2009, the themes were reconfigured to food security, sustainable economic growth, children and youth, advancing democracy, security and stability, with three crosscutting themes: increasing environmental sustainability, advancing equality between women and men and helping to strengthen governance institutions and practices.

In relation to sustainable economic growth and the advancement of gender equality, CIDA promoted, through its programs, the creation of a favorable commercial environment for lowincome indigenous women, facilitating access to credit and acquiring the necessary skills and knowledge to help the beneficiaries, mostly with their entrepreneurship activities. These financing initiatives enabled women in the Yucatan Peninsula to create microenterprises with the aim of earning an income that could ensure the livelihood of their families (Agence Canadienne de Développement International, 2007). CIDA's actions were in line with the Millennium Development Goals (2000) promoted by the signatory countries of the United Nations, the Monterrey Consensus on Financing for Development (2002), the Paris Declaration on Aid Effectiveness (2005), the Accra Agenda for Action (2008) and the Sustainable Development Goals (SDGs) (2015) (Action Canada et al., 2016).

\footnotetext{
${ }^{34}$ CIDA administered approximately 80 percent of the aid budget. The other 20 percent was administered by the Department of Finance and the Department of Foreign Affairs.

${ }^{35}$ The number of countries focused on varied from 20 to 25 according to the government administration.

${ }^{36}$ Prior to the creation of CIDA, the Canadian international aid for development was related to commercial, political, and security interests, which remained in force, as stated in an official declaration of the Canadian government. This affirms the need to "rebuild the influence of Canada in the world" through international development assistance (AQOCI, 2007).
} 
At a national level, the agency's actions were in accordance with the Official Development Assistance Accountability Act (ODAAA) which came into force in the year 2008, its purpose being to ensure that all Canadian ODA is focused on poverty reduction and is consistent with aid effectiveness principles and Canadian values. In context of the Act, ODA is defined as international assistance that is administered with the principal objective of promoting the economic development and welfare of developing countries or that is provided for the purpose of alleviating the effects of a natural or artificial disaster, or other emergency, occurring outside Canada (Développement et Paix, 2012, Government of Canada, 2016).

In 2013, the Canadian government merged the Canadian International Development Agency (CIDA) with the Department of Foreign Affairs and International Trade Canada (DFAIT), creating the Department of Foreign Affairs, Trade and Development (DFATD), which meant greater government control in development cooperation and international aid actions, transferring their design and implementation of humanitarian assistance policies to DFATD (Carment et al., 2013). One of the official reasons for the merger included greater policy coherence in the Canadian government's actions in diplomacy, trade and development, eliminating unnecessary administrative costs and simplifying bureaucratic procedures. As a counterpart, it was seen as a tool for the advancement of Canadian national interests, mainly security and trade (Brown, 2016, Bülles \& Kindornay, 2013, Schmitz, 2013).

Among the main criticisms that CIDA faced during its management was the fragmentation of its economic support due to the large number of countries in which the agency was involved and a significant gap between its policies and the ineffectiveness of their implementation in developing countries (Schmitz, 2013, The McLeod Group 2014, Johnston, 2010). In the last decade of CIDA's existence, actions were strengthened through civil society and private sector organizations, along with actions undertaken through local governments in developing countries.

\subsubsection{The national NGO}

The national NGO requested to remain anonymous. The origins of this organization date back to 1963 as a support organization for low-income farmers with the support of the Pan American Development Foundation ${ }^{37}$, based in Washington, D.C.

The declared objective of the NGO is the prosperity of the countryside, working with the peasant population to strengthen agricultural activities for own consumption. The model of participation with which they work in conjunction with the beneficiaries is called Basic Social Education. This model functions under the following premises: respect for the personality, culture, skills and knowledge of the peasant, establishment of a horizontal

\footnotetext{
${ }^{37}$ The Pan American Development Foundation was created in 1962 as one of the organizations related to the Alliance for Progress (1961), an initiative of the U.S. President John F. Kennedy to foster cooperation and development between U.S. and Latin America, with the support of the Organization of American States with financial backing from the U.S. Agency for International Development, the Inter-American Development Bank, the Social Progress Trust Fund, and corporate and private donors with the purpose of creating an institution that could mobilize the private sector to assist the most vulnerable people of the hemisphere through productive employment in microenterprises, technical training, civil society development, national entrepreneurship, and the facilitation of corporate social responsibility (PADF, 2016).
} 
relationship between the promoter and the peasant, reinforcement of human values that lead to positive attitudes and behaviors and a productive organizational approach for each project.

Based on their model of collaboration, the NGOs work with communities using participatory techniques and taking into consideration the culture and traditions of the grassroots population, which has been shown to produce sustainable results (Geilfus, 2002, Action Canada et al., 2016). The same applies to the decentralization of functions, bringing decisionmaking closer to the people and reinforcing values as a fundamental part of human development. The reinforcement of positive attitudes towards honesty, effort, and work is fundamental for human beings to take responsibility for their own development.

The organization promotes the development of microenterprises with the objective of generating income and sources of employment for the population, considering social, cultural and environmental factors in the process. The organization also works in coordination with the private sector, organizations, national and international foundations, the Mexican government and foreign governments.

Some of the activities are posters advertising fairs, training activities and assisting the beneficiaries in writing a project seeking international and national support. The organization conducts workshops in favor of gender equality to achieve the involvement of women beneficiaries in economic activities, improving life skills, promoting job training, entrepreneurship and self-worth. In these workshops, the organization identifies potential participants for the creation of micro-businesses based on their capabilities. While strengthening the skills of women, the NGO can be prepared for any proposal convenient for the target group.

Based on the program and practice of the Canadian Fund and its NGO aid, it can be concluded that they work within the parameters of the theory of interdependence in foreign development aid.

\subsubsection{The Female Cooperative}

The cooperative was made up of 7 indigenous Maya women, 6 with basic education and one with a completed baccalaureate, catholic, married with children, and with an average age of 48. All of them lived in the same community, but not all of them were originally from there, some of them were born in nearby towns. They were not bound by previous ties of friendship or kinship.

They found out about the activities promoted by the NGO when the organization posted signs in the schools where the mothers were invited to take courses and training workshops. When the women attended the courses, the NGO staff informed them that they would not receive money, but instead would be trained and given aid so that they could submit a project for funding. They were also told that the purpose of the NGO was independent of any political party and only to support them with training and advice.

The women who formed the cooperative met in the courses provided by the NGO, and although they all lived in the same village and their houses were relatively close to each other, 
they did not interact frequently. It was due to their interest in obtaining funds for the creation of a micro-business that the NGO ended up supporting them to submit the project and to establish a cooperative.

For two years, they were trained in different areas, which included technical skills and strengthening of values and self-esteem. At that time, they participated in different calls for national programs such as those issued by the National Commission for the Development of Indigenous Peoples (CDI) Social Development (Sedesol) and the delegation of the Agrarian Reform to obtain resources. However, it was the Canada Fund that selected them and gave them economic support for the first time.

Prior to the granting of the Canada Fund support, they faced many challenges since only one of the partners spoke Spanish. When trying to request resources at their offices in Mexican cities, the procedures took several hours, which was rather discouraging for them as they had to leave their homes and their responsibilities. They were not accustomed to visiting the cities where these procedures are carried out. The implementing agencies for these programs should take into consideration these obstacles in order to increase the accessibility of the program for the rural population.

\subsubsection{The submission of the project for approval, its granting and follow-up}

For the project to be approved and to receive support from the Canada Fund, it had to respond to the Canadian government's geographic and sectoral priorities, meeting the development promotion criteria specified in the call for proposals. Once the call for proposal was open to the submission of projects, the NGO advised the women that it was time to request resources. They supported the Maya women in drafting and submitting the required documentation. They asked for their credentials to vote (INE), proof of domicile for approval, and subsequently requested their registration in the national tax regulation program for the operation of the micro-business. In November 2012, three weeks after submitting the project, the women were notified that the funding had been approved, and the micro-business was inaugurated in March 2013 in the presence of Mexican and Canadian officials.

It was mentioned that the group of women cried tears of joy when the NGO notified them that they had been selected to receive support from Canada Fund, since some of the women were facing serious financial problems at home. The income provided by the tortilleria helped them to buy food. As a result, even the children of these women were appreciative of this positive change in the family.

The implementation of the support provided by the Canada Fund was carried out through the national NGO. Before starting the business, staff from the Canadian Embassy in Mexico made two visits to the place where the grinder and tortilla maker was to be installed, located in one of the houses of the associates, and took photos. The NGO was present during the whole process and visited the women frequently before and after the installation of the microbusiness and sent photos to CIDA as part of the process to verify the expenses incurred. This meant that the follow-up process was carried out through the NGO, not through the Canadian agency that provided funding to Maya women. They were given training in the management of the machinery, which was included in the project. 
The funds received were non-refundable. This means that the resources used were not reimbursed, the commitment of the beneficiary women in addition to carrying out the microbusiness, was to make known that the Canadian government had supported them, painting an image of the Canada Fund in a visible place where the grinder and tortilla maker was installed. One woman participating in the cooperative subject of this study mentioned that people in rural areas are accustomed to receiving non-refundable government support. It was also commented that there is a strong problem of indebtedness in the Maya communities and the inhabitants are just waiting for the next support of the government.

Once established, thanks to the support from the Canada Fund, other aids were made available to women, including the ADO Foundation, the Walmart Foundation and the Kellogg Foundation. For example, the Kellogg Foundation is constantly inviting them to hammock making courses and other activities which foster women's entrepreneurial skills. However, few women attend because, according to one interviewee, the courses are in the city and many of them do not like to go since they do not know how to move around outside their community and have difficulty communicating in Spanish. The interviewees also mentioned that the state government continually invites them to attend fairs to present their products, because of other national support received. However, they also find that they are unable to generate enough profitable deals at fairs and also their husbands do not allow them to attend.

\subsubsection{The internal organization of the cooperative and its development}

Among the organizational aspects, the group was not formed based on ties of friendship or kinship that would have fomented the trust. Consequently, there was no presence of social capital as a resource from the beginning, as a support network among community members ${ }^{38}$.

When this study started, the cooperative had already disintegrated; however, the microbusiness continued functioning. In the beginning, the operating hours of the business started from 6:30 in the morning, to turn on the machine that makes the tortillas, and finished around 3 in the afternoon. If necessary, they continued working after hours if there was a special order for parties, baptisms and weddings. Due to the strenuous work load, they took turns working in pairs. One woman attended the machine for the manufacture of tortillas and maize dough and the other served the customers for sales. They repaired the tortilla machine themselves, thanks to the training they had received when they started the business. However, when people from the community saw them with their hands in the machine, they commented saying that "that is a man's job". Because of this sense of gender roles inside the Maya communities, men offered to help them, and they were surprised that the women could do it themselves.

In other cooperatives, often sales stop because the tortilla machine requires constant maintenance. If the machine does not receive maintenance, the tortillas start changing shape. The technician who repairs them usually comes from the city and they must wait several days

\footnotetext{
${ }^{38}$ It is in the community where social capital is developed and expanded, understood as the accumulation of productive resources centralized in solidarity, trust and community values, amongst other traits of community identity (Sojo, 2006: 69).
} 
since he is very busy attending other businesses. To avoid wasting time and resources, they decided to learn for themselves how to maintain the machines. Some of the husbands supported the operation of the tortilleria, mainly loading bundles of corn and flour since they can be quite heavy for the women.

Originally, when the cooperative was formed, there were 7 women involved. When production started and the required amount of labor became obvious, 2 partners left in the first months of the micro-business. Later, during the first year, the 5 remaining women began to have strong confrontations due to non-compliance with the work shifts that had been agreed upon. They had divided the hours of attention to the public and some of them did not arrive on time, with no prior notice or a justified reason, thus causing the other women to have to work a double shift and giving rise to difficulties among the members of the group.

In this situation, NGO support was requested to act as an intermediary, and the organization agreed to intervene once the situation was explained. The NGO staff urged the partners who were not carrying out their duties as agreed in the beginning, to respect the commitments made, but this was not fulfilled. Finally, 2 more members left the cooperative, leaving 3 members working in the tortilleria in the first year of the establishment of the micro-business. As the members ceased to be part of the cooperative, the NGO made a list of the expenses made and the cost of the machinery with the depreciation of the equipment included. The members that had left were granted a proportional amount to what was obtained in the project in cash, and bags of corn and flour, so that the business could continue to function with the remaining partners on good terms.

In the second year of operation, two more members decided to leave the business since they argued that they could not fulfill their responsibilities at home and in the micro-business. One of them mentioned that her husband claimed that she was no longer at home to serve the food and be aware of his needs, which forced her to leave her work in the tortilleria and lose it as a source of income. Currently, due to the productivity of the tortilleria, the remaining partner has obtained support from the National Institute of the Social Economy (INAES), a decentralized unit of the Secretariat of Social Development (Sedesol) for the development of new micro-businesses. Thus, the microenterprise is still continuing, but it has been turned into a single partner business.

To summarize, among the main challenges that were faced, it was evident that not all the partners felt that equal distribution of the income obtained should also mean working equal hours. The workload was not equally exercised and this led to many internal conflicts. Also mentioned among the internal problems was a lack of vision regarding savings and good treatment for the client. Although they had been taught good administrative practices in the NGO, not all the partners applied what was learned in the courses. For example, not all agreed to save part of the proceeds for the purchase of inputs and maintenance of the equipment. There were also differences in terms of innovation orientation. One of the partners had seen the use of solar panels in the state of Quintana Roo. However, proposals to install them found resistance among other members because they did not know how they worked.

Among the women who deserted the business, the presence of alcoholism was detected in one family. This is a factor that requires time at home, since the women feel the responsibility 
of caring for the family member who suffers from this disease. Also, criticism and lack of support through "family politics" were present for some of the women. They feel that their husbands are being manipulated because they "allow" their wives to be involved in productive activities.

In contrast, the remaining partner who now runs the micro-business, commented that she has changed significantly as a human being throughout the development of the micro-business. Before, she only had contact with her children's teachers and family members. Now, because of her participation in the micro-business of the tortilleria, all the people of the community know her, and she receives respect and support because of her entrepreneurial activities.

\subsubsection{Analysis of the process using CIT}

The implementation process of the Canada Fund was analyzed with the Contextual Interaction Theory as a theoretical framework. By 'implementation' we mean the process(es) that concern the application of relevant policy instruments. The main elements of CIT are motivations, resources and cognitions of the actors involved. Motivations drive the actors' actions, cognitions represent the subjective knowledge held to be true, and resources provide the actors with the capacity to act and with power over other actors (Bressers, 2004). Taken together they should explain the nature and results of the process.

In this case, it will be applied on the three principal actors throughout the implementation process: (i) the Canadian government through the Canadian International Development Agency (CIDA), as the government agency promoting the development of the target group; (ii) the Mexican NGO as the implementer and responsible for promoting the application, and; (iii) the Cooperative as the target group defined as the actor that needs to cooperate or accept to realize the application.

To facilitate an understanding of the motivations, resources and cognitions of the actors involved in the implementation process, table 5.1 describes them in accordance. 


\begin{tabular}{|c|c|c|c|}
\hline & Motivations & Resources & Cognitions \\
\hline CIDA & $\begin{array}{l}\text {-Enhance sustainable economic growth } \\
\text { and advance equality between women } \\
\text { and men in Mexico } \\
\text {-To strengthen ties of cooperation with } \\
\text { Mexico as part of its foreign policy } \\
\text {-Comply with what is established in } \\
\text { international treaties that promote } \\
\text { development aid } \\
\text {-Geostrategic interests in the region }\end{array}$ & $\begin{array}{l}\text {-Economical Resources } \\
\text {-Human Resources } \\
\text {-Diplomatic resources } \\
\text {-Member of the OECD } \\
\text { and other organizations } \\
\text { governing the economy } \\
\text { and international } \\
\text { security }\end{array}$ & $\begin{array}{l}\text {-Experience in the } \\
\text { application of } \\
\text { development programs in } \\
\text { indigenous populations } \\
\text {-Development of public } \\
\text { policies with a bottom-up } \\
\text { perspective }\end{array}$ \\
\hline NGO & $\begin{array}{l}\text {-To promote agricultural activities of } \\
\text { self-consumption, human values and } \\
\text { microenterprise entrepreneurship with the } \\
\text { aim of generating income and sources of } \\
\text { employment for the rural population in } \\
\text { Mexico }\end{array}$ & $\begin{array}{l}\text {-Human Resources } \\
\text {-Participatory } \\
\text { methodologies } \\
\text {-International } \\
\text { connections } \\
\text {-Local participation } \\
\text {-Support from Mexican } \\
\text { government }\end{array}$ & $\begin{array}{l}\text {-Management of work } \\
\text { techniques with rural } \\
\text { population of low } \\
\text { schooling (Basic Social } \\
\text { Education) } \\
\text {-Consensus skills and } \\
\text { conflict resolution } \\
\text {-Communication skills in } \\
\text { other languages }\end{array}$ \\
\hline Coop & $\begin{array}{l}\text {-Alternative source of family income } \\
\text {-Procure better food for the family } \\
\text {-Better educational opportunities for their } \\
\text { children } \\
\text {-Strengthening the participant's self- } \\
\text { esteem through productive activity } \\
\text {-Recognition by the community }(+/-) \\
\text {-Strengthening the family union }(+/-)\end{array}$ & $\begin{array}{l}\text {-Machinery for the } \\
\text { production process } \\
\text {-Administrative skills } \\
\text {-Need of the product for } \\
\text { consumption by the } \\
\text { community } \\
\text {-Responsibility towards } \\
\text { work by some of the } \\
\text { members }(+/-) \\
\text {-Family support present } \\
\text { for some of the } \\
\text { members }(+/-)\end{array}$ & $\begin{array}{l}\text {-Use, repair and } \\
\text { maintenance skills of } \\
\text { machinery } \\
\text {-Control of the Spanish } \\
\text { language by one of the } \\
\text { members (+/-) } \\
\text {-Technical skills for the } \\
\text { production process } \\
\text {-Entrepreneurial and } \\
\text { long-term vision skills } \\
\text { (+/-) } \\
\text {-Internal social capital (-) }\end{array}$ \\
\hline
\end{tabular}

Table 5.1 Overview of motivations, resources and cognitions of main actors.

Source: Main author, 2017.

It is important to note that among the characteristics mentioned for the members of the cooperatives there are also a number of aspects that were negative or lacking in several members. These are illustrated by the signs "+" or " - ".

Implementation is a process related to public policies. It is a process in which different actors intervene by interacting in social processes, which are unequal in influence and power. In this case, the programs that promote the socioeconomic development of indigenous Maya women in the Yucatan Peninsula were carried out with a bottom-up perspective. The implementation was also carried out through a NGO, using participatory techniques and working with the target population, the Maya women.

For any interaction to evolve, the application of the instrument must contribute positively to the motivation of at least one actor. At the beginning that was certainly the case, every actor involved contributed to active cooperation. However, as the micro-business evolved, internal conflicts arose among the women. Resistance was present inside the target group and interventions of the NGO were invited but the conflicts became unavoidable, thus, active cooperation became forced cooperation. The most conflictive point in the process was when the third and fourth partner resigned from their work in the cooperative. In a sense, the story 
of this case is not one of implementation failure, but one of tensions and conflict among the members of the target group. The implementation process, with the phases of the submission of the project for approval, its granting and follow-up, had in fact proceeded quite smoothly. It was the developments in the cooperative itself that failed to keep the cooperative group intact.

This situation did not lead to full obstruction and the total collapse of the enterprise, since both NGO and CIDA constantly supported the work of the women, being the dominant players in this interaction. That was already true from the very start: if the NGO had not provided them with information about the Canadian government's call for proposal, the training needed through their workshops, and support for submitting the proposal, implementation of the Canada Fund would never have taken place. While the motivations, cognitions and resources of the Canadian Fund and the implementing NGO were all positive, the fact that the process was fully dependent on them at the beginning (and later to prevent it from derailing) can also be seen as a weakness.

Once the situation between the partners was resolved, the cooperation evolved as actively and constructively as before among the remaining participants, however as was mentioned before, two other partners left in good terms, transforming the cooperative into a microbusiness.

Among the relevant external pressures, we can identify a prevailing patriarchal family structure, which was actually a direct factor for some of the partners to stop participating in the micro-business. Some of the husbands refused to allow their women to continue working in the tortilleria, seeing it as a distraction from their family responsibilities, and in order to understand this one must take into consideration that in most of the Mayan populations the men make the decisions and women obey. Previously we concluded that the role of the Canadian Fund and the NGO in the implementation process was quite positive, and that it was the internal developments within the cooperative that resulted in the defection of so many of the initial partners. Now we can add that the developments in the cooperative can also be seen as a multi-actor process. Not only were there initially 7 women involved, but also the community and their families are relevant actors to explain the developments.

As was mentioned before, the Canada Fund for Local Initiatives (CFLI) and its implementation led to a rather smooth process of the submission of the project for approval, and its granting and follow-up contributed to some positive changes in the personal lives of the beneficiaries; however, major constraints were found in the implementation and cooperative business processes as follows:

- The implementation process was carried out entirely through the NGO and as shown by literature review and empirical evidence, the Canadian International Development Agency (CIDA) follow up activities were incipient. This indicates that once the business started they did not return to visit the women, and all monitoring process was carried out through the NGO.

- Different levels of commitment to business and responsibility among participating Maya women, this situation should have been foreseen in the formation of the cooperative, whose members joined to attend the call of proposal, without ties of friendship or kinship that would 
unite them. The social capital between them was not consolidated at the time of the implementation of the Canada Fund.

- Training workshops were given in Spanish through the NGO in a Mayan-speaking population with low knowledge of the Spanish language, thus the level of achievement was uneven among the participating members.

From this analysis, it can be inferred that the implementation could have been carried out with a greater participation of CIDA and with a better selection of the participants. Nevertheless, the results endured. Today the micro-business of the tortilleria is still in function even though it is no longer a cooperative.

\subsection{Discussion}

The international support case researched in this study has some similarity to the national programs being carried out with indigenous populations in Mexico (Osorio et al., 2016). Both the Canada Fund and entrepreneurship programs of Mexican origin work as non-refundable funds, which means a lower level of engagement, a situation that could promote dependency instead of economic development.

Since they provide non-refundable resources, for some of the beneficiaries, this did not imply a commitment to the sustainability of micro-business over time. Furthermore, in both schemes of development programs, the language is a barrier when requesting support through submission of a project in a language that the beneficiaries do not dominate. This leaves them extremely vulnerable and dependent on outside support. Another challenge related to the language faced by the partners is that the courses provided by the NGO were given in Spanish to a population of Maya speakers, which made it difficult for the women to understand the information and training they were given. It is important to mention that in this case study there were no difficulties in accountability, which indicates a level of transparency in relation to the implementation of resources.

The main motivation of Mayan women to become involved in these entrepreneurial initiatives was strongly related to promoting the well-being of their family, improving their access to food and supporting their children so that they can continue to focus on their studies. They also commented on the importance of being self-reliant, they have already observed many women like them who endure physical and mental abuse on the part of their husbands because they economically maintain them. They mentioned this because they think "it is important to value yourself as a woman in order to find the necessary strength to keep going". Sometimes this is possible because they obtain their own income through their participation in cooperatives. Their position in the micro-businesses gives them flexibility at work. Since it is possible to work from home, they can take care of their children and at the same time generate their own income. In addition, personal satisfaction such as community recognition is also obtained. It is known that work is not only a source of stability and material income, but is also a means of obtaining symbolic "gains" that can be associated with the stimulation of self-esteem, entrepreneurship, and the spirit of achievement (UN Women 2015: 66). The women also mentioned that the economic aspect is not the only motivation; manifesting that a love of their work is also a motivational source. Hence, their activities can follow through, denoting incentives beyond the material ones. 
Given all of these positive motivations, it is even more pitiful that for many women these advantages were only enjoyed for a short time and proved to be insufficiently strong to motivate them to stay on board at the cooperative, when other household tasks and family disapproval challenged this. It is illustrative that in the interview process, one of the women expressed that when she was single she wanted to continue studying, but her family did not support her because of her gender. This is mentioned here to show the cultural barriers that the Maya women must face every day.

From a theoretical approach, it was observed that the implementation of the Canada Fund related to the Theory of Interdependence (Keohane \& Nye, 1988), taking into account the interaction among the actors, such as civil society, local government, NGO's, stakeholders and private sector, and the relations promoted by Canadian International Development Agency (CIDA) as a foreign government agency.

This emphasis on the network of actors is the international trend related to foreign aid implemented in developing countries. As an analytical framework, CIT was ideal for taking into account the strong organizational problems faced during the implementation process, as proof of the importance of the interactions between human beings that goes beyond external support, even if it is conducted in an efficient way, as it was by the Canada Fund in this case study.

\subsection{Conclusions}

In the analysis of program implementation, it was possible to note that from the submission of the project for approval, to its granting and follow-up, all the phases went quite smoothly. The inclusion of the NGO functioned as a source of additional support to the objectives of the agency that funded the initiative: the Canadian International Development Agency (CIDA). Nevertheless, the subsequent problems in the development of the beneficiary cooperative itself could also indicate some aspects to be taken into account in the setup and implementation of support schemes.

The interviewees' experiences provided us with an understanding beyond the research question of this study, not only the conditions that hampered its contribution to the stated goal, which was to promote sustainable economic growth and advance equality between men and women among the beneficiaries. The comparisons made with the Mexican programs with the same purposes (cf. Osorio et al., 2016), allow us to establish some general errors in the implementation processes that should be prevented when working with indigenous people in rural areas, which include a greater facilitation in the procedures that the beneficiaries must carry out, which should be in their language and near their place of residence. In this case, they were sufficiently helped by the NGO, but it would have been more effective if the language and location of the procedures were adapted so that the women could feel more capable and less dependent on help. Similarly, the provision of aid in the form of soft loans (partially) as well as the non-refundable funds could contribute to a feeling of self-reliance and priority for having contributed to the cooperative. Another lesson learned is that it is necessary to strengthen the internal organization and "social capital" of the members of the cooperative before receiving financial support, since it is a recurrent reason for conflicts and subsequent dissolution of the micro-business. Members who continue to be involved in 
micro-businesses stand out for having a proactive, responsible, and entrepreneurial personality. Even before receiving the economic support, they were already involved in productive activities, the source of support that was received was not the starting point of this entrepreneurial behavior, but rather led to a greater involvement in these income alternatives. Women mention the importance of business flexibility, because being in their homes or close to them allows them to be close to their family, while strengthening their self-esteem and community recognition towards their work.

In conclusion, it can be said that monetary resources are necessary to start a business, but it is the intrinsic will of the people that allows it to be sustainable while at the same time representing honesty, responsibility, and work ethics.

\section{Acknowledgments}

This research project was funded by the Nestle Foundation for the Study of Problems of Nutrition in the World.

The authors would like to recognize the work carried out by María Francisca Poot Cahun, who was the Mayan to Spanish translator during the interviews carried out as part of this research.

The authors are grateful to Liliana López and Leigh-Ellen Keating from Lakehead University for facilitating the search for information related to this paper, also with special appreciation we would like to mention Beth Ponka, director of administration at Kinna-Aweya Legal Clinic in Thunder Bay, Ontario who drove the first author to different NGO's working in favor of the self-reliance of indigenous women in Canada.

We thank Dr. George Ingram for helpful comments on an earlier draft of this paper. 


\title{
Chapter 6. Promoting Food Sovereignty through a Cooperative Model in the Maya Region ${ }^{39}$
}

\author{
María Cristina Osorio Vázquez ${ }^{40}$, Hans Th.A. Bressers ${ }^{41}$, María Laura Franco García
}

\begin{abstract}
Purpose: The purpose of this investigation is to demonstrate if working in cooperatives favors an increase in food sovereignty among indigenous Mayan women living in rural communities of the Yucatan Peninsula, located in southeast Mexico. The support networks created within the working relationship are expected to transcend beyond the economic activities and provide a basis for deeper ties which promote food sharing in times of scarcity and foment bartering of fruit and vegetables among the participants.

Design/methodology/approach: A quantitative methodology was used by means of a questionnaire with a Likert scale to measure the attitudes of the participants. The qualitative methodology of social investigation was also applied through open interviews, semistructured interviews, participant observations and ethnography.

Findings: Working in cooperatives strengthens support networks among the participants in this study, thereby favoring their food sovereignty; however, this is also related to cultural and family aspects of the Maya people.

Originality/value This paper explains community strategies implemented by indigenous women to confront poverty and to improve, with their limited resources, their access to food and income through association.
\end{abstract}

Key words:

Women-Cooperatives-Food Sovereignty-Strategies-Support

\footnotetext{
39 This paper has been presented at the LI Congress of the Southwest Council of Latin American Studies organized by Texas State University held in Universidad Autonoma de Campeche (Mexico), March 9-12, 2017 and has been submitted to peer review procedure for publication in the journal Generos.

${ }^{40}$ M.C. Osorio

School of Economics and Business

Universidad Anáhuac Mayab

e-mail : maria.osoriov@anahuac.mx

${ }^{41}$ H. Bressers \& L. Franco-Garcia

Department of Governance and Technology for Sustainability (CSTM)

University of Twente

e-mail: j.t.a.bressers@utwente.nl

e-mail: m.l.francogarcia@utwente.nl
} 


\subsection{Introduction}

Access to food is an inalienable right, as stipulated in the Universal Declaration of Human Rights - article 25: "Everyone has the right to a standard of living adequate for the health and well-being of himself (or herself) and his (or her) family, in particular food..." (UN 1948). This was also ratified in 1976 in the International Covenant on Economic, Social, and Cultural Rights (ICESR) promoted in the General Assembly of the United Nations in which mention is made of article 11, stating that "the States Parties to the present Covenant recognize the right of everyone to an adequate standard of living for himself and his family, including adequate food, clothing and housing, and to the continuous improvement of living conditions"; both international documents received the signature of Mexico. On a national level, article 4 mentions: "everyone has the right to sufficient, nutritious food of quality" as established in the Constitution of the United States of Mexico.

However, despite the legislative advances achieved in the area of food, when we talk of the right to food access in the rural communities of the Mexican Southeast, we find that this is influenced by political, economic, social and cultural aspects which affect the access to this human right, mainly due to the marginal living conditions of the inhabitants.

Besides the aspect of food security or food sovereignty, the following reflections are presented; the right to food is established according to the organization which is defining it, but this is often done without taking into account the uses and customs of the indigenous people or the agricultural production of the regions in which they live. Other factors that should be considered include the bad conditions of the roadways in the rural areas furthest away from urban centers, which complicate the transportation of food; also the soil erosion resulting from the use of technological packages which have led to impoverishment of the soil, reducing its productivity considerably. Such circumstances may be sufficiently met in any city of the developed world, but could be inadequate or insufficient in the milpa ${ }^{42}$ of a Mayan farmer in the southeast of Mexico.

Moreover, very often the right to food is not only associated with the level of development and customs but also with gender roles; women are responsible for the preparation of food in the Mayan rural areas of Mexico. In addition to the cooking process, they also participate in agricultural activities and assist in the feeding process of other family members who require help due to their age or infirmity, such as children, relatives with disabilities and the elderly, in both the nuclear and extended family.

The indigenous Maya women participate in the provision of food in regions with low agricultural productivity, where migration of the men to tourist areas of the southeast of Mexico and to the U.S and Canada appears to be the only alternative source of subsistence

\footnotetext{
${ }^{42}$ The milpa is the agricultural production system characteristic of the Maya culture. It is an agricultural production system of corn, beans and squash under slash, fell and burn conditions in the tropical Maya area which is based on the management of the ecological succession and starts with the clearing by slash and burn of fragments, with subsequent years of cultivation and periods of abandonment to induce recovery of the vegetation (Granados, López \& Trujillo, 1999).
} 
viable for families in the rural area, and where the level of education among the population is incipient (INEGI, 2010).

It is in this environment that some women begin working together in their free time. Despite the lack of economic resources or effective programs to finance and train them, they invest what little time they have left, after their agricultural labor and the housework, in the establishment of micro-businesses with other women in order to obtain a higher level of income and thus ensure the future of their children through their studies and a balanced diet, which will allow them to be intellectually capable of doing schoolwork.

With this focus in mind therefore, the present study was developed in an attempt to answer the following research question: Does the participation in cooperatives contribute to food sovereignty among Maya women in the Yucatan Peninsula? and, if it does, to what extent and with which specific practices. Another aim was to establish if the participants in cooperatives help each other with the provision of food through exchange or barter of fruit and vegetables, and to clarify if this occurs because they are members of a cooperative or because they are related to each other or due to a cultural or family aspect of the indigenous Maya population. These are the questions to be addressed in this research paper. In order to provide the contexts that are necessary to position this analysis we will first introduce these backgrounds.

Section 2 will deal with the social movements relating to food and the emergence of the concept of food sovereignty; section 3 will address the uses and customs of the Maya people inhabiting the Yucatan Peninsula in the Mexican southeast. Section 4 will explain the theoretical framework on which this research was based. In section 5 the methodology used and the selection of cases will be mentioned. The results will be presented in section 6 . In section 7 an analysis and discussion of the data obtained will be carried out and in section 8 the conclusions will be presented.

\subsection{Social Movements and the emergence of Food Sovereignty}

First we will address the concepts; what do we understand as cooperatives? The figure of the cooperative is defined as an autonomous association of persons who have been united voluntarily to meet their common economic, social and cultural goals in the figure of a democratically controlled company (ICA, 2016). This way of working and producing is related to social economy and is known as the third sector among economies, between the private (business) and public sectors (government). It includes organizations such as cooperatives, nonprofit organizations and charities with an ethical component as a core element (Nicholls, 2008).

Social economy studies the relationship between economy and social behavior. It analyzes how consumer behavior is influenced by social morals, ethics and other humanitarian philosophies (WHE, 2016). Social economy develops because of a need for new solutions for issues (social, economic or environmental) and to satisfy needs which have been ignored (or inadequately fulfilled) by the private or public sectors. By using solutions to achieve notfor-profit aims, a social economy has a unique role in creating a strong, sustainable, prosperous and inclusive society (Curl, 2009). 
Having defined a cooperative as an organization related to social economy, we will now discuss which concept should serve as a referential framework for this investigation, in other words, what is the correct term for the objectives of this investigation? Is it food security as defined by the Food and Agricultural Organization of the United Nations (FAO) or food sovereignty, a concept relating to the Latin American social movements headed by the organization La Vía Campesina?

We will begin with the declarations emitted by the FAO. At the first United Nations World Food Conference held in 1974 in Rome, it was proclaimed that "every man, woman and child has the inalienable right to be free from hunger and malnutrition in order to develop their physical and mental faculties" (UN, 1974). In an attempt to reach these goals by increasing global food production, Mexico participated in the green revolution, which was a government strategy to reach the high levels of production required. This meant an increase in the use of pesticides, herbicides and fertilizers, as well as the intensification of high yield monoculture in order to achieve a significant increase in the food production of the country. The consequences of these actions are still felt today in Mexican agriculture, as current cultivations do not produce the same yield due to impoverishment of the soil as a consequence of the chemicals used in agricultural activities, in addition to a greater incidence of pesticide resistant organisms and more prolonged droughts (Altieri, 2009).

The term food security was defined at the 1996 World Food Summit (also known as the Declaration of Rome) as follows: "food security exists when all people, at all times, have physical and economic access to sufficient, safe and nutritious food to meet their dietary needs and food preferences for an active and healthy life" (FAO, 1996).

Among the main deficiencies presented by the term food security is the fact that it does not take into account the knowledge possessed by the original cultures regarding food subsistence or the role of women as participants in agricultural labor and as food providers for their families (Ehlert \& Voßemer, 2015). Similarly, the definition of food security avoided discussing the social control of the food system (Patel, 2009). It has been argued that food security does not seek to identify where food comes from or the conditions under which it is produced and distributed. The argument is that food security targets are often met with food sources produced in environmentally destructive and exploitative conditions, and supported by subsidies and policies that destroy local food producers (Gross, \& Feldman, 2015:438). Food Security is also supported by the World Bank, and the World Trade Organization, organizations which have historically been known for their economic recipes susceptible to failure in Latin America (Sogge, 2009, Llistar, 2016).

From the global food security perspective, outdated agricultural economies of the global south need to be improved through the adoption of biotechnology developed by scientists and corporations in the global north (Hopma \& Woods, 2014: 773), which would represent the abandonment of traditional methods of subsistence in a country like Mexico with strong indigenous roots, as well as a high economic and environmental cost for the country.

In contrast, the concept of food sovereignty comes from the International Peasant Movements across the global south and was presented in a document titled "Food Sovereignty: A Future without Hunger" during the "World Summit on Food Security" organized by the FAO, in 
Rome, Italy in 1996 as a criticism of the focus of food security which was influenced by the prevailing perspectives of international commerce based on neoliberal politics, as well as the credit conditions imposed by the World Bank and the International Monetary Fund on developing countries. This document emitted by the international movement La Via Campesina defines food sovereignty as the "right of each nation to maintain and develop their own capacity to produce foods that are crucial to national and community food security, respecting cultural diversity and diversity of production methods"'(La Vía Campesina, 1996). Food sovereignty pays special attention to the most marginalized, vulnerable, or disadvantaged populations, focusing on the structural forms of marginalization embodied in gender, caste, and ethnic relations (Walsh-Dilley, Wolford \& McCarthy 2016:5). Food sovereignty is predicated upon the rights of communities to determine culturally meaningful methods of agricultural cultivation in order to ensure the security of their diets and their lifeworld (Cuevas, Fernandez \& Olvida, 2015: 27).

Social rural movements embrace the concept of food sovereignty as an alternative to the neoliberal approach that puts its faith in an inequitable international trade to solve the world's food problem. Instead, it focuses on local autonomy, local markets, local productionconsumption cycles, energy and technological sovereignty, and farmer-to-farmer networks (Altieri, 2009:111) with a bottom-up perspective. These ideals are opposed to the neoliberal economy policy perspective. In the last 30 years, these policies have prevailed in Mexico and have meant the implementation of a number of measures that have increased inequality and social exclusion, to the detriment of the living conditions of the majority sectors of the population (Espadas, 2015). This economic model of western development has been a predator of human and cultural resources of the world, while the traditions of indigenous people in counterparty are based on the worldview, spirituality, social organization, and skills in implementing survival strategies in situations of extreme adversity (Dureyttere, 2003: 1).

The definition of food sovereignty emphasizes principles of rights and social justice, formed by support networks among farmers, with a particular focus on small-scale family farmers and peasants, with respect for the environment and with a democratic, participative process in agricultural policy decision making. Furthermore, it recognizes the value of the knowledge and abilities of subsistence of the original inhabitants, as well as ethics in the food system which go beyond economic values, while emphasizing the contribution of women for food preparation and caring for their households in terms of producing and attaining food, keeping in mind that, according to the Food and Agricultural Organization of the United Nations, women grow between 60 and 80 percent of the food in developing countries (Patel, Balakrishnan \& Narayan, 2007).

This aspect was emphasized in the World Forum on Food Sovereignty in Havana, Cuba in 2001, which states: "Food sovereignty is understood to be the right of the people to define their own policies and sustainable strategies for food production, distribution and consumption which guarantee the right to food access for all the population, based on small and medium-scale production, respecting their own cultures and the diversity of farming, fishing and indigenous modes in agricultural production, commercialization and management of rural areas, in which women play a fundamental role." (World Forum on Food Sovereignty, 2001). Similarly, the social movement La Via Campesina, an organization 
which promotes the concept of food sovereignty, also defends the rights of women and gender equality at all levels and combats any type of violence against women.

In Mexico an estimated 18.2 percent of Mexicans do not meet their nutritional requirements and basic needs (CONEVAL, 2010), 42\% of the population (51 million) lives in poverty (World Bank, 2013) and poverty is most severe and widespread among indigenous peoples, especially women. Among the indigenous Maya population, a lack of educational opportunities, food deficiencies, the violence arising from the frustration generated by marginal living conditions and lack of opportunities have all contributed to maintain women under the control of the father-figure, brother, son or husband. However, when these persons are absent, due to abandonment or neglect for the household, Mayan women often group together to work in cooperatives which provide alternative sources of income as well as a support network from which additional help can be received to sustain their families.

\subsection{Customs of the Maya population living in the Yucatan Peninsula}

The following section describes relevant aspects of the Maya population in the rural areas of the Yucatan Peninsula in order to understand the context of the participants in this research work.

\subsubsection{Agriculture}

Among the Mayan people, the milpa is the ancestral agricultural system which unites them with divinity. For the Maya, maize is the material from which they were created, according to the Popol-Vuh, a book which contains stories and sacred legends describing how they originated in this world. They continue to carry out ceremonies directed by a Mayan priest to thank the gods for their protection and to ask for rain and an abundant harvest. It is interesting to note that in most of these ceremonies women do not participate.

The milpa is a production system which is characteristic of the Maya economy. Its activities basically depend on the seasons and the knowledge possessed by these farmers is transmitted from father to son; thus, the practices are sustained by extensive historical experience (Granados, López \& Trujillo, 1999:58).

The milpa combines maize variants ranging from white to yellow (zea mays) together with beans (phaseolus vulgaris), lima beans (phaseolus lunatus), cow pea (vigna unguiculata), lentil (cajanus cajan), squash (cucurbita moschata), sweet potato (ipomoea batatas), cassava (manihot esculenta crantz), habanero chili pepper (capsicum chinense), bell pepper (capsicum annuum), tomato (lycopersicon Iycopersicum), and jicama (phachyrhizus erosus), cucumber (cucumis sativus). It is also possible to find the following among the most representative crops in a milpa: water-melon (citrullus lanatus), melon (cucumis melo), papaya (carica papaya) and pitahaya (hylocereus undatus).

A variety of fruits are cultivated in the backyards of the houses, such as citrics: lemon (citrus $\times$ limon), sweet orange (citrus $\times$ sinensis), bitter orange (citrus $\times$ aurantium), also huaya fruit (melicoccus bijugatus), sapote (manilkara zapota), star apple (pouteria caimito), avocado (persea americana), soursop (annona muricata), mamey (mammea americana), red 
currant (phyllanthus acidus), plum (spondias purpurea), red nance (byrsonima crassifolia), ciricote (cordia dodecandra), among other tropical fruits.

The harvest of the milpa is for family subsistence and the production of the land is not sufficient for commercialization on a large scale; however, when there is a surplus, the exchange of fruit and vegetables with the extended family and neighbors is common, or it is sold in local markets; although this last option may depend on the cost of transportation and the bad conditions of the roadways in the rural areas of the Yucatan Peninsula.

Mayan agricultural production is centered on family work, which contributes to the union of interrelated families under a system of mutual help, with the characteristic of communal collaboration in the milpas (Flannery, 1982).

\subsubsection{Migration}

In the Mayan area, it is common to find communities majorly composed of women, children and elderly people. Low productivity of the land, in addition to low formal education levels make it difficult for people of a productive age to find well paid jobs which would allow them to satisfy the economic needs of their families.

On the one hand, there is an internal migration, where young men and women work in hotel resorts located in the Riviera Maya, Playa del Carmen, Cancun, Isla Mujeres and Cozumel, all of which are tourist destinations in the state of Quintana Roo, one of the three federal entities that form the Yucatan Peninsula. It is common to find buses sent by the human resources departments of these luxury hotels, which provide "free" transportation for the employees from their villages, in order to ensure the number of employees needed to keep the hotel chains functioning.

On the other hand, there is also an external or international migration, most often to the United States, which involves mostly men and is usually carried out illegally. The resultant increased poverty in the countryside has forced the emigration of many rural men to seek low-paid farm work jobs in the United States. Thus, Mexican immigrants are working for U.S. agribusinesses, leaving women and children to fend for themselves at home in Mexico (Ferguson, 2009:22).

The social consequences of these international, male migrations include disintegration of the families. As the years go by, sometimes the remittances sent to the families begin to diminish considerably until they cease completely, often with no prior communication, leaving the rural families uncertain as to the well-being of their family member/provider.

If the man does return, sometimes with savings, more often without, he may have contracted diseases during his stay abroad, putting at risk not only his wife's health but also the welfare of his family due to the poor medical services in these rural villages and the social stigma represented by such illnesses.

The economic situation and lack of employment continues to force these peasant farmers of the Mexican southeast to migrate, thereby damaging the form of organization in these 
indigenous and rural communities (González, 2008:19). In consequence, displacement strips their indigenous knowledge of relevance and nullifies valuable social capital (Cuevas, Fernandez, \& Olvida, 2015:37).

\subsubsection{Diet and physical activity}

The diet of the inhabitants in the Maya area depends on the production of the milpa, which provides them with maize to make tortillas; beans and squash, which are basic foods, as well as other garden products, including vegetables and greens. It is common to see poultry and pigs in the backyards of their houses. The meat of these animals is usually consumed on festive days.

The meat of wild animals is also an important source of animal protein. The meat obtained from hunting is usually consumed by the family, although, in some cases, part of the meat is given to a friend or sold within the community. Many of these animals are caught inside the milpa, where they come to feed. Among the species of mammals often consumed can be found: white-tail deer (odocoileus virginianus), brocket deer (mazama americana), wild boar (tayassu tajacu), badger (nassua narica) and paca (agouti paca), which are the organisms providing the largest contribution of meat to the family diet. With respect to wild fowl, the most representative are pheasant (crax rubra) and chachalaca (ortalis vetula) (Granados, López \& Trujillo 1999:58).

In these communities, there is an excessive consumption of sugar-based drinks, pastries and crispy fries made from maize, which have contributed to the high indices of malnutrition and obesity in the population. We are faced with a scenario of malnutrition with two facets: in one we find under-nutrition, and in the other obesity. Nearly $74 \%$ of the population in Yucatan classify as obese (CONEVAL, 2010). At the same time a large percentage of children suffer from chronic malnutrition, which hinders cognitive development, compromises the immune system, and affects their ability to pay attention in school.

According to the World Health Organization (WHO), recent statistics on food consumption are quite conclusive: most importantly, they show a significant increase in caloric intake. This intake of excess nutrients is leading to the startlingly sharp rise of nutrition-related health problems including coronary heart disease, high blood pressure and type- 2 diabetes, among others.

Physical activity is almost non-existent among married women or women with partners, except for their agricultural labors or in the home. It is not the custom for women to practice physical exercise, this in relation to cultural aspects which dictate that women should not be seen on the streets without a socially justified reason, even if she is doing exercise with other people of the same gender. Women, in general, are lagging behind, even in the domestic sphere and their participation in the public sphere is strongly questioned and rejected by the community, both by men and women because of prevailing sexist traditions (Perez, Vazquez $\&$ Zapata, 2008). These attitudes are changing, in part due to the installation of sports domes, football pitches and sports areas financed by the Mexican government, where the people of the communities can gather to talk in the afternoon, while the youngsters play baseball, basketball, football and other sports. Due to this, little by little, groups of women can be seen 
doing exercise, such as dancing zumba ${ }^{43}$. This activity is being encouraged by local authorities as a way of activating the population given the high indices of obesity in these communities.

\subsubsection{Cooperation as part of the culture}

The Maya culture integrates ancestral traditions, nature, community and family in a collective vision of goods and production, based on a community economy, which seeks more than the simple satisfaction provided by material needs (Guillen \& Phélan, 2012).

The villages are located in remote areas that lack access to basic utilities such as a good electricity system and frequent public transportation; situations which motivate the inhabitants of these areas to work together. The cooperative basis originates in the nuclear family, later including the extended family and subsequently the community. The family unit is of vital importance, serving as a basis for the principles of solidarity in the communities.

Satisfying the basic needs presupposes the construction of a support network. In this sense, insufficient income for the procurement of basic foodstuffs gives impulse to the generation of solidarity strategies at a nuclear family level or in the extended family which will resolve their precarious situation (Soria, Palacio \& Trujillo, 2014:257). These initiatives can include the cooperatives, which are created by the members of these communities. These forms of community organization have been recognized by the Economic Commission for Latin America and the Caribbean (ECLAC) and the Inter-American Development Bank (IDB), encouraging the creation of micro-businesses and supporting projects that integrate participatory community development, which has proven to strengthen cultural identity and promote sustainable socio-economic development (Dureyttere, 2003, Lerner, 1996).

It must be emphasized that community participation usually begins with a bottom-up approach involving major stakeholder groups (Kay \& Alder, 1999). These initiatives of social economy and solidarity are not really a part of the capitalist mentality in which profit is the only goal. Most of the resources mobilized are not in the form of money, but rather in support networks. With the focus on cooperativism, commercial relationships are not restricted to economic aspects alone, but also take into consideration social and cultural values based on mutual trust (Cabañes \& Gómez, 2014).

Another perspective focuses on the implications for distributive justice. Cooperation, by contributing to the economic and moral progress of the socially disadvantaged, contributes to the progress of society as a whole, not just of the social groups concerned (Mori, 2014: 332).

\subsubsection{Women participating in cooperatives}

The discrimination of rural women, together with the lack of an effective application of legislation on equality of gender, is a phenomenon which extends all over the world. Traditionally, women have been responsible for feeding and taking care of the family,

\footnotetext{
${ }^{43}$ Dance movements combined with a series of aerobic exercise routines.
} 
consequently they have developed productive tasks which facilitate the combination of productive and reproductive activities in agricultural exploitation (Escurriol, Binimelis \& Rivera-Ferre, 2014:3). One of these initiatives that allows women to help in agricultural labor, do their housework and bring up their children, is the creation of micro-businesses in the form of cooperatives, which has shown to be a strategy which can reduce the level of poverty in which they live (Osorio et. al., 2016).

These cooperatives provide a basis to strengthen their access to social capital, defined as the connections among individuals, social networks and the norms of reciprocity and trustworthiness that arise from them. These networks act to engage citizens in trustworthy practices of neighborliness, political participation, or assistance in providing employment opportunities (Putnam, 2000).

It is important to reflect on the fact that, in general, the farmers, both men and women, and the indigenous communities are seen as vulnerable groups, beneficiaries and poor, instead of people living in conditions of poverty or people who have been impoverished as a consequence of the model of economic development. Far from being considered subjects with rights, economic agents and actors of development, these indigenous communities are considered a burden for the State, and as "statistical data" to measure poverty, extreme poverty and economic growth or decline (Sánchez, 2012:14).

In the cooperatives, indigenous women are recognized as actors of change, with a profile of entrepreneurship which encourages cooperation, honest work and the respect of the community and their families. This is achieved thanks to the participation of the women who dared to go outside the domestic environment in search of an alternative income in order to provide a better future for themselves and their dependents.

\subsection{Theoretical Framework}

The frame of reference used in this article is as follows: the Critical Consciousness Theory of the Brazilian educator Paulo Freire will be presented as a reflection on the recognition of the human being of his or her essential value and the process of becoming responsible for one's own development. This will be complimented by the contribution of the English professor Jonathan Seglow on the concept of self-respect as a way to alleviate the social and economic disadvantages suffered by minorities, in this case Maya women. In addition, reference will be made to the Buen Vivir or Sumak Kawsay, an indigenous notion of life related to cooperation as a strategy to confront the consequences of consumerism and poverty as a result of capitalism.

\subsubsection{Critical Consciousness Theory}

The Critical Consciousness Theory was created in the Brazilian context of marginalization of rural areas and analphabetism during the decades of 1960 and 1970. It refers to the process by which the human being discovers his (or her) value as a person, through reflection and dialogue. It is during this process that the person recognizes and initiates the process of change with which s/he can give impulse to their own development in different aspects of their lives, social, economic or political. For the purposes of this research work, this theory 
will be referred to, taking into account the relationship between the cooperative work of indigenous Maya women and the social transformation of women arising from their participation in these micro-businesses, with a special focus on the aspect of food sovereignty and the subsequent formation of support networks which are of great benefit in times of scarcity in the communities.

In the theory of critical consciousness, human beings abandon their role as objects, objects of the state and objects of the family or their life circumstances and begin to be the subjects or actors of their own destiny. As they become conscious of their value as human beings, a dialogue is developed regarding their poverty, their lack of formal education, the absence of opportunities; this dialogue can be internal or with their peers, the aim being to find alternatives in order to achieve better living conditions. These actions are carried out based on a critical reflection of their own circumstances; in some instances, it is an economic necessity or the oppression of machismo ${ }^{44}, \operatorname{sexism}^{45}$ or racial discrimination ${ }^{46}$ which motivates them to interiorize their life situation and encourages the formation of an organization with other women, based on their similar needs.

It is within this dialogue with other indigenous Mayan women that the change begins; paternalism $^{47}$, assistentialism ${ }^{48}$ and social control are impediments to this process of selfdiscovery of their skills. The women themselves must create the circumstances for the change through reflection, self-discovery and action, as strong capable women characterized by a strong desire to provide their children and dependent family members with better living conditions. Within this dialogue of respect and reciprocity, the commitment to equality begins, transforming the participants and, once the individual has changed, propitiating changes in the social structures. In this regard, Freire explains that any policy, program or project without a bottom-up perspective has little hope of prospering, as they are imposed on the people and do not originate in the community for the development and well-being of the population.

Assistentialism is a particularly dangerous method in this context, as it treats human beings as passive objects, incapable of participating in the process of their recovery. Moreover, it contradicts the fundamental democratization by imposing the conditions of their development, achieving nothing but the loss of the transformation of their consciousness. The importance of this process resides in helping mankind and the nations of the world to

\footnotetext{
${ }^{44}$ A set of beliefs, conducts, attitudes and social practices which justify and promote discriminatory attitudes towards women. It is associated with the roles and family hierarchies which preserve male privileges. It is considered to be a form of coercion which underestimates the capacity of women based on their supposed weakness. It punishes any autonomous female behavior (Inmujeres, 2007).

${ }^{45}$ Discrimination based on the sex of a person. It benefits one sex over the other, based only on this criterion. It represents women as inferior beings due to their biological differences compared to men (Inmujeres, 2007).

${ }^{46}$ Racial discrimination is any distinction, exclusion, restriction or preference based on motivations of race, color, lineage or national or ethnic origin, whose aim or effect is to nullify or undermine the recognition, enjoyment or exercise, under conditions of equality, of human rights and of fundamental liberties in the ambits of politics, economy, social, cultural or any other ambit of public life (ACNUDH, 2003).

${ }^{47}$ Paternalism is the tendency to apply the rules of authority or protection traditionally assigned to the parent to other areas of social relations such as politics and the work field (Alemany, 2005).

48 Political attitude oriented to resolving social problems through assistance programs which produce dependence in the population (Coraggio, 2011).
} 
help themselves, by being critical of their own consciousness in order to confront their problems, making them agents of their own recovery. In contrast, assistentialism robs mankind of a fundamental human necessity: responsibility (Freire, 1974:12).

Taking into consideration that raising awareness is achieved through a critical analysis of the life situations of each human being, integration is the characteristic behavior of democratic regimes, in which people require their maximum capacity for reflection, learning democracy by experience, actively participating with their neighbors, in their churches, in their rural communities and in cooperative work. Democracy is learnt with actions, by getting involved in this type of associations, it cannot be taught or explained with words; it must be experienced (Freire, 1974). These interactions with other human beings must be carried out through dialogue within a horizontal organizational structure, where love, humility, hope, faith, and trust predominate; only then does dialogue truly communicate (Freire, 1974:40).

Developing deeper ethical concern for and political engagement with food systems in general is another core aspect. Freire argues that through understanding the political and ethical ramifications of the system in which people operate (in our case, food systems), action can be taken (Davila \& Dyball, 2015:35).

\subsubsection{The concept of self-respect and its contribution to personal autonomy and self-reliance}

Another concept that will be used in this study is that of self-respect (Seglow, 2016). It is based on the importance of recognizing our value as a human being in our relationships with our fellowmen. By recognizing ourselves with an inalienable, intrinsic value emanating from within ourselves, our interactions with others change, leaving no place for humiliations, abuse or denigrating actions. Self-respect is based on moral reasons and is associated with values such as personal autonomy, where a human being understands that he or she has the freedom to pursue different options in life. The exercise of critical reflection helps individuals pursue aims and attachments which they value and endorse (Seglow, 2016:9). An equally important contribution is the recognition of others, family members, neighbors or members of our community, that we all have the right as human beings to make our own decisions, even though it may represent breaking with certain traditions, as in the case of women in rural Mayan areas.

Pursuing one's aims successfully involves skills such as planning, perseverance, selfreliance, negotiation, and co-ordination as agents to overcome the challenges people inevitably face as they seek to realize their intentions in the world (Seglow, 2016:9).

\subsubsection{Indigenous Perspectives associated with social economy}

As a complement to the theoretical contributions presented previously, the Buen Vivir is a worldview of life originating from the indigenous populations; Buen Vivir is the term used in Ecuador, synonymous with Vivir Bien used in Bolivia. In the Aymara language it is known as Suma Qamaña among the indigenous populations inhabiting the western region of Bolivia, the south of Peru, the north of Chile and in northern Argentina; it is also known as Sumak Kawsay in the Kichwa language spoken by the indigenous populations inhabiting the Sierra and East of Ecuador, the south of Colombia and the lowland forest in the north of Peru. 
Buen Vivir has important coincidences with ideas from other traditional cultures such as the Maya. They conceive the world for the service to others, in an environment of balance and harmony. Maya culture integrates their ancestors' traditions, nature, community and family in a collective vision of goods and production, based on a community economy, which seeks more than the simple satisfaction provided by material needs. As for the social sphere, it is opposed to wasteful consumption, individualism and selfishness, proposing first the collective and community interest before the personal interest (Guillen \& Phélan, 2012).

This vision is closely related to that of social economy, which includes the cooperatives, family enterprises, barter networks and other initiatives where the human being is valued more than economic gain and there is a contribution to mutual support among the population in non-competitive terms in order to evolve into more supportive societies (Pavia, 2013, Villegas, Ortubia, \& Lillo, 2011). Indigenous people understand sustainability with a communitarian approach: economic and production relations are related to the general benefit. In their view, work ethic is related to their traditions and customs. Indigenous rural associations such as cooperatives promote "give to receive", because it is a reason to bring families together and unite rural communities. It is also a way to overcome economic hardship (Viteri, 2002, Guillen \& Phélan, 2012, Wallace, 1993).

It is in this sense, therefore, that cooperativism and the practice of barter arise as an alternative to the neoliberal capitalist model governing Mexico which has acted to the detriment of the Mayan population, given that these communities, which are located in areas of difficult access, with low education levels and marginal living conditions, cannot participate in the development on equal terms.

Although there are a number of specialized government programs in place for the promotion of social and economic development, these still provide limited benefits for the population, making it necessary for them to establish their own communal strategies as part of their own economy; for example, exchange or barter of food in which money is not involved (Tocancipá, 2008).

The use of barter among the indigenous communities of south Mexico is an alternative to the economic model in which they do not see themselves as participants, as they are not able to compete in equal conditions in the market, whereas barter can be used as a contribution to the food sovereignty of these communities.

\subsection{Methodology and Case Selection}

This section will describe the methodology used and the selection of cases for this study carried out in the Mayan communities of the Yucatan Peninsula in southeast Mexico.

\subsubsection{Case selection}

Case selection was carried out in two stages, the first corresponds to Group 1, which originated from a database of 90 productive associations generated by the Center for Evaluation and Monitoring Quality Professional Services (CECS), a department of the Maya 
Intercultural University of Quintana Roo, dedicated to research, promotion and evaluation of business activities in the Maya area to encourage their socioeconomic development.

From the list of 90 productive associations, one sample was selected with the following characteristics: (a) the cooperatives should have more than $80 \%$ of female participation; (b) they should have received financial support from the Mexican government (c) the participants should have an indigenous background; (e) they should have dependents (either children under 18 years old or elderly family members or relatives with a chronic illness) living in the same household. According to pre-established characteristics, 10 groups were selected to participate in this study. However, one of the groups did not want to participate and in another case it was noted that in reality there were no women participating in the group. These two groups were eliminated, leaving 8 groups for the realization of this research study. From these 8 groups 24 women working in cooperatives were interviewed.

Group 2 also corresponds to 24 women who carry out economic activities independently with no affiliation with a cooperative; these activities include the sale of food in their houses or in parks and schools, the sale of various basic products on a small scale and nixtamal mills for the elaboration of tortilla dough. All of these women belong to the Mayan communities in which the cooperatives under study can be found, thus it was possible to carry out a comparison between both groups to measure the contribution of associative work to the food sovereignty of the participants. The purpose of including this second group was to determine to what extent the answers reported are the result of belonging to the Mayan community and being economically active within it (all interviewees), and also to what extent being economically active in a specific work context (the cooperatives) further contributes.

The sample was selected following the methodology established by Guerrero (2002), resulting in two representative samples of 24 women each from a population classified as economically active female population, with the following characteristics: women, 12 years old or older who worked in micro-businesses, one group in the work context of cooperatives and one group acting independently.

The women were interviewed as voluntary participants, that is to say, they received an explanation of the objectives of this study and after complying with the characteristics described previously and having received their consent, the survey was applied, usually in the afternoon in their homes or at their point of sale.

All the women who participated in this study also work in agricultural labors in the mornings, as well as doing their housework which includes the collection and preparation of food, looking after the children and other dependents such as members of the family with health problems living in the same house. In addition to all these activities, they have assumed the responsibility for their own business.

\subsubsection{Data gathering and analysis}

This research is based on data collected during fieldwork in 2016 using a variety of mixed research methods which included a quantitative methodology based on questionnaires with Likert scale answer categories and a qualitative methodology through open and semi- 
structured interviews, informal talks, direct observation, ethnography and documental revision (Hernández, Fernandez \& Baptista, 2007). Living in the Maya region where the communities that participate in this study are located allowed the first author to gain a deeper understanding of the priorities, internal conflicts and concerns surrounding food and economic needs from the point of view of local people.

The questionnaire was applied to 24 women who work in cooperatives and was also used with 24 women who work alone and are not associated in cooperatives. All of the women belong to Mayan communities located in the Yucatan Peninsula. Overall, 48 interviews and several informal talks were conducted, mainly in the local Maya language and Spanish. The interviews were conducted with the support of a native interpreter and transcribed with the support of a native translator fluent in Spanish and Maya. All interviews were applied to women who are involved in micro businesses, many of them in their homes, or where their business is located during working hours.

The questionnaire was divided into 4 thematic sections. The first section deals with aspects of their diet, their consumption of fruits, vegetables, protein sources and the practices of food barter. The second section addresses economic aspects and advances in the self-reliance of the participants. The third section was used to measure aspects of sustainability and environmental care with respect to their economic activities. The fourth and last section was used to measure non-material aspects such as self-esteem, respect, support and family integration. The aspects chosen were inspired by the issues discussed in the previous sections.

The questionnaire contained 20 questions, with Likert scale answer categories. The participants could choose from the following response options in order to measure their attitudes: (a) Strongly agree, b) Agree, c) Undecided, d) Disagree, e) Strongly disagree, according to the proposal by Hernández et al. (2007). Each option was assigned a numerical value, in this way each item obtained a score depending on the answer. Scoring was on a scale of 1 to 5 . If the answer was favorable, it received the highest value, which in this case was 5 , and so on. While both favorable and unfavorable statements were used, the scores were consciously recoded to make favorable answers score highest. After the application of this part of the questionnaire, the women of Group 1, who work in cooperatives, were asked an open question regarding the circumstances which strengthen or weaken the improvements that the association has brought about in their lives. Both groups, the women working in cooperatives and those working independently shared their life experiences extensively through informal talks which were registered and will also be presented in the section of results.

The questionnaires were applied in the form of interviews, in which the translator read the question to the participant in the Mayan language and registered the answer for their subsequent interpretation. The interviews were transcribed, systematized and ordered into categories using SPSS Statistics for subsequent analysis. Apart from direct counts, Spearman's correlation coefficient also known as Spearman's Rank Order or Spearman's Rho was used to interpret the data, especially the differences between the two samples.

Like all correlation coefficients, Spearman's correlation coefficient measures the strength of association of two variables expressing the strength of linkage between the variables in a 
single value between -1 and +1 . A positive correlation coefficient indicates a positive relationship between the two variables while a negative correlation coefficient expresses a negative relationship.

The results were related to the contributions of Critical Consciousness Theory, the concept of self-respect and indigenous perspectives associated with social economy. This implies relating the data and their analysis to the theoretical framework selected for this research in order to interpret their practices related to food sovereignty and entrepreneurial activities.

For the background sections presented above, a document review was also carried out on the uses and customs of the Mayan populations in the Yucatan Peninsula, which was compared with the opinions from key informants within these communities in order to confirm the information obtained with the reality in which they live. Ethnography was used to analyze the particularities of the human groups through the observation of their daily activities.

\subsection{Empirical Results}

The results of data collection are presented by categories. The first section deals with food sovereignty, the second section with economic factors, the third section with environmental practices and the fourth section is related to non-material aspects such as self-esteem.

\subsubsection{Category 1. Food Sovereignty}

In this category, the aim was to measure the extent to which the participation of the women in their work, in cooperatives or individually in micro-businesses, contributes to food sovereignty. We used 10 of the 20 statements in the questionnaire for this category. The clarification of additional information from the qualitative conversations will be added separately.

The first statement presented to the women was: "To be part of the community helps me to eat better". Just two from each group disagreed. The vast majority agreed or agreed strongly. In the group working independently this response seems to be even more representative, in comparison with the other group (Rho $=-.189, \mathrm{p}=.102$ ). Perhaps some women from the cooperatives interpreted the scope of the question as narrower, relating only to their cooperative group.

The next statement referred to the barter of fruits and vegetables. Here there was a clear difference between the two groups. While the women working independently most often disagreed (14 of 24) with the statement that this was common practice, 17 of the 24 women in cooperatives agreed or strongly agreed to it (the correlation between the work context and these answers is Rho .234, $\mathrm{p}=.048$ ).

The statement "because of my work in the community I can eat meat more often" was only agreed by 5 in the cooperatives and 3 among the independent works. Many in both groups were indecisive.

In conversations, the women mentioned that beans or ibes, from their work in the milpa, are habitually eaten. These are preferred by the family as they are not accustomed to consuming 
much meat, only a little and accompanied by vegetables. The women also commented that they try to have poultry in their yards from which they can obtain meat and eggs, also they have pigs in the backyards of their houses, the meat of these animals is usually consumed on festive days; another source of protein is the meat of wild animals obtained from hunting.

The statement linking their work to the ability of their children to drink milk showed a similar phenomenon: while the answers are varied in both groups, slightly more of the women working independently gave positive answers. Based on the conversations, drinking milk proved to have a specific background.

The women commented that it is only consumed if it is received free from the government. Children in primary generally receive milk through the government agencies responsible for food and social development and it is not usually acquired in any other way. Thus, meat and milk are not proper indicators for the impact of work on food sovereignty in these communities.

The next statement was on the ability to rely on people from the community when they have nothing to eat. While both groups are positive about the help to be expected, the women working in cooperatives are clearly much more confident than the women in the other group. Of the women working independently 9 disagree ( 2 strongly) and 13 agree. Among the women in cooperatives only 3 disagree and 17 agree ( 7 even strongly) (Rho $=.343, \mathrm{p}=.008$ ).

\begin{tabular}{|c|c|c|c|c|c|c|c|}
\hline & & \multicolumn{5}{|c|}{ Get help when nothing to eat } & \multirow[b]{2}{*}{ Total } \\
\hline & & $\begin{array}{l}\text { strongly } \\
\text { disagree }\end{array}$ & disagree & undecided & agree & $\begin{array}{c}\text { strongly } \\
\text { agree }\end{array}$ & \\
\hline \multirow[t]{2}{*}{ Work context } & Working independently & 2 & 7 & 2 & 13 & 0 & 24 \\
\hline & Working in cooperative & 1 & 2 & 4 & 10 & 7 & 24 \\
\hline Total & & 3 & 9 & 6 & 23 & 7 & 48 \\
\hline
\end{tabular}

Table 6.1 Get help when nothing to eat.

Source: Main author, 2016.

As this shows, the members of the cooperatives can give support to each other, but in open interviews they mentioned that they can also count on their community and family members for help in situations of food scarcity.

The following statement was "when I am too busy my neighbors will cook for me and my family". The majority in both groups responded negatively. Just nine of the independently working women and eight of the cooperative women were positive. The main difference being that in this last category, 5 responded by agreeing strongly.

In the conversations, the women clarified that cooking is a responsibility that each woman has for her own family; therefore, the companions in the cooperative would not help. However, they also commented that the companions would help by carrying out her part of the work in the cooperative so that she could cook for her family. The women in both groups mentioned that if any problem arose, the female members of the family, daughters, sistersin-law, sisters, mothers or mothers-in-law would come to their aid in order to feed their children. 
Most of the women were in agreement that their work allowed them to spend less of their income on food, although there are some differences between the groups. Of the women working independently 11 agreed, 10 were indecisive and 3 disagreed. Of those working in cooperatives 3 disagreed also, but only 6 were indecisive and 15 agreed. The correlation is not significant however.

All the women agreed that a significant amount of their total income is spent on food, but added that they also have to spend on education, clothing and other items. One of the interviewees mentioned savings.

A large majority in both groups reported that "sickness caused by deficiencies and imbalances in their diet" have actually occurred (18 of the women working independently and 17 working in cooperatives). However, 4 of the women that work in cooperatives (and none of the others) denied that.

With regard to diseases associated with deficiencies and imbalances in their diet, both groups mentioned type 2 diabetes, and they also mentioned an excessive consumption of sugar-based drinks distributed in the communities, where children begin to drink them at an early stage of life. It is important to mention the presence of respiratory diseases caused by the smoke the women inhale when they cook, due to the use of charcoal in the food preparation process.

The practice of "exchanging prepared food with others" showed quite a difference between the two groups. While 9 of the women working independently disagreed (6 strongly), 14 of the women in cooperative agreed (10 strongly). The correlation is Rho .244, $\mathrm{p}=.047$.

The participants also clarified that the exchange of prepared food is common, but usually in association with village festivals, novenas and funeral services, in other words it is related to religious and community causes.

The last statement in this block on food sovereignty was "because I'm part of this community I do not worry about food anymore". The answers of both groups are quite varied and on average indecisive. The main difference is that the women in the cooperatives agree a little more (11 compared to 9 ) and strongly agree particularly more often (6 compared to 1 ).

Despite these varied scores, the participants of cooperatives mentioned that being part of a cooperative has given them the certainty and confidence that this need will be covered and that being part of a cooperative has diminished their concern about food access. On the other hand, the women working independently stated that this concern is always present, and mentioned that last year they had suffered a severe drought. However, in times of food shortage for the family, they always try to have beans from the milpa and eggs from the poultry they raise in their yards.

From the responses to the ten statements of this block on food sovereignty we can observe that while two did not seem to be good indicators (on meat and milk), most of the others confirmed the idea that Maya communities provide mutual support; however, they also showed that the women working in cooperatives were often somewhat more positive about these aspects of food sovereignty, even when compared to other economically active women. 
The most significant differences can be observed in the ability to exchange (fruits and vegetables, prepared food) and relying on others when they have nothing to eat.

\subsubsection{Category 2. Economic aspects}

In this category the participants were asked if their economic situation has improved the ease with which they can commercialize their production, and whether this has increased selfsufficiency. Of course, all the women in the two samples have been active. As such, we are looking at a subset of Maya women that are trying to develop extra (micro) businesses. We will see whether doing this in the work context of a cooperative provides extra benefits.

The women were asked if their economic situation has improved due to their participation in cooperatives or independently in micro-businesses. Among the women working independently, most (15) were indecisive, with 7 agreeing and 2 disagreeing. Among the women in the cooperatives 8 were indecisive and 5 disagreeing. However, there were also 11 agreeing, with 4 strongly agreeing.

During the conversations, the women mention that the income from their activities is small. The number of clients that they now have does sustain the business, given that they usually receive orders in advance. They also mentioned that their motivation to continue with the business is that these activities provide the means for their children to continue studying.

The next statement was "because I work in the community I can sell my product more easily". Many of the women working independently answered indecisive (13x), perhaps not knowing how to interpret the statement. The women working in the cooperatives responded mostly positive (12 agree, 5 agree strongly, only 3 disagree - Rho $=.210, \mathrm{p}=.075$ ).

Referring to the statement on self-sufficiency ("because I am part of this community I am more self-sufficient than before"), nobody disagreed. More of the women working in cooperatives agreed more strongly $(11 \mathrm{x})$, compared to the women working independently $(5 x)$.

Some of the women working in the cooperatives mentioned that their work provided them not only with a sense of self-reliance but also with a distraction which helped them not to worry so much about family issues. Not working alone, but with colleagues might be of help here.

As for the economic aspects, the differences between the two groups are not significant. Much of the gain is already captured by the women through their economic activity, one way or another. The small, extra differences seem to be on the side of the women working in cooperatives.

\subsubsection{Category 3. Environment}

In this category the objective was to measure the participants' opinions about whether their economic activities are carried out in a sustainable manner, according to the definition established in the Brundtland Report, in order to ensure the satisfaction of present-day needs 
without compromising the needs of future generations (UN, 1987). We used two statements for that. The participants were asked if their activities were respectful for the environment and nature and if their products contained chemicals, fertilizers or pesticides in any form.

When the women were asked if their activities are "respectful for the environment and nature", both groups said almost equally that their activities are mindful of the environment, (taken together) 2 disagreeing, 16 agreeing and 30 strongly agreeing).

In the following question however, when they were asked if their products are chemical free, 7 of the women working in cooperatives and only one woman working independently disagreed (while the majority in both groups still strongly agreed).

Some women from the cooperatives declared that they do use chemicals, fertilizers or pesticides in their activities. The interpretation of this is not quite clear: are these women better informed about the reality of the products they work with and are honest about it, or do their responses demonstrate a lack of information about how harmful some of these substances could be to their health and to the environment?.

\subsubsection{Category 4. Self-esteem}

In this category, the attitudes reflecting the degree of self-esteem in relation to the participants' involvement in productive activities were registered. Self-esteem is understood according to the definition provided by the National Institution of Women (INMUJERES) of Mexico. Self-esteem is the assessment that a person has or feels regarding him or herself. It is the inner perception of each person, constructed from thoughts, feelings, sensations and experiences throughout life. In the analysis of gender, self-esteem is considered to be an indicator of empowerment for women which allows an understanding, at an individual level, of the internal legitimization that women have of themselves, their wishes, needs and projects (INMUJERES, 2007).

In this category, we used five statements. The women were asked if they feel better about themselves because they are working in micro-businesses, if they feel valued by the community, if they perceive greater respect from their husbands or partners now that they are involved in these economic activities, regarding the support they receive from their children and if they feel valued by other family members.

Regarding "feeling better with themselves because they work in micro-businesses" both groups agreed (combined: 1 disagree, 3 indecisive, 11 agree, 33 strongly agree). Though the one disagreeing and 2 of the 3 indecisive were from cooperatives, this is a far from significant difference. The conclusion is that the economic activity as such is a great boost for selfconfidence.

When they were asked if they felt "more valued in their community", again the vast majority of both groups agreed or strongly agreed (39 of the 48). There is some difference between the groups. Of the women working independently 6 disagreed and 16 agreed. Among the women in cooperatives, 1 disagreed and 23 agreed (12 strongly). 
Regarding an "increase in the respect of the husband or partner as a result of the woman's participation in productive activities", a very similar picture arises. Here in both groups 21 of the 24 are agreeing. The main difference is that the women in the cooperatives are more often strongly agreeing: 14 of them against 8 of the independently working women.

Some women mentioned that they have the option to let their husband replace them when they are not able to fulfill their work in the cooperative.

Again, a very similar picture arises when asked "since I started working, my children encourage me and support me in my labor". In both groups an overwhelming 22 of the 24 are agreeing. The difference is just how strongly they agree. Among the women in the cooperatives 18 agree strongly and 4 just agree. Among the others that is 12 and 10 .

When participants were asked if they felt "appreciated by other family members", the two groups differ strongly. It is the biggest difference we encountered in this survey. Among the women working independently, the number of women who have to face the disapproval of their relatives is practically the same as those who receive support, while for the women working in cooperatives there is (strong) appreciation.

\begin{tabular}{|c|c|c|c|c|c|c|c|}
\hline & & \multicolumn{5}{|c|}{ Appreciation of relatives } & \multirow[b]{2}{*}{ Total } \\
\hline & & $\begin{array}{l}\text { strongly } \\
\text { disagree }\end{array}$ & disagree & undecided & agree & $\begin{array}{l}\text { strongly } \\
\text { agree }\end{array}$ & \\
\hline \multirow[t]{2}{*}{ Work context } & Working independently & 5 & 6 & 2 & 10 & 1 & 24 \\
\hline & Working in cooperative & 0 & 0 & 1 & 7 & 16 & 24 \\
\hline Total & & 5 & 6 & 3 & 17 & 17 & 48 \\
\hline
\end{tabular}

Table 6.2 Appreciation of relatives.

Source: Main author, 2016.

The correlation between work context and this factor is strong (Rho =.713, $\mathrm{p}=.000$ ). This demonstrates a higher level of family support to women working in cooperatives. Among family members the work of women in the context of a cooperative is clearly much more widely accepted than working independently.

Taking the self-esteem items together, we were able to observe that, while many aspects are already favorably influenced by the economic activity of all women in the samples, there are additional small benefits (and in case of family support even a significant difference) in favor of the women working in cooperatives.

After the application of the questionnaire, the women working in cooperatives were asked an open question regarding the circumstances that strengthen or weaken the improvements that the cooperative has provided in their lives.

Among the circumstances which have propitiated improvement in their lives, due to their participation in cooperatives, the women mention teamwork, mutual cooperation, increased sales and flexibility (on occasions when the woman cannot work, she can send her husband to do her part of the work and her companions accept that). 
They also appreciate the mutual respect among the women regarding political and religious aspects, the fact that they now have clients due to participations in diverse fairs, punctuality, the fact that their participation promotes family unity and they mention the support from their partners and children. They feel that with their work they can help their partners to cover family expenditure. The women manifested that, thanks to their work, they now have more than before. These activities promote responsibility as a human being and emphasize that it is important not to fear or be ashamed. If you do not leave your home, you will learn nothing and if you do not work, you do not really learn. The desire to see the business grow has improved their lives. They have always enjoyed the work carried out in the cooperative, and now they can count on the support of all their companions.

Among the circumstances that weaken the improvements provided by their cooperative work, the women mentioned that sometimes they do not receive economic support from the Mexican government and that they are not always able to sell their production. They are also concerned about the rising cost of raw materials and the fact that sometimes they do not have enough time to do their housework, agricultural work and attend their businesses. They also feel that they could improve aspects of their organization. Similar remarks were found among women working independently.

It is important to mention that in 5 of the 48 interviews, the husband was present and listening to the application of the survey and questioning why his wife was being interviewed. The interview could not be carried out until they gave their permission; however, none of the women were ever prohibited from participating in this study.

\subsection{Discussion on the information obtained}

From the data obtained in the first category of the questionnaire, it was possible to observe a higher degree of food sovereignty among the women working in cooperatives. This is reflected more particularly with the exchange of fruit and vegetables in the form of barter, alternative sources of food should the family not have enough food, exchange or barter of prepared food and the level of concern regarding food scarcity.

It is interesting to note that meat consumption and milk consumption were not influenced by the women's participation in the cooperatives. This could be explained by the fact that the consumption of milk is not a custom among the Mayan people. Instead, the consumption of atole (a hot beverage made with corn flour) and hot chocolate is very common, according to the women participants.

The women commented that meat is usually consumed in small portions with abundant vegetables. During the interviews, they also mentioned that their children prefer the taste of beans.

Regarding the exchange of prepared food, both groups of women clarified that the custom of exchanging prepared food is more often associated with the rites of the catholic religion, such as the religious guilds and praying the rosary. 
With respect to the preparation of food for the family, the responses of both groups were the same: it is the responsibility of each woman to cook for her own family. However, the women belonging to a cooperative, or other family members, are willing to help by taking the woman's place at work so that she can finish her duties at home, but they will not offer to cook for her.

In category 2, on the economic factors, the collaboration in cooperatives was found to improve the sense of self-reliance of the participants. However, when they were asked if their economic situation had improved due to their business activities, many were undecided. Of the women working independently only 7 agreed. Among the women in cooperatives, 11 agreed, of which 4 strongly agreed.

Being part of a cooperative greatly facilitates the commercialization of their products. With respect to this aspect, the participants commented that they are often invited to state and national fairs to sell their production. Such invitations are generally related to government support schemes which they have received.

Category 3 questions if their economic activities are carried out in a sustainable manner, thereby preserving their natural resources. Although the vast majority of both groups claimed this to be the case, neither of the two groups were able to clarify if the use of chemicals, fertilizers or pesticides was harmful in any way.

The category presenting the most significant data was number 4 , corresponding to indicators of self-esteem. For the women working in cooperatives, these intangible benefits showed some small benefits over women working independently, but a great benefit in terms of the support of their relatives.

From the additional comments expressed by the women, it was possible to observe that many of these groups are comprised of women united by family ties, neighbors or godmothers of each other's children. Thus, their union in cooperatives is already founded on affective bonds which are stronger than just economic interests.

The social capital existing among the participants can be perceived within the cooperative and within the support networks inside the community. The women mentioned that flexibility is vital for them to be able to participate in these initiatives. This flexibility derives from their companions in the cooperative and from their family members, allowing them to carry out all their duties. While it is not always possible to get together with the work group, they can still do the work in their free time, after completing their duties in the milpa and at home.

Their inclusion in these businesses can be related to the Critical Consciousness Theory of Paulo Freire. Although these women are known to live in difficult circumstances, in isolated communities far from urban centers where the family income is not sufficient to cover all their needs, nevertheless through a concerted dialogue with themselves and with other women, they have decided to find alternatives to migration and low productivity in agricultural activities by undertaking a commercial venture in the form of micro-businesses. 
This decision to venture into the business world as a Mayan woman is an intrinsic process, as they must confront cultural barriers which dictate that it is not appropriate for a woman to interact with other people outside the family. However, taking the freedom to consider one's alternatives and make decisions has an influence on the concept of self-respect and its contribution to personal autonomy and self-reliance as developed by Professor Seglow, mentioned previously. It is a product of emerging self-respect and also contributes further to such self-respect.

This is reflected in the sense of value that is described by the participants. Once they perceive themselves as successful, capable women, even though the financial gain is barely incipient, they can better deal with future challenges.

This context can only be understood within the context of the sense of unity existing among the indigenous Mayan population, where the concept of sharing is fundamental in order to confront difficulties. In addition, support networks and the system of barter are mechanisms which have been used for millennia. Only by understanding the foundations of their indigenous culture can we interpret the results of this study.

\subsection{Conclusions}

The indigenous Mayan woman, participant in this research, has demonstrated through this investigation that her concept of responsibility goes far beyond just looking after her own welfare and is closely related to providing for her family.

The cooperative as a means of entrepreneurship has given them recognition within the community, greater self-esteem, additional income and an increase in food sovereignty among the participants, in relation to the social capital based on support networks.

The mutual help strategies that are present in the indigenous communities are strengthened by the cooperatives. Among the benefits measured in this study, the most important were the intangibles relating to strengthening of family ties, the respect of the community and family members and the development of the concept of self-esteem, even though many of these businesses do not represent a large contribution to the family income.

In response to the research question, as to whether the participation of these indigenous Mayan women in cooperatives contributes to their food sovereignty, the answer is positive. Many of the alliances that were already present in their traditions, in particular among family members and in religious festivities, are seen to be further strengthened by working in a cooperative.

In cases of extreme necessity, it is the family members that provide the food. If this is not possible then the companions of the cooperative will help or, in the last instance, the members of the wider community. The family members mentioned included the mother, mother-inlaw or sister, which contribute to the establishment of a source of support based on gender. It is important to mention that the fact that these women participate in such initiatives is very often questioned by fathers, husbands and sons, since it is not common for the women of these communities to participate in business ventures if they do not have the approval of the 
family. However, once the business has been established and has shown to be sustainable, these same core family members represent the most important source of support, having understood that the women are capable. While we observed support from husbands and children for the work of both groups of women, one can imagine that there must be others that would have liked to be involved in micro-businesses but were not allowed to. A very strong control can be observed within the wider family. In our study, participation in cooperatives is shown to evoke far less resistance from relatives in comparison with the women working independently. Cooperatives could therefore serve as an enabling device for women to become economically active.

Little by little, through critical reflection and an intrinsic decision-making process, the women of the Mayan area that participated in our study were able to decide for themselves to undertake new projects which provide greater food sovereignty and self-respect, allowing them to increase their autonomy.

\section{Acknowledgment}

This research project was funded by the Nestle Foundation for the Study of Problems of Nutrition in the World.

The authors would like to recognize the work carried out by María Francisca Poot Cahun, Rudy Rubén Chan Tuz and Gilberto Ku Mukul who were Mayan translators to the Spanish language during and after the interviews carried out as part of this research paper.

We are grateful to Prof. Marisol Cen Caamal for her comments on the Mayan milpa in this article. 


\section{Chapter 7. Conclusions}

This chapter will present the conclusions of this research.

\subsection{Introduction}

The conclusions of this research were directly drawn from the findings gathered from field research activities in the Mayan region, including several conversations with Maya women and members of their families, trying to understand their perspectives. The research uses the information shared by the participants and also endeavors to make a contribution to their knowledge of the subject of this study, the formation and development of microbusiness cooperatives. Only a better understanding of their situation can help to improve it, working with a bottom-up perspective.

The findings will be presented by answering the research questions leading each chapter of this thesis, thereby summarizing the content of this study. The results will answer the overarching research question and present the acquired knowledge that could support the creation of public policies which are responsive to the needs of the target population and lead to more efficient results for the wellbeing of the people.

In the last section of this chapter and thus of the dissertation, the aim is to establish best practices when working with the indigenous population inhabiting remote areas of Mexico, who, as stated before, live in precarious conditions with high poverty rates and insufficient services. Hence, it is the author's intention to make this information available to governments, civil society, NGO's, international agencies and grassroots groups to be used in the design process of programs that work in the area.

In this way, the role of cooperatives will be analyzed in relation to the programmes of these organizations which intend to contribute to a more just and equitable society. Entrepreneurship creating micro-businesses is one of the ways to achieve better conditions of life. This study also reflects on the value of self-sufficiency as an essential step towards human development, based on self-effort and honesty.

\subsection{Summary and answering of the research questions}

In this section, some final reflections will be made in relation to the results found during field research, based on the social economy framework. With the selected methodology, we take into account the perspective of the participating actors, study their context, and analyze the implementation processes. The results are related to the five research questions that give structure to this study, which refer to motivations, elements of success, implementation of national and international support programs and food sovereignty.

Chapter two deals with the motivations of Maya women who decide to participate in cooperatives, taking the definition established by Bressers; "motivations drive the actors' actions" (2004). Considering that the participating women live in the countryside of the 
Yucatan Peninsula, and usually perform household chores, care for others ${ }^{49}$ and also take part in agricultural activities, it was important to understand as a starting point: What are the actual motivations of Maya women in the Yucatan Peninsula to participate in the development and exploitation of cooperative micro-businesses? The question could easily lead to "economic purposes" as a simple but superficial answer. However, through the qualitative methodology of social research the results showed that their motivations were not limited to material purposes.

During the first part of the research, when speaking to participants and observing the context, the responses of the women were related to the search for additional income, to cover the costs of education and improve the nutrition of their children, respectively in that order of importance. Additional reasons why resources were obtained were also mentioned, such as helping their husbands with family expenses. It was not found that the additional income earned in the cooperative was for the sole benefit of the participating woman. Saving ${ }^{50}$ was mentioned only once. This information also allows us to understand that the profits of the microbusiness are used for subsistence purposes.

It was mentioned that the economic gain is low, but in addition to the motivations described above, the women expressed a love for their work. They mentioned that the activities they currently carry out as part of a cooperative, which were previously carried out on their own, are now shared with female family members and other women, keeping them occupied and distracted from their personal problems.

This indicates an orientation towards the protection and well-being of the family, although non-material gains were also recorded, such as perceiving a greater recognition of the community for their work in the cooperative. Once they are recognized as female entrepreneurs and workers, the support they receive from their husbands and children increases.

When they are tired because of all the work they are responsible for, inside and outside the home, it is the husband or children who occasionally cover their shift. This was observed during the field work, where some husbands became more involved than others, carrying heavy bundles for the women.

This chapter demonstrated the existence of goals such as the provision of family well-being, the ability to provide better educational opportunities for their children in contrast with the opportunities the women themselves had in life, and the improvement of their family's nutritional level through access to more nourishing and diverse foods. However, it was also found that they have obtained additional benefits in relation to their business activities, such

\footnotetext{
${ }^{49}$ Caring for others. Cultural values that promote the idea that women should take care of their husbands, daughters and sons, mothers, fathers, grandmothers, grandfathers, sick aunts or the elderly and in general, everything that requires care. This is unrecognized, unpaid work and is not only a disproportionate burden on women but also, in practice, an invisible subsidy to the economic system (Lavalle, 2010: 54).

${ }^{50}$ In the Maya region savings are commonly represented in the purchase of gold jewelry, which is much appreciated in Mayan communities as part of the traditional Mayan women's wardrobe known as terno which is a festive clothing worn by the Mayan woman of the Yucatan Peninsula consisting of three pieces embroidered in colors.
} 
as greater family integration, improvement in their levels of self-esteem, and community recognition of their work.

In Chapter three, several Mayan communities were visited and interviews were conducted with the women working in cooperatives. However, three specific cases highlighted the success of their initiatives, leading to the development of the second research question: Which are the key elements found in the cooperatives selected as subjects of this study that promote success?

The first cooperative decided to establish a store dedicated to the sale of livestock food with the support of the National Commission for the Development of Indigenous Peoples (CDI). The main factor that led them to sustainability was the social capital present among the women, based on their Mayan culture, specifically the Mayan language they all spoke. This was an element that brought them together and made them so successful that on the last follow up visit, they had already expanded to a second place within the same community.

What is important to emphasize in this cooperative is that the factor that makes them internally strong as an organization, makes them weak in the external market. They rarely travel outside their community and have to be assisted by their children in the follow-up process of the support given by the CDI, in which the use of the Spanish language is sometimes required. Because of this, they decided to expand within the community, diminishing their opportunities to have a stronger presence in a broader market. Nevertheless, this cooperative continues to be a successful case within the same community for its sustainability, understood herein as its permanence over time in the market.

The second successful case presented factors identified in the Social Economy approach (Lavilla, 2004) such as the presence of elderly and experienced people included in productive activities. This cooperative at the time of the study had already received different supports, from the Mexican government through the National Commission for the Development of Indigenous Peoples (CDI), the Secretariat of Agriculture, Livestock, Rural Development, Fisheries and Food (SAGARPA), and technical training through workshops supported by the National Institute for Training and Development of Rural Sector (INCA Rural). Similarly, they have received international funds from the United Nations Development Program (UNDP). At the time of the study, it was already a consolidated micro-business.

In addition to having a strong presence in the community, this cooperative already exported its products to the international market and had presence in other regions of Mexico, its elements of success are the social capital among the participants and the monitoring activities. The leader of this cooperative spoke Maya, Spanish, and understood English, which allowed her to conduct herself more easily in the business environment and the supports related to them. The social capital found among the members, as in the first case, was based on sharing a culture and a common language, the Maya. The women participated mainly working in their homes and due to their advanced age they did not leave their communities very often. Because of this, the representative of the cooperative made the arrangements and attended events organized by the Mexican government, such as promotional fairs and trade events. 
Monitoring activities were mentioned as being important for the sustainability of the microbusiness over time, however, these activities were carried out with greater presence and efficiency by representatives of the international funds (UNDP). They also mentioned that the representative of the United Nations visited them often, not only because of the support received, but as a friend, which strengthens the ties of trust between them, sharing information that goes beyond the advancement of the microbusiness.

In this cooperative, the incorporation of the internet as a marketing tool was present and growing. This proved to be advanced, considering that in Mexico 74.5\% of micro-businesses do not use the computer in their activities (INEGI, 2016). In the last visit to this cooperative, improvements had been made in the living room of one of the members, where the microbusiness is located. This allows them to have more available space to increase and diversify their production, a sign of its expansion. In addition, it was mentioned that they had been granted additional support from the Mexican government through the National Institute of the Social Economy (INAES).

The third cooperative, which inspired the subject of this dissertation, stands out for the presence of ethical leadership, in this case, in the figure of a Catholic ${ }^{51}$ nun, who was able to obtain numerous sources of support from national and international agencies, from the public and the private sector, with the aim of benefiting the women of the Maya communities through the enhancement of work and effort as a way to achieve a better life.

This cooperative has a common characteristic with the first case, its strength can become a weakness if not well managed. In the last visits to the cooperative, due to the nun's advanced age, she was no longer head of the organization, leaving in charge a person who also behaves in an honest manner. However, it was recognized by the members that the leadership of the nun strongly encouraged this initiative, because of her multiple connections in the region and outside of it. Given that this effective source of support is not present anymore, the number of supports has decreased significantly.

The motivation to develop this phase of the research was to identify elements that could be replicated in other cooperatives formed by Maya women in similar contexts. Thus, it was found that the social capital was understood as a support network among community members and that the monitoring activities carried out by the representatives of the organizations that provided the resources, and the presence of ethical leadership ${ }^{52}$ favored the sustainability of a micro businesses over time.

In relation to the Social Economy approach, which prioritizes associative work for the accomplishment of common interests and goals (Villegas, Ortubia \& Lillo, 2011), we perceived the presence of human values such as honesty and cooperation above greed, and the participation of vulnerable groups of the population in the economy, such as indigenous women with an emphasis on the elderly, as mentioned in the second case.

\footnotetext{
${ }^{51}$ In Mexico $83 \%$ of the population is catholic (INEGI, 2010).

${ }^{52}$ Ethical leadership is defined as the demonstration of normatively appropriate conduct through personal actions and interpersonal relationships, as well as the promotion of such conduct to followers through two-way communication, reinforcement, and decision-making (Brown, Treviño, \& Harrison, 2005:120).
} 
During the development of this research, we observed that the implementation of support programs from the Mexican government was carried out differently in comparison with those originating from international sources, impacting on their degree of success. Because of this, we decided to compare the implementation of a federal program of the Mexican government administered by the CDI and a program of international aid administered by the Canadian International Development Agency (CIDA). The objectives of both support programs were to promote the economic development of vulnerable populations, in this case indigenous women. In analyzing the implementation of both national and international programs, Contextual Interaction Theory (CIT) was used.

Chapter four answered the following research question: What aspects in the implementation process of the Program of Productive Organization for Indigenous Women (POPMI) for the Mayan population of the Yucatan Peninsula hampered its contribution to its stated goal, which was to encourage self-sufficiency among the population?

As a background for the results it is useful to mention that there is an intermediary figure between the CDI and the beneficiaries, known as CDI promoters. These are young women from the same rural communities in which the cooperatives are located, who speak Maya and Spanish, with secondary education. These young women served as a source of support for the entrepreneurial women. One thing we found that could be improved in their functioning is that their monitoring work was more related to the verification of the appropriate use of the resources, instead of (also) encouraging further development of the business.

In Mexico, information from official sources indicates that the permanence of microbusinesses in the market at a national level is 5.9 years (INEGI, 2015). However, the empirical evidence for the cases in this research shows just three years. Our study indicated that this relatively low number of years is related to an incipient monitoring activity of the Mexican government representatives and to the classification of the resources as nonrefundable, among other reasons.

As mentioned before, most of these programs are non-refundable, which means that the beneficiaries do not have to return the economic support received. Quite frequently the granting of these funds is related to political activities. We also found that the information regarding the funds is mainly shared among relatives of the people who hold a position of popular representation within the communities. This limits the spread of information among the population, and diminishes the equal participation opportunities for the rest of the inhabitants. The grouping of women to form cooperatives which was mentioned by the interviewees, was carried out by the same government representatives. In those cases, the women did not have any relation to each other which, according to one of the interviewees, led to short term dissolution of the cooperative after the distribution of the economic support.

Despite all the aforementioned, there was also positive information related to the POPMI program. The training was carried out according to the guidelines of the program, taking into account that in Mexico only $11.5 \%$ of micro-enterprises receive training (INEGI, 2015). In this study, in all cases, the participants mentioned having been trained at no additional cost to them since it was included in the project that they started. Additionally, as the guidelines stated as a goal of the POPMI program, an improvement in their self-esteem was registered, 
in relation to the feeling of accomplishment, and to community and family recognition due to their work in the cooperative.

To summarize, the results of Chapter four were developed with the help of Contextual Interaction Theory (CIT) to analyze data, emphasizing the motivations, cognitions, and resources of the women who benefited from the programs. It demonstrated deficiencies in the implementation process when granting financial support, the execution of the business project, and in the selection of beneficiaries. However, it has also shown that, despite the structural failures and implementation deficiencies of the Mexican government program, some objectives of the POPMI program were achieved for the target population, such as the development of skills and capacities through the training they received, raising levels of selfsufficiency and self-esteem among these indigenous women.

In Chapter five, in order to facilitate the process of comparison between the implementation of support programs with different sources, a case of support by the Canada Fund for Local Initiatives (CFLI) was analyzed, under a similar research question: What aspects in the implementation process of the Canada Fund for Local Initiatives for the Maya population of the Yucatan Peninsula helped or hampered its contribution to its stated goal, which was to promote sustainable economic growth and advance gender equality among the beneficiaries?

Unlike the POPMI program of the Mexican government, the Canadian program worked through a Mexican NGO, which resulted in an increase in the effectiveness of monitoring actions. However, the sustainability of the cooperative was compromised due to strong internal problems between the partners, which led to the dissolution of the cooperative, transforming it into a micro-business with the participation of only one of the founding members.

A strong point was the transparency in the use of the resources and the intervention of the NGO to support the women with training and in the submission of the project without cost for the women. Nevertheless, as a deficiency, we found that the training courses where given in Spanish instead of the Maya language, making the learning process uneven since many of the participants did not fully understand the Spanish language.

Although the case study allows the analysis of unique experiences and provides knowledge that should not be generalized, the results of this chapter demonstrate the importance of understanding the cultural context in the implementation of programs that promote the economic development of Maya women. It emphasizes the importance of monitoring activities and considering aspects of the participant's profile that are not easy to evaluate at first hand, such as the development of responsibility in the human being, intrinsic entrepreneurial skills, and a positive attitude towards work. These elements could make the difference in achieving sustainable economic development for the women beneficiaries of these programs. This shows that external supports can act as a lever to achieve better levels of income, but it is the intrinsic attitudes of the participants that makes it sustainable. 
In Chapter six, a study of the relationship of entrepreneurial activities and food sovereignty was presented under the research question: Does the participation in cooperatives contribute to food sovereignty among Maya women in the Yucatan Peninsula? In response to this research question, two groups of women were interviewed. The first group was participating in entrepreneurial activities with other women in cooperatives and the second group was formed by women who carried out productive activities without being affiliated to a cooperative association.

The results showed a positive relationship between the work in cooperatives and the increase of food sovereignty levels, but only to an incipient degree. The time the women spend together working in cooperatives enables an extra support network besides family and friends to deal with food scarcity.

Considering that in these communities at least $70 \%$ of the population live in marginal conditions, and more than $25 \%$ of the population cannot meet their food needs (CONEVAL, 2014), if they do not have enough food, first they turn to their nuclear and extended family, later to their partners inside the cooperative and thereafter to the community. This constitutes an additional support network to confront food shortages. An increase in barter activities between cooperative members was registered as well, and rituals of food exchange related to religious festivities.

It is important to mention the courage of the women who are involved in entrepreneurial activities on their own. In Maya communities it is not easily accepted by members of the communities (women included) if a woman behaves in an independent way, as in this case, starting a business without the company of other women. Independent behavior among women is not commonly observed in this context. The biggest difference observed between the two groups was that the women working independently expressed very mixed opinions regarding the appreciation or disapproval they got from the wider circle of relatives, while the women working in cooperatives reported strong support.

The results of this chapter suggested that there is a relationship between the formation of women in cooperatives and an increase in their food sovereignty levels. The presence of related factors was found which strengthens these practices as the celebration of rituals of Mayan culture and Catholic religion and contributes to community union in the face of difficulties based on the social capital present in rural communities in the Yucatan Peninsula.

The overarching research problem was formulated in the following main question for this research: What factors support or restrict the contribution of cooperatives to the improvement of the development of Maya women on the Yucatan Peninsula and their families?

On the basis of the studies in this dissertation this question can now be answered. First of all about the dependent variable: "the contribution of cooperatives to the improvement of the development of Maya women". It is clear that this is a complex concept with many aspects. While so many cooperatives do not survive in the market and consequently cannot provide any contribution thereafter, in this dissertation the capacity to survive has been viewed as a sort of necessary condition and in that sense part of the success variable. This aspect got 
therefore a lot of attention, especially in chapter three, but also in chapters four and five. But of course, fulfilling a necessary condition is not the essence of success.

Other aspects that got ample attention in this dissertation were implications for the food sovereignty and economic results for the women and their families, respect for the environment and personal self-esteem. The factors contributing to this are at a superficial level already indicated by the structure of this dissertation. The activities of the cooperatives need to be: well motivated, well organized, well supported and well rewarding.

At the end of this dissertation we can give some further specification for these, as has been described above in this section. A concise summary: motivations need not just be restricted to economic gain. If this is the case it can even be threatening to the continuity of the cooperative by opportunistic behavior. Broader motivations like striving to maintain the integrity of their families and the community and its culture matter, as do the pride and joy of working with others.

For the quality of the organization we found three important factors: the building and use of social capital in the form of mutual trust, the frequent monitoring by supporting organizations (in which not the control element was important but the prolonged attention that was paid and the opportunity to give advices, making them feel that they were not neglected), and lastly the presence of ethical leadership that inspires and permeates the organization.

Chapters four and five studied the quality of external support and its implementation. This provided a big number of items for which attention is needed. We will not repeat them all here, as above in this section but also below in section 7.4 on policy implications they are mentioned. While of the four main issues, support is most related to policy, many items discussed there relate to these chapters. Here it is just mentioned that good support is not restricted to giving money, but also needs to include giving prolonged attention.

Lastly, the activities of the cooperative need to be rewarding. This was studied along the lines of food sovereignty, economic gains, respect for the environment and self-esteem. In the perspective of the participants the cooperatives performed quite well on all but a few of the items surveyed. In the study was also a comparison made with women working independently. This comparison showed that the women in the cooperatives were more confident that they could barter food and that they would get support when necessary. Also, the support for their work by relatives in these patriarchal communities was much stronger when working in the context of a cooperative. Thus, working in cooperatives seems rewarding and in some cases, it might even be the only option for women to get support for working in economic activities.

\subsection{Implications for the debate on the role of cooperatives}

In this section, a reflection will be presented based on the literature provided regarding the cooperative movement (Culti, 2002, Teixeira \& Soler, 2002, Mori, 2014) and the results found in the Maya region. At the beginning of this research, a theoretical framework known as social economy (Lavilla, 2004) was selected because it maintains the primacy of human beings over capital and considers the sectors of society not often included in productive 
activities, which nevertheless can contribute to the creation of livelihood. This theoretical approach explains the behavior found in several cooperatives located in the Maya zone where the benefits of the combination of the production factors did not mean the enrichment of a few, but of the majority. The cooperatives are one of the most representative figures of social economy theory (Coque, 2005).

One of the aims of the cooperative movement, according to their founders, is to "perfect" the human being through collective work, to enhance the consensus process and communication inside the organization and to meet common needs (Teixeira \& Soler, 2002). In reality, we found several cases where the particular needs of each woman were put above the objectives of the organization, creating strong confrontations between them. We also found communication problems, since the intervention of CDI and NGO's representatives was often required to solve conflicts and create agreements among the women.

This was commonly observed in the associations specifically created by the Mexican government without prior ties of friendship or kinship among the participants. It was also registered in the NGO's case who received support from the Canada Fund, where the women met in the workshops, but did not know each other before. Communication, the creation of emotional bonds at work, support for each other, the search for group interest over personal interest, were all observed in groups of women who already had ties of friendship or kinship before obtaining resources. As a reference, these women usually spend time together, talk about their children and rely on each other in times of challenges and joy.

Moreover, in these cooperatives a high degree of work responsibility was also mentioned. Among the participants in cooperatives that are sustainable over time can be found women with a more developed sense of responsibility who respect the agreements established in the group and who are willing to take on even more work in favor of the development of the micro-business. While working in a cooperative comes with mutual obligations, it can also produce new opportunities for self-reliance that provide empowerment when compared with passiveness. That is the paradox of free engagement.

Among women who work in sustainable cooperatives a proactive behavior was observed. In that sense, we observed that the work in cooperatives can contribute to women's empowerment. They are continuously taking action in order to have a greater presence in the market. Women such as these are continuously participating in productive programs and create networks of contacts in order to receive information that could contribute to their business. Women who do not meet these characteristics do not stay long in the cooperatives. In general, they give up in the first months of the micro-business, declaring that they cannot cope with the additional work load, the responsibilities at home and the agricultural activities. Similarly, those who are not fully engaged with the objectives of the group, fail to fulfill their duties, staying at home, thereby increasing the workload of the women who remain involved actively in the cooperative. As a result the unequal workload leads to many internal conflicts.

Below a comparison is made between the results of this research with Mayan women and the principles established by the International Cooperative Alliance (ICA), the latter established in 1995: 
Democratic control of members and Economic participation of members: In the majority of the cases these occur only at the beginning of the micro-business. However, as time goes by, some of the members desert, and thus, they no longer participate in equal conditions in the decision-making process or in the distribution of profits. Obviously this is the consequence of not contributing with what they had committed to, their labor.

Autonomy and independence: This principle is not fulfilled. There is a great dependence on the resources granted by the support programs and the public agencies that direct them. However, once a certain level of success and recognition is perceived, this prompts them to seek new supports for the development of their micro-business, which is a sign of autonomy.

Education, training and information: In the support programs addressed in this study, the women effectively received training and education, with no additional cost to them since it was included in the project. This allowed them to develop their skills, which in turn gave them a greater degree of self-confidence. However, the availability of the information is unequal in the communities, motivated by political interests. Training by follow-up guidance was not adequate in the studied cases of the national support program.

Cooperation between cooperatives: This network of cooperatives is known as second degree cooperatives, found mostly in Europe. In the cooperatives studied this relationship is nonexistent. Although it is known that in other zones of Mexico there are more advances in the cooperative field, being beneficiaries of the fair-trade movement (Fridell, 2006).

Commitment to the community: This is related to the traditions and customs of the Mayan communities. Women who participate in these initiatives have mostly suffered the effects of family disintegration linked to the labor migration of the men in their families. Therefore, they understand the value of community integration based on their own experience. In the case of expanding the cooperative, this is mostly carried out within the same community instead of developing in new markets, due to the flexibility at work that this provides.

All in all, some of the characteristics of the cooperatives that were studied are consistent with those established by the International Cooperative Alliance (ICA), but not in a comprehensive manner, as yet. This does not mean they will never be fulfilled. The process leading the cooperatives there could develop over the years, by learning from their experiences.

\subsection{Policy implications}

This section presents suggestions for the formulation of public policies to improve the actions already undertaken in order to encourage the economic development of women through micro-businesses. It should be noted that the following recommendations are formulated based on the results of this research and proposed with the intention that these programs have a positive and sustainable impact for the women involved.

First it should be mentioned that, during this research, we encountered many committed people who really make an effort in favour of these communities. They come from international and national agencies, as well as from all hierarchical levels of public functions 
and private sector. Some of them work to achieve these goals with integrity and with an honest desire to improve the lives of the Maya women. Therefore, the following recommendations, focusing on both the international and regional levels, are certainly not meant to criticize their efforts, but to improve the sustainability of these initiatives.

Mexico is considered as an emerging country (OECD, 2015). This means that much of the international aid for development is no longer directed towards this country and its inhabitants. However, there are sectors of the population that still benefit from international programs for geo-strategic and humanitarian reasons.

Among the best practices of the international programs that can be found is the use of participatory methodologies interacting with the population, with a bottom up perspective. Such programs often use NGO's as intermediaries which provide support to the participants in the search for grants through projects, create transparency in resource management and continuous training offered to women in the region at no cost, whether they have approved projects or not (chapter five).

However, they do not always facilitate the use of translators from Spanish to Maya to improve the training process of the women. The participants also mentioned the difficulties they have to face in order to carry out procedures and paperwork in the cities, since they are not familiar with the formalities of the city, and on occasions even experience discrimination in the urban context. This is accentuated by the difficulties they encounter trying to explain their needs and purposes in Spanish since the Maya language is their mother tongue, commonly used in their communities. They have to depend on others to communicate and sometimes the translation is not accurate (chapters three, four and five).

The training and follow-up should be in their mother tongue, the Maya, carried out by bilingual people (Maya and Spanish), preferably female, with the same background, from the same community or at least from the same region, as this favors the trust to talk openly about the advancement of the business, their challenges and their aspirations. The procedures should be conducted close to the place of residence of the participants, in public places inside their communities, since the transportation and the realization of paper work in the cities is a real challenge for the majority of the Maya women who live in isolated areas.

It was also observed that the use of national NGOs as intermediaries to facilitate the implementation process can obstruct the contact between the beneficiary population and the donor country's representatives. In the case study of the cooperative that received the Canada Fund support, the recipient women kept the photos of the visits made by the Canadian Embassy staff in Mexico, with much appreciation. Moreover, the Canada Fund logo is still painted in a visible place in the micro-business. In addition to the commitment for the sponsorship, this is a source of pride for the beneficiaries who received the support as described in chapter five.

While the beneficiaries pay such great importance to the prolonged interest shown by the donor organizations, it is important that such follow-up attention is not just outsourced. This is not to be seen as a way of control, but as a sign of interest and potential opportunity for giving further advice (chapter five). Contact with people is often lost with distance and time, 
but the follow-up visits increased the commitment for the funds granted, which is why a greater involvement of the Embassy personnel in agreement with the national NGO in the follow-up activities is also recommended for future ventures.

Another aspect to mention is that often the granting of national funds is strongly related to political interests, and this can be perceived as detrimental to the Maya population. In chapter four it is mentioned how the monitoring is done through the CDI promoters, who are young women from the same community whose first language is the Maya, but their activities are more focused on the verification of the use of resources and only secondly to support the development of the micro-business. In Mexico, there is a serious problem of corruption, which is present in both the public administration and civil society. Examples of this may be mentioned as some of the interviewee's reflections (chapter four):

- Requesting money from the women in exchange for support in writing the project, which should be at no cost for them.

- Information relating to the supports only transmitted to the people close to the local authorities.

- The support being used as political marketing.

- Repartition of the funds among the women, without starting the microbusiness.

There are sectors within the Mexican public administration that engage in promoting transparency and accountability, such as the National Institute for Transparency, Access to Information and Protection of Personal Data (INAI) and the Secretariat of Public Function (SFP). These organizations regulate these types of incidents and strongly punish those who carry out dishonest practices to the detriment of the Mexican population while working in public administration. These preventive actions should be strengthened along with a change of attitude, through work and honest practices among Mexican society.

Besides, this research showed the importance of taking into account other intangible aspects in the selection process of the beneficiaries, such as the profiles of the women participating in cooperatives, their experience in productive activities, their vision of life, their goals, their understanding of responsibility, and commitment among the members to carry out the business (chapter two).

To begin with, it is important to hear the opinion of the participants. Programs and projects should be involving the target population in the formulation of public policies, to achieve higher levels of success (Pech, 2012, Dureyttere, 2003). In this way they are better able to take their perspectives and their experiences into consideration. The participants know the context in which they live better than the implementers. Furthermore, these conversations facilitate a deeper knowledge of their needs and even their weaknesses, which should be taken into account during the development of adequate programs.

It is also relevant to consider the expectations, hypothetical choices, cognitive abilities, and expressed attitudes (Kimball, 2015) when selecting possible beneficiaries of these productive programs. This is important because if the selection of the beneficiaries is correct, the opportunities to achieve sustainability will be enhanced (chapters three, four and five). It is of the highest importance to ask the groups of women if they have previously worked together, for how many years and what their experience has been. It is crucial to support 
groups already consolidated and not to start with groups of women who have no prior ties or common interests. Among the factors constraining the development of Maya women working in cooperatives, internal conflicts were observed within the organization, often related to the poor selection of participants, made by government representatives who are mostly outsiders and do not know how the community works.

Furthermore, the management of expenses should not require the signature of the local authority, since these representatives often have their own political agenda and this could pressure the women to condition their vote or to be involved in activities that could compromise them. Involvement of NGO's, external agencies or committees with the participation of local population should be encouraged to ensure transparency in resource management and avoid political bias.

Finally, from our analysis we concluded that the status of the support fund as non-refundable should be reconsidered. This form of support scheme accommodates low engagement and correspondently, does not promote responsibility (chapter four). Furthermore, it can accommodate low levels of follow-up guidance by the sponsor which can be interpreted as disinterest, or lead to just checking for which expenses the support has been used. Given the high levels of poverty in this zone, at least one third of the money received should be returned with work if the microbusiness fails. With this proposal, Maya women would share their knowledge with other women in any field in which they feel competent. It could be related to cooking, embroidery, traditional medicine and even teaching typical dances of the region, as a way to give something back to their communities for the support received.

Most importantly, given the serious dependence of rural populations on the support programs from the Mexican government, government programs aimed at encouraging economic development must foster self-sufficiency capacities in the population. Specific programs to encourage savings, talent and capacity building, leadership, sport and art programs should be encouraged since these activities sustain hope, so necessary to aspire higher. 


\section{References}

Abdel-Malek, T. (2015). The Global Partnership for Effective Development Cooperation German Development Institute, available at:

http://www.die-gdi.de/uploads/media/Studies_88.pdf (accessed November 25 2016).

Abu Jaber (2014). Breaking through Glass Doors: A Gender Analysis of Womenomics in the Jordanian National Curriculum, available at:

https://www.brookings.edu/research/breaking-through-glass-doors-a-gender-analysis-ofwomenomics-in-the-jordanian-national-curriculum/ (accessed November 4 2017).

Acosta, A. \& Martínez, E. comp. (2009). El buen vivir. Una vía para el desarrollo. Quito: UPS Publicaciones.

Action Canada pour la santé et les droits sexuels, Oxfam Canada, et Inter Pares à l'Examen de l'aide internationale du Canada; appuyée par AQOCI, AWID, CARE Canada, Gender at Work, USC Canada, le YWCA, EUMC et le Fonds MATCH international pour la femme (2016). Une approche féministe de l'aide internationale du Canada Canada's Aid Efectiveness Agenda, available at: http://www.sexualhealthandrights.ca/wp-content/uploads/2016/08/Une-approchef\%C3\%A9ministe-de-1\%E2\%80\%99aide-internationale-du-Canada.pdf (accesed August 26 2016).

Aerden, M. (2011). "Women's Leadership as Means for Sustainable Change", available at: http://www.ncbi.nlm.nih.gov/pubmed/21368242 (accessed November 4 2014).

Agence Canadienne de Développement International (2007). L'Aide Internationale du Canada à l'ouvre, le développement axé sur les résultats, available at: http://www.acdicida.gc.ca/inet/images.nsf/vLUImages/Results/\$file/Rapport\%20sur\%20les \%20r\%C3\%A9sultats.pdf (accessed November 14 2016).

Aguado, R. (2011). "Políticas Públicas para el desarrollo. El papel de las ONGDs en el marco de la agenda de las Naciones Unidas”, pp. 97-110 in Santacoloma, J. \& Aguado, R. (coords.). Economía y Humanismo Cristiano. España: Universidad de Deusto.

Aguilar, L. (2011). "Políticas públicas y transversalidad", Ramos, J.; Sosa, J. \& F. Acosta (coords) La evaluación de políticas públicas en México, El Colegio de la Frontera Norte, México.

Alemany, M. (2005). "El concepto y la justificación del paternalismo”, available at: http://www.cervantesvirtual.com/obra/el-concepto-y-la-justificacion-del-paternalismo--0/ (accessed April 16 2016).

Alonso, M. (1991). "El cooperativismo valenciano: desde sus inicios hasta la Ley de 1974", Revista de economía pública, social y cooperativa, $\mathrm{n}^{\circ} 11$, pp. 53-68. 
Alonso, J. (2015). Más allá de la ayuda: redefiniendo el sistema de cooperación para el desarrollo, available at: http://repositorio.cepal.org/handle/11362/38855 (accessed October 16 2016).

Alterinfos, available at: http://www.alterinfos.org/spip.php?article6411 (accessed January 20 2014).

Altieri, M. (2009). "Agroecology, Small Farms, and Food Sovereignty". Monthly Review, No. 61, pp. 102-113.

Alvarez, L. \& Gálvez, A. (2014). "Food Sovereignty in a Socioecological Transformation Context in the Caribbean", available at:

http://www.tandfonline.com/doi/abs/10.1080/21683565.2014.881951

(accessed Feb 12 2016).

Amin, S., Arrighi, G. Gunder, A. \& Wallerstein, I. (1983). Dinámica de la Crisis Global. España: Siglo XXI.

APA Fundación Ayuda para Ayudar, available at:

http://a7.com.mx/index.php?notaid=4975 (accessed September 14 2014).

Aranguren, L. (2010). Solidaridad: ¿moneda de cambio o imperativo ético? México: Instituto Mexicano de Doctrina Social Cristiana.

Arias, Y. (2012). "La Naturaleza como sujeto de derecho: posibilidad de medir lo intangible", Guillén, A.; Phélan, M. comp. Construyendo el Buen Vivir, Ecuador: Ed. Pydlos.

Arroyo, G. (1999). Metodología de las Relaciones Internacionales. México: Ed. Oxford.

Azkona, N. (2013). La implementación del concepto de desarrollo en las políticas de cooperación al desarrollo y en materia migratoria, available at:

http://www.revistaei.uchile.cl/index.php/REI/article/viewFile/29993/31764

(accessed September 26 2016).

Bakaikoa, B., Begiristain, A. Errasti, A. \& Goikoetxea, G. (2004). "Redes e innovación cooperative", available at:

http://www.redalyc.org/pdf/174/17404912.pdf (accessed April 27 2017).

Balam, Y. (2010), Tulum: Mayas y Turismo, UQROO, México.

Bandura, A. (1977). Social learning theory. Englewood Clivs, NJ: Prentice-Hall.

Bastidas, O. \& Richer, M. (2001). "Economía social y economía solidaria: intento de definición”. Capaya Revista Venezolana de Economía Social, núm. 1, pp. 2-28. 
Bello, A. \& Rangel, M. (2002). "La equidad y la exclusión de los pueblos indígenas y afrodescendientes en América Latina y el Caribe”, Documento CEPAL No 76, Santiago de Chile.

Boisier, S. (2005). Hay espacio para el desarrollo local en la globalización?. Chile: CEPAL.

Bourdieu, P. (1997). Capital cultural, escuela y espacio social. Madrid: Siglo XXI.

Bressers, H. (2004). "Implementing sustainable development: how to know what works, where, when and how" William Lafferty (ed.), Governance for sustainable development: The challenge of adapting form to function, Edward Elgar, pp. 284-318.

Bressers, H. (2009). "From public administration to policy networks: Contextual interaction analysis" Stephane Narath and Frederic Varone (eds.), Rediscovering public law and public administration in comparative policy analysis, Haubt Verlag, pp. 123-142.

Brown, M. E., Treviño, L.K. \& Harrison, D. (2005). "Ethical leadership: A social learning perspective for construct development and testing". Organizational Behavior and Human Decision Processes, No. 97, pp. 117-134.

Brown, M. \& Treviño L. (2006). "Ethical Leadership: A review and future directions", The Leadership Quarterly No. 17, pp. 595-616.

Brown, S. (2013). Canada's foreign aid before and after CIDA: Not a Samaritan state, available at: http://ijx.sagepub.com/content/68/3/501 (accessed November 14 2016).

Brown, S. (2015). Aid Effectiveness and the Framing of New Canadian Aid Initiatives, available at:

http://stephenbrown.xyz/wp-content/uploads/Stephen-Brown-aid-effectiveness-3rd-ed.pdf (accessed October 13 2016).

Brown, S. (2016). The instrumentalization of foreign aid under the Harper government, available at:

http://www.tandfonline.com/doi/pdf/10.1080/07078552.2016.1174461 (accessed

September 12 2016).

Bülles, A. \& Kindornay, S. (2013). Beyond Aid: A Plan for Canada’s International Cooperation, available at:

http://www.nsi-ins.ca/wpcontent/uploads/2013/05/BuellesKindornay.2013.CNDPolicyCoherenceEN.pdf (accessed November 2 2016).

Burgos, L. \& Osorio, M. (2017), “Avances sociales de la mujer en Yucatán” en Barroso, F., Patrón, R. \& Santos, R. (comp.) La competitividad y el desarrollo sustentable de las organizaciones. México: Universidad Anáhuac Mayab (on press). 
Cabanes, M. \& Gómez, J. (2014). “Economía social y Soberanía Alimentaria. Aportaciones de las cooperativas y asociaciones agroecológicas de producción y consumo al bienestar de los territorios". Revista de Economía Pública, Social y Cooperativa, No. 82, pp. 127-154.

Cabrero, E. (2000). "Usos y costumbres en la hechura de las políticas públicas en México. Límites de las Policy Sciences en contextos cultural y políticamente diferentes", Gestión y Política Pública. Vol. IX, Núm. 2 Pp: 180-229.

Cajiao, F. (1999). Cooperación Internacional y Producción de Significados, available at: https://doaj.org/article/1f7d502fc9d445ea97bcf3e65b93ea92 (accessed November 14 2016).

Calderón, G. (2001), "Reflexiones sobre Estado, gobierno y políticas públicas”, Ramírez Jaime \& Eduardo Torres (coord.), Reformas del Estado, políticas públicas y problemas socioeconómicos del México contemporáneo, $1^{\mathrm{a}}$ edición, Universidad Autónoma Metropolitana, México.

Calderón, G. (2003). "Notas sobre las políticas públicas en México”, available at: http://siare.clad.org/fulltext/0050708.pdf (accessed September 13 2015).

Calderón, G. (2009). "Las Políticas Públicas y el combate a la Pobreza", Gestión y Políticas Públicas en la era del Neoliberalismo, No. 1, pp. 1-28.

Calderón, G. (2011). "La cooperativa una alternativa", Revista Electrónica de Ciencias Sociales, No. 16. Pp. 1-17.

Calvez, J. \& Perrin, J. (1965). Iglesia y Sociedad Económica. Paris: Ed. Montaigne.

Canada's Coalition to end global poverty CCIC (2016) Le point sur l'aide publique au développement canadienne, available at:

http://www.ccic.ca/_files/fr/what_we_do/2016_10_Brief_Update_Canadian_ODA.pdf (accessed August 15 2016).

Canadian International Development Agency (2006), Estimates 2006 - 2007, available at: http://www.tbs-sct.gc.ca/rpp/2006-2007/cida-acdi/cida-acdi-eng.pdf (accessed November 14 2016).

Canadian International Development Agency (2007), Estimates 2007 - 2008, available at: http://publications.gc.ca/site/eng/308056/publication.html (accessed November 16 2016).

Cárdenas, V., Fernando, A., Jouannet, A., Padilla, G., Maldonado, L., Jijón, V., Soberanis, C., Reyes, F., Ospina, J. \& Salmón, E. (2011). "Participación Política Indígena y Políticas Públicas para Pueblos Indígenas en América Latina" available at:

http://www.kas.de/wf/doc/kas_30218-1522-1-30.pdf?120217163033 (accessed September 12 2015). 
Carment, D., Calleja, R. \& Samy, Y. (2013). Comparing Canada's Aid Effectiveness: Coherence and Focus at Risk, available at: http://carleton.ca/npsia/wp-content/uploads/Aid-Effectiveness.pdf (accessed October 13 2016).

Cazeres, A., Ríos, J. (1999). "Capital social y democracia: una revisión crítica de Robert Putnam", available at:

http://investigadores.cide.edu/julio.rios/papers/Rios\%20\&\%20Rios\%20on\%20Robert\%20P utnam.pdf (accessed June 20 2014).

Caulier-Grice, J., Davies, A., Patrick, R. \& Norman, W. (2012). “Defining Social Innovation", available at: https://youngfoundation.org/wpcontent/uploads/2012/12/TEPSIE.D1.1.Report.DefiningSocialInnovation.Part-1-definingsocial-innovation.pdf (accessed May 23 2017).

Ceceña, A. (2009). "Pensar la vida y el futuro de otra manera" en León, I. coord. Buen vivir y cambios civilizatorios, Ed. Fedaeps, Ecuador.

Centre d'Informació i Documentació Europea d'Economia Pública, Social i Cooperativa, available at :

http://www.uv.es/cidec/c/bases.shtml (accessed January 12 2014).

Centre International de Recherches et d'information sur l'Economie Publique, Social et Coopérative (2008). «Innovación y economía social ». Revista de Economía Pública, Social y Cooperativa, núm. 60, pp. 5.

CEPAL (1973). Desarrollo Económico, Planeamiento y Cooperación Internacional, available at: http://archivo.cepal.org/pdfs/cdPrebisch/328.pdf (accessed November 13 2016).

Cerón, H. y Yunez-Naude, A. (2004), "Diversificación en la economía rural hacia actividades no agropecuarias y sus impactos en pobreza y desigualdad", available at: http://precesam.colmex.mx/images/secundaria/seminarios/Desarrollo_rural/Diversificacion. pdf (accessed September 12 2014).

CGEIB Coordinación General de Educación Intercultural y Bilingüe, available at: http://eib.sep.gob.mx/diversidad/ (accessed May 1 2017).

Chase, R., Hill, E. \& Kennedy, P. (1996). Pivotal states and US strategy, available at: https://www.foreignaffairs.com/articles/algeria/1996-01-01/pivotal-states-and-us-strategy (accessed November 16 2016)

Chaves, R. (2008). "Panorama de la investigación en Economía Social”. Estudios de Economía Aplicada, núm. 1, pp. 29-55. 
Chiroque, H., Mutuberría, V. (2009). "Procesos de construcción de otras alternativas: desarrollo y planteamiento de la Economía Social Comunitaria en América Latina". Revista de Economía Pública, Social y Cooperativa, núm. 66, pp. 147-163.

Cienfuegos, M. \& Sanahja, J. (eds.) (2010). La construcción de una región. Unasur y la integración en América del Sur. Barcelona: CIDOB.

Cockburn, J. (2014). Bolivia's Food Sovereignty \& Agrobiodiversity: Undermining the Local to Strengthen the State?, available at: http://transformativestudies.org/wp-content/uploads/10.3798tia.1937-0237.14028.pdf (accessed November 9 2016).

Coleman, J. (1988). "Social capital in the creation of human capital", available at: https://www.jstor.org/stable/2780243?seq=1\#page_scan_tab_contents (accessed March 13 2017).

Collí, M. (2014), Lengua Maya Yucateca de Palabra en Palabra se aprende, México: SEP.

Comisión Nacional para el Desarrollo de los Pueblos Indígenas (2014), available at http://www.cdi.gob.mx (accessed 10 September 2014).

Comisión Nacional para el Desarrollo de los Pueblos Indígenas, available at: http://www.cdi.gob.mx/ (accessed April 28 2017).

Comisión Nacional para el Desarrollo de los Pueblos Indígenas. Diagnóstico del Programa para Mejoramiento de la Producción y Productividad Indígena (2014), available at: http://www.cdi.gob.mx/coneval/2014/S-249-programa-mejoramiento-producciondiagnostico-2014.pdf (accessed 14 September 2015).

Comisión Nacional para el Desarrollo de los Pueblos Indígenas (2015), available at: http://www.cdi.gob.mx/popmi/ (accessed 23 October 2015).

CONAFE Consejo Nacional para el Fomento Educativo, available at: http://www.gob.mx/conafe (accessed May 2 2017).

CONEVAL El Consejo Nacional de Evaluación de la Política de Desarrollo Social, available at: http://www.coneval.org.mx/Paginas/principal.aspx (accessed May 2 2017).

CONEVAL (2011). Medición de pobreza en los municipios de México, 2010. México, available at: http://www.coneval.gob.mx/Medicion/Paginas/Medici\%C3\%B3n/Medicion-de-la-pobrezamunicipal-2010.aspx (accessed March 12 2015).

Consejo Pontificio "Justicia y Paz" (2000). Los derechos humanos y la misión pastoral de la Iglesia. Ciudad del Vaticano: Tipografía Vaticana. 
Constitución Política de los Estados Unidos Mexicanos, available at:

http://www.diputados.gob.mx/LeyesBiblio/htm/1.htm (accessed 20 June 2016).

Coque, J. (2005). Compartir soluciones: las cooperativas como factor de desarrollo en zonas desfavorecidas. Madrid: Ed. Consejo Económico y Social.

Coraggio, J. (2011). Economía social y solidaria. El trabajo antes que el capital. Ecuador: Ed. Abya-Yala.

Correa, R. (2005). Construyendo el ALBA. "Nuestro Norte es el Sur". Caracas: Lauki.

Creswell, J. (1998). Qualitative inquiry and research design: choosing among five traditions. US: Sage Publications.

Creswell, J. (2003). Research design: Qualitative, quantitative, and mixed method. US: Sage Publications.

Cuevas, S., Fernandez, J., \& Olvida, I. (2015). "Where peasants are kings: Food sovereignty in the Tagbanua traditional subsistence system". Austrian Journal of SouthEast Asian Studies, No. 8, pp. 27-44.

Culti, M. (2002). "El Cooperativismo Popular en Brasil: Importancia y Representatividad", available at:

http://www.unitrabalho.uem.br/administracao/bd_artigos/arquivos/010614145946.pdf (accessed April 27 2017).

Curl, J. (2009). For All the People: Uncovering the Hidden History of Cooperation, Cooperative Movements, and Communalism in America. US:PM Press.

Da Silva, C. \& Salanek, P. (2009). "Capital social y cooperativismo agropecuario: una evaluación del funcionamiento de la cooperativa COPACOL/Paraná/Brasil", available at: http://www2.congreso.gob.pe/sicr/cendocbib/con4_uibd.nsf/3B8363FFF1EE38CB05257B5 C0077AC2C/\$FILE/28011674005.pdf (accessed May 2 2017).

Davila, F. \& Dyball, R. (2015). "Transforming Food Systems through food sovereignty: An Australian urban context". Australian Journal of Environmental Education, No. 31(1), pp. $34-45$.

De Boer, C. (2012). "Contextual water management. A study of governance and implementation processes in local stream restoration projects", available at: http://doc.utwente.nl/81724/1/thesis_C_de_Boer.pdf (accessed August 10 2014).

De Boer, C. \& Bressers, H. (2011). Complex and Dynamic Implementation Processes, University of Twente: The Netherlands. 
Deblock, C. \& Benessaieh, A. (2001). Les relations économiques entre le Canada et le Mexique dans un contexte d'intégration en profondeur, available at: https://politique.uqam.ca/upload/files/PDF/PDF-137relations_economiques_Canada_Mexique.pdf (accessed September 18 2016).

Del Arenal, C. (1984). Introducción a las Relaciones Internacionales. Madrid: Ed. Tecnos.

Dell, C. \& Lyons, T. (2007). Harm reduction policies and programs for persons of Aboriginal descent, available at: http://www.addictionresearchchair.ca/wpcontent/uploads/Harm-Reduction-Policies-and-Programs-for-Persons-of-AboriginalDescent.pdf (accessed September 18 2016).

Denmark, F. (1993). "Women, Leadership, and Empowerment", available at: http://pwq.sagepub.com/content/17/3/343.full.pdf+html (accessed August 2 2014).

Dente, B. \& Fareri, P. (1998). Siting waste facilities: Drawing lessons from success stories. In: Dente, Fareri, Ligteringen (Eds.), The waste and the backyard, Dordrecht: Kluwer, pp. 3-46.

Denzin, N. \& Lincoln, Y. (2000). Handbook of Qualitative Research. US: Sage Publications. Développement et Paix (2012). Questions \& Responses sur le développement International, available at: http://www.devp.org/files/IMCE/files/morethanever/devpaix_questions_reponses_aide_internationale.pdf (accessed August 18 2016).

Dirección General de Educación Indígena DGEI, available at: http://dgei.basica.sep.gob.mx/ (accessed April 30 2017).

Diario Oficial de la Federación (2013), available at: http://www.dof.gob.mx/nota_detalle.php?codigo=5289143\&fecha=27/02/2013 (accesed September 10 2015).

Díaz, B. (2006). "Políticas públicas para la promoción de cooperativas en Venezuela (19992006)", available at: http://www.saber.ula.ve/bitstream/123456789/18733/2/articulo8.pdf (accessed Feb 2 2017).

Domínguez, R. (2014). Perspectivas de la cooperación internacional y el desarrollo sostenible después de 2015, available at: http://www.ciberoamericana.com/pdf/PB.pdf (accessed September 10 2016).

Dror, Y. (1996). La capacidad de gobernar: Informe al Club de Roma, FCE: México.

Dureyttere, A. (2003). Pueblos indígenas, recursos naturales y desarrollo con identidad: riesgos y oportunidades en tiempos de globalización, US:BID. 
Eagly, A. \& Karau, S. (2002). "Role congruity theory of prejudice toward female leaders". Psychological Review, No. 109, pp. 573- 598.

ECLAC Economic Commission for Latin America and the Caribbean, available at: http://www.cepal.org/en (accessed March 2 2017).

Economía del Bien Común, available at:

www.economia-del-bien-comun.org (accessed January 22014 ).

Ehlert, J. \& Voßemer, C. (2015). "Food sovereignty and conceptualization of agency: A methodological discussion”. Austrian Journal of South-East Asian Studies, No. 8, pp. 7-26.

Ellen MacArthur Foundation (2013). Towards the circular economy. Economic and Business rationale for an accelerate transition. USA: Partners of Ellen MacArthur Foundation.

Engel, S. (2014). The Not So-Great Aid Debate, available at: http://www.tandfonline.com/doi/abs/10.1080/01436597.2014.946251 ?journalCode=ctwq20 (accessed November 12 2016).

Escurriol, V., Binimelis, R. \& Rivera-Ferre, M. (2014). "The situation of rural women in Spain: the case of small-scale artisan food producers". Athenea Digital, No. 14(3), pp. 3-22.

Espadas, F. (2015). "Embestida contra radios indígenas" available at: http://yucatan.com.mx/editoriales/embestida-contra-radios-indigenas (accessed December 27 2015).

Espinosa, G. (2006). "La participación en la actividad económica de las mujeres del programa Oportunidades y su relación con la corresponsabilidad de éste y otros programas sociales" en López, M., Saller, V. (comp.) El Programa Oportunidades examinado desde el género, México: COLMEX.

Fay, B. (1987). Critical Social Science: Liberation and its Limits. Cambridge: Polity.

FCIL Fondo Canadá para Iniciativas Locales, available at:

http://www.canadainternational.gc.ca/mexico-mexique/dev/c_fund-fonds.aspx?lang=es (accessed Nov 17 2016).

Felber, C. (2012). La Economía del bien común. España: Ed. Deusto.

Ferguson, A. (2009). "CEDESA and the Food Sovereignty Movement in Mexico. The Organizing Power of Women”. Against the Current, No. 25, pp. 19-22.

FIA Fundación Interamericana, available at: http://www.iaf.gov/ (accessed April 22 2017). 
Fillion-Lauzière, C. (2008). Évolution de l'aide publique au développement: Le cas du Canada, available at:

http://www.ccic.ca/f/docs/002_aid_2008-12_oda_hr_standards.pdf

(accessed August 14 2016).

Flannery, K. (1982). Maya subsistence. New York: Academic Press.

Food and Agriculture Organization of the United Nations, available at:

http://www.fao.org/economic/ess/ess-fs/en/ (accessed May 18 2016).

Fonseca, G. \& Giacomelli, A. (2004). La cooperacion económica y social en las Naciones Unidas, available at:

http://www.anales-ii.ing.uchile.cl/index.php/REI/article/viewArticle/14571

(accessed August 14 2016).

Foro Mundial sobre Soberanía Alimentaria, available at:

http://www.alliance21.org (accessed July 20 2016).

Francis Canavan, S.J. (1993). "Political Choice and Catholic Conscience", pp. 21-34 in When Conscience and Politics meet: A catholic view. San Francisco: Ignatius Press.

Francis, M. (1972). La ayuda económica de Estados Unidos a América Latina como instrumento de control político, available at:

https://www.jstor.org/stable/27753544?seq=1\#page_scan_tab_contents

(accessed November 17 2016).

Freire, P. (1974). Education for critical consciousness. London: Bloomsbury.

Freire, P. (1993). Cartas a quien pretende enseñar. México: Siglo XXI.

Fridell, G. (2006). “Comercio justo, neoliberalismo y desarrollo rural: una evaluación histórica", available at:

http://www.redalyc.org/articulo.oa?id=50902405 (accessed June 7 2017).

Fonchingong, C. (1999). "Structural adjustment, women, and agriculture in Cameroon", available at:

http://www.jstor.org/stable/pdfplus/4030412.pdf?acceptTC=true\&jpdConfirm=true (accessed September 8 2014).

Fukuyama, F. (1995). Trust: The Social Virtues and the Creation of Prosperity, US:Free Press.

Ganga, F., Burotto, J. \& Antonioletti, M. (2010). “Aproximación teórica a las

organizaciones del tercer sector”. Espacio Abierto, núm. 1, pp. 51-77.

Geilfus, F. (2002). 80 Herramientas para el desarrollo participativo. Costa Rica: IICA. 
Gelauff, G. (2003). "Social capital: an indispensable asset in the knowledge-based economy", available at:

http://citeseerx.ist.psu.edu/viewdoc/download?doi=10.1.1.202.7967\&rep=rep1\&type=pdf (accessed May 3 2017).

Gemelli, M. (2008). "Mercadeo de los productos orgánicos en Bolivia. El caso ASOPEC”, available at:

http://www.fao.org/3/a-at739s.pdf (accessed March 21 2017).

Global Affairs Canada (2016). International Assistance Review, available at:

http://www.international.gc.ca/world-monde/assets/pdfs/iar-consultations-eai-eng.pdf (accessed October 25 2016).

Goldfarb, D. \& Tapp, S. (2006). How Canada Can Improve Its Development Aid. Lessons from Other Aid Agencies, available at:

https://www.cdhowe.org/public-policy-research/how-canada-can-improve-its-developmentaid-lessons-other-aid-agencies (accessed August 24 2016).

Gómez, J. (2004). "Las cooperativas agrarias de la comunidad valenciana frente al proceso de globalización”, available at:

https://dialnet.unirioja.es/descarga/articulo/1185848.pdf (accessed Feb 11 2017).

González, A. (2008). Maíz, contaminación transgénica y pueblos indígenas en México. México: PRD.

González, A. (2009). “Economía Solidaria y Comercio Justo”. Revista Pueblos y Fronteras Digital, núm. 7, pp. 1-4.

González, G. (2016). La pobreza material y la pobreza spiritual, available at: http://www.diariocatolico.info/index.php/12-opinion-religiosa/55-la-pobreza-material-y-lapobreza-espiritual (accessed January 2 2017).

González, H., Molina, M. Padrón, E. De la Rosa, J. Segovia, J. \& Huitrón, R. (2013). "Reflexión sobre el comportamiento ético de los individuos en las organizaciones en México”. Revista Internacional Administración \& Finanzas, Vol. 6, No. 6, pp. 73-85.

Goody, A. (2009). International development: the aid effectiveness debate, available at: http://www.lop.parl.gc.ca/Content/LOP/ResearchPublications/prb0907-e.htm (accessed October 25 2016).

Government of Canada (2016). Report to Parliament on the Government of Canada's Official Development Assistance 2015-2016, available at: http://international.gc.ca/gac-amc/publications/odaaa-lrmado/daaa 1rmado_1516.aspx?lang=eng (accessed January 5 2017). 
Granados, D., López, G. \& Trujillo, E. (1999). “La milpa en la zona maya de Quintana Roo”. Revista de Geografía Agrícola, No.28, pp. 57-72.

Green, M. (1971). Inversión extranjera, ayuda y dependencia en América Latina, available at:

http://www.forointernacional.colmex.mx/index.php/fi/article/download/496/486 (accessed October 25 2016).

Groos, A. \& Feldman, T. (2015). "We Didn't Want to Hear the Word 'Calories':

Rethinking Food Security, Food Power, and Food Sovereignty-Lessons from the Gaza Closure". Berkeley Journal of International Law, No. 33:2, pp. 379-441.

Guerrero, V. (2002). Estadística básica para estudiantes de economía y otras ciencias sociales, México: FCE.

Guillén, A. \& Phélan, M. (comp). (2012). Construyendo el Buen Vivir. Ecuador: Ed. Pydlos.

Hernández, R. Fernández, C. \& Baptista, P. (2007). Fundamentos de la Metodología de la Investigación. España: McGraw-Hill.

Hernández, R., Fernández, C. \& Baptista, P. (2010). Metodología de la Investigación. México: Ed. Mc Graw Hill.

Heron, J. \& Reason, P. (1997). "A participatory inquiry paradigm", available at: https://pdfs.semanticscholar.org/362c/bd2962357b57b3dab97063569e8256e846e2.pdf (accessed May 17 2017).

Hirschman, A. \& Bird, R. (1968). Asistencia Externa: Una Crítica y una Proposición, available at:

http://revistas.bancomext.gob.mx/rce/magazines/742/8/RCE8.pdf (accessed September 12 2016).

Hopma, J. \& Woods, M., (2014). "Political Geographies of 'Food Security' and 'Food Sovereignty"”. Geography Compass, No. 8, pp. 773-784.

Hynes, W. \& Scott, S. (2013). The Evolution of Official Development Assistance: Achievements, Criticisms and a Way Forward, available at: http://www.oecd.org/development/stats/documentupload/Evolution\%20of\%20ODA.pdf (accessed November 22 2016).

ICA International Cooperative Alliance, available at: http://ica.coop/es/ (accessed April 23 2017).

IDB Inter-American Development Bank, available at: http://www.iadb.org/en/inter-american-development-bank,2837.html (accessed Feb 24 2017). 
Ikeda, D. (2008). "Humanizar la religión y crear la paz", available at:

http://www.daisakuikeda.org/es/humanizar-la-religion-para-crear-paz.html

(accessed November 15 2015).

INAES National Institute of the Social Economy, available at:

http://www.gob.mx/inaes (accessed May 2 2017).

INEA Instituto Nacional para la Educación de los Adultos, available at:

http://www.gob.mx/inea/ (accessed April 29 2017).

INEGI (2010). available at: http://www.inegi.org.mx/ (accessed March 1 2016).

INEGI, (2013). "Encuesta Nacional de Ingresos y Gastos en los Hogares (ENIGH) 2012", available at:

http://www.inegi.org.mx/inegi/contenidos/espanol/prensa/boletines/boletin/Comunicados/E speciales/2013/Julio/comunica5.pdf (accessed September 5 2014).

INEGI (2015). “Esperanza de vida de los negocios en México: Metodología”, available at: http://www.inegi.org.mx//prod_serv/contenidos/espanol/bvinegi/productos/nueva_estruc/70 2825068431.pdf (accessed March 17 2015).

INEGI Instituto Nacional de Estadística y Geografía, available at:

http://www3.inegi.org.mx/sistemas/sisept/Default.aspx?t=medu14\&s=est\&c=35008 (accessed May 19 2016).

INEGI Instituto Nacional de Estadística y Geografía, available at: http://www.inegi.org.mx/ (accessed April 28 2017).

Ingram G., Johnson, A. \& Moser Monday, H. (2016). USAID’s public-private partnerships: A data picture and review of business engagement, available at:

https://www.brookings.edu/research/usaids-public-private-partnerships-a-data-picture-andreview-of-business-engagement/ (accessed January 4 2017).

Instituto Nacional de las Mujeres (2007). Glosario de Género, available at: http://cedoc.inmujeres.gob.mx/documentos_download/100904.pdf (accessed May 25 2016).

Instituto Nacional de las Mujeres, Inmujeres (2012). Diagnóstico elaborado con perspectiva de género sobre los programas de financiamiento a proyectos productivos a cargo de mujeres, desarrollados en la zona maya de Quintana Roo para la elaboración de una propuesta de mejora de estos programas, available at:

http://cedoc.inmujeres.gob.mx/ftpg/QRoo/QROO_MA10_PP_dx_Proyectos_Productivos_2 012.pdf (accessed October 12 2015). 
International Co-operative Alliance, available at:

https://ica.coop/en/whats-co-op/co-operative-identity-values-principles (accessed May 19 2016).

Janvry A. y Sadoulet, E. (2004). "Estrategias de ingresos de los hogares rurales de México: el papel de las actividades desarrolladas fuera del predio agrícola", available at:

http://www.cepal.org/publicaciones/xml/4/22444/lcl2096edejanvrypdf.pdf

(accessed September 10 2014).

Jarosz, L. (2011). "Nourishing women: toward a feminist political ecology of community supported agriculture in the United States", available at:

http://www.tandfonline.com/doi/pdf/10.1080/0966369X.2011.565871

(accessed July 24 2014).

Jenks, B. (2015). Cooperación para el desarrollo de las Naciones Unidas: las raíces de una agenda de reforma, available at:

http://repositorio.cepal.org/handle/11362/38855 (accessed October 16 2016).

Joblin, J. S.J. (1994). Los Pueblos Autóctonos en la Enseñanza de Juan Pablo II. Colombia: Consejo Episcopal Latinoamericano CELAM.

Johnston, P. (2010). Modernizing Canadian Foreign Aid and Development: Challenges old and new, available at:

http://gordonfoundation.ca/sites/default/files/Johnston_ModernizingCdnForeignAid\&Dev.p df (accessed October 25 2016).

Jubinville, P.C.S.SP. (2016). Mensaje del Obispo Pedro Jubinville, C.S.Sp. Obispo de San Pedro Apóstol y obispo responsable de CEBs. Durante la Celebración de Clausura del X Encuentro Continental de CEBs, available at:

https://app.box.com/s/86kngigkwvlns2y7bsbzyqqcxzuahuup (accessed August 22 2016).

Kay, R. \& Alder, J. (1999). Coastal Planning and Management, US: Routledge.

Keohane, R. \& Nye, J. (1988). Poder e interdependencia: la política mundial en transición. Argentina: Grupo Editor Latinoamericano.

Kemmis, S. \& Wilkinson, M. (1998). "Participatory action research and the study of practice". In B. Atweh, S. Kemmis, \& P. Weeks (Eds.), Action research in practice: Partnership for social justice in education, pp. 21-36. US: Sage.

Kimball, M. (2015). "Cognitive Economics", available at:

www.nber.org/papers/w20834.pdf (accesed Feb 12 2017).

King, L. (coord.) (2000). International Survey on Adult Education for Indigenous Peoples. Country Study: Canada, available at:

http://www.unesco.org/education/uie/pdf/Canada.pdf (accessed September 21 2016). 
Kissinger, H. (1995). La diplomacia. México: Ed. FCE.

Klepak, H. (2012). Espacio y rol de Canadá en las Relaciones Internacionales con América Latina en el siglo XXI, available at:

https://books.google.com.mx/books?isbn=9871867484 (accessed August 14 2016).

Klisksberg, B. (2003). "La discriminación de la mujer en el mundo globalizado y en América Latina. Un tema crucial para las políticas públicas", en: Instituciones y Desarrollo, núm. 12-13, enero.

L'Association québécoise des organismes de cooperation Internationale AQOCI (2007). L'aide publique au développement: le Canada à la veille de perdre la face? available at: http://www4.uqo.ca/ries2001/General/jan2008_aqoci/Aidepubliqueaudeveloppement.pdf (accessed November 18 2016).

Landau, G. (1990). La cooperación internacional para e desarro de América Latina y el Caribe, available at:

http://revistas.bancomext.gob.mx/rce/magazines/158/3/RCE3.pdf (accessed August 18 2016).

Langlois, D. (2016). "El Buen Vivir y la cuestión del Desarrollo" available at: http://www.alterinfos.org/spip.php?article7366 (accessed April 27 2016).

Lavalle, C. (2010). Paridad es la meta. Mujeres en los ayuntamientos de Quintana Roo, México: Inmujeres.

Lavilla, J. (2004). Economía Social y Solidaria: una Visión Europea. Argentina: Ed. Universidad Nacional de General Altamira.La Vía Campesina, Movimiento Campesino Internacional, available at: https://viacampesina.org/es/index.php/temas-principales-mainmenu-27/soberanalimentarycomercio-mainmenu-38/314-que-es-la-soberania-alimentaria (accessed May 25 2016).

León, I. (2009). "Ecuador: la tierra, el Sumak Kawsay y las mujeres” en León, I. coord. Buen vivir y cambios civilizatorios, Ecuador: Ed. Fedaeps.

León, M. (2000), “Gender mainstreaming”, available at: www.un.org/womenswat- ch/resources.htm (accessed November 18 2015).

Lerner, B. (1996). América Latina: Los debates en política social, desigualdad y pobreza, México: Ed. Porrúa.

Lett, L. (2014). "Las amenazas globales, el reciclaje de residuos y el concepto de economía circular", available at: http://www.redalyc.org/articulo.oa?id=213030865001 (accessed September 7 2015). 
Ley de Creación del Instituto Nacional Indigenista (1948), available at: http://www.gob.mx/cms/uploads/attachment/file/32276/cdi-antecedentes-ini.pdf (accessed November 19 2015).

Ley de la Comisión Nacional para el Desarrollo de los Pueblos Indígenas (2012), available at:

http://www.gob.mx/cms/uploads/attachment/file/32281/cdi-ley-de-la-cdi.pdf (accessed November 19 2015).

Llamazares, G. (2003). "Por el fomento de la Economía Social”. Revista de Economía Pública, Social y Cooperativa, núm. 47, pp. 29-34.

Llistar, D. (2016). Anticooperación Norte Sur. Cuando la coherencia es más importante que la ayuda. El caso de Ecuador y la "cooperación” española, available at: http://www.tdx.cat/handle/10803/384633 (accessed October 28 2016).

López-Torres, R., Vargas-Hernández, J. (2005). Impacto de los programas oficiales de gobierno en los últimos diez años en la comunidad de Jahuara II, El Fuerte, Sinaloa, México, available at:

http://www.redalyc.org/articulo.oa?id=46110106 (accessed November 4 2017).

Lovera, S. (2010). "Testimonios y experiencias de promotoras indígenas del Programa Organización Productiva para Mujeres Indígenas (POPMI)”, available at: http://www.cdi.gob.mx/dmdocuments/promotoras-indigenas-popmi.pdf (accessed April 22 2016).

Loza, M.S.J. (1992). Mensajes sociales para el mundo de hoy. México: Instituto Mexicano de Doctrina Social Cristiana.

Macdonald, L. \& Ruckert, A. (2014). Continental Shift? Rethinking Canadian Aid to the Americas, available at:

http://aix1.uottawa.ca/ brown/Brown,\%20den\%20Heyer\%20and\%20Black\%20\%20Rethin king\%20Canadian\%20Aid\%20(2014).pdf (accessed November 16 2016).

Malacalza, B. (2014). La política de cooperación al desarrollo como dimensión de la política exterior desde la Teoría de las Relaciones Internacionales, available at: www.e-publicacoes.uerj.br/index.php/muralinternacional/article/download/.../12128 (accessed September 28 2016).

Manzone, G. (2001). El Mercado. Teorías económicas y doctrina social. México: Instituto Mexicano de Doctrina Social Cristiana.

Marbán, V. (2006). "Estado de bienestar y tercer sector social en España. El estado de la investigación social”. Revista de Economía Pública, Social y Cooperativa, núm. 56, pp. 117-139. 
Martínez, L. (2009). “La Economía social y solidaria ¿mito o realidad?’. Revista de Ciencias Sociales, núm. 34, pp. 107-113.

Maslow, A. (1943). A Theory of Human Motivation. US: Sublime Books.

Massolo, A. (2004). "El gobierno municipal y la equidad de género", Barrera Bassols, D., Massolo, A. y Aguirre Pérez, I., Guía para la equidad de género en el Municipio, INDESOL, México.

Masson, S. (2011). Sexo/género, clase, raza: feminismo descolonial frente a la globalización. Reflexiones inspiradas a partir de la lucha de las mujeres indígenas en Chiapas, available at:

http://www.redalyc.org/pdf/628/62821337007.pdf (accesed September 28 2016).

Mateo, G., Méndez J. \& Solveira, B. (2011). "Estudios de caso en Argentina y México Mundo Agrario". Dossier Economía Social, cooperativismo agrario e intervención estatal, núm. 22, pp. 1-13.

Mayntz, R. (2001). "El Estado y la sociedad civil en la gobernanza moderna", available at: http://www.clad.org/portal/publicaciones-del-clad/revista-clad-reformademocracia/articulos/021-octubre-2001/el-estado-y-la-sociedad-civil-en-la-gobernanzamoderna (accessed September 15 2015).

Mijangos-Noh, J. \& Cardos-Dzul, M. (2011). The Mayas of Yucatán, Mexico: Their Fight Against School Dropout, available at:

http://www.jstor.org/stable/43608613?seq=1\#page_scan_tab_ contents (accessed November 4 2017).

Milani, C. \& Pinheiro, L. (2013). Política Externa Brasileira: Os Desafios de sua Caracterização como Política Pública, available at:

http://www.scielo.br/scielo.php?pid=S010285292013000100001\&script=sci_abstract\&tlng $=p t$ (accessed October 3 2016).

Mohlakoana, N. (2014). "Implementing the South African Free Basic Alternative Energy Policy, A Dynamic Actor Interaction”, available at: http://doc.utwente.n1/93045/ (accessed November 20 2015).

Monje, P. (2011). “Economía solidaria, cooperativismo y descentralización: la gestión social puesta en práctica”. Cuadernos EBAPE.BR, núm. 3, pp. 704-723.

Montaño, S. (2001). Políticas para el empoderamiento de las mujeres como estrategia de la lucha contra la pobreza, CEPAL, Chile.

Montero, D. (2002). América Latina: Organizaciones No Gubernamentales y

Endeudamiento, available at:

http://revistas.bancomext.gob.mx/rce/magazines/24/4/RCE.pdf

(accessed November 15 2016). 
Monzón, J. (2003). "El cooperativismo en la historia de la literatura económica". Revista de Economía Pública, Social y Cooperativa, núm. 44, pp. 2-24.

Monzón, J. \& Defourny, J. (1993). Economía Social, entre economía capitalista y economía pública. Valencia: Ed. CIRIEC.

Mora, A. (2011). El cooperativismo en América Latina. Una diversidad de contribuciones al desarrollo sostenible. Visión histórica del movimiento cooperativo en América Latina, available at:

http://www.aciamericas.coop/IMG/pdf/wcms_188087.pdf (accessed August 22 2016).

Morales, E. (1981). Dos decenios de Diálogo Norte-Sur. El papel de las comisiones independientes no gubernamentales, available at:

http://revistas.bancomext.gob.mx/rce/magazines/385/7/RCE8.pdf (accessed September 19 2016).

Morgenthau, H. (1948). Politics Among Nations. The Struggle for Power and Peace. US: McGraw-Hill.

Mori, P. (2014). "Community and Cooperation: The Evolution of Cooperatives towards new models of citizens". Annals of Public and Cooperative Economics, No. 85, pp. 327352.

Morris, S. \& Klesner, J. (2010). "Corruption and Trust: Theoretical Considerations and Evidence from Mexico". Comparative Political Studies. No. 43 (10), pp. 1258-1285.

Moscoso, T. (1965). Es Adecuada la Actitud Actual de EUA Hacia la Alianza para el Progreso?, available at: http://revistas.bancomext.gob.mx/rce/magazines/532/11/RC11.pdf (accessed October 25 2016).

Muñoz, G. (2006). Consideraciones básicas de la descentralización en México, SEGOB, México.

Nicholls, A. (2008). Social Entrepreneurship: New Models of Sustainable Social Change. UK: Oxford University Press.

Nwagbara, U. \& Babatunde, A. (2012). "The Impact of Work-Life Balance on the Commitment and Motivation of Nigerian Women Employees", available at: https://www.academia.edu/1479875/The_Impact_of_WorkLife_Balance_on_the_Commitm ent_and_Motivation_of_Nigerian_Women_Employees (accessed September 2 2014).

Observatorio de Economía Social, available at:

http://observatorioeconomiasocial.es/cidec/ (accessed January 3 2014). 
Ocampo, J. (2015). Gobernanza global y desarrollo la descolonización de la agenda para el desarrollo después de 2015, available at: http://repositorio.cepal.org/handle/11362/38855 (accessed October 16 2016).

OECD (2006). Dac in dates. The History of OECD's Development Assistance Committee, available at:

http://www.oecd.org/dac/1896808.pdf (accessed November 24 2016).

OECD (2008). Is it ODA?, available at:

http://www.oecd.org/dac/stats/34086975.pdf (accessed January 4 2017).

OECD (2015). Official Development Assistance 2015, available at:

http://www2.compareyourcountry.org/oda?cr=oecd\&lg=en (accessed January 3 2017).

OECD Organization for Economic Co-operation and Development, available at: https://www.oecd.org/eco/surveys/Mexico-Overview-2015.pdf (accessed May 26 2017).

Oficina del Alto Comisionado de las Naciones Unidas para los Derechos Humanos (ACNUDH) (2003). Las dimensiones del racismo, available at: http://www.ohchr.org/Documents/Publications/DimensionsRacismsp.pdf (accessed May 25 2016).

OIT Organización Internacional del Trabajo, available at: http://www.ilo.org/global/lang--es/index.htm (accessed Feb 14 2017).

ONU (1987). Nuestro futuro común: Informe Brundtland, available at: http://www.un-documents.net (accessed May 26 2016).

ONU Mujeres (2015). El Progreso de las Mujeres en el Mundo 2015-2016, available at: http://200.23.8.225/odm/Doctos/ONU_Mujeres_Summary_ES.pdf (accessed July 25 2016).

Osorio, M., Bressers, H., Franco, L., De Boer. Ch. \& Reyes, O. (2016). "Elements of success in cooperatives conformed by Maya women in the Yucatan Peninsula, Mexico", International Journal of Research and Education, Vol. 1, No. 2, pp. 1-11.

Osorio, M., Bressers, H. \& Franco, L. (2017). “Analysis of federal Mexican program POPMI that supported female entrepreneurship initiatives in the Yucatan Peninsula, Mexico" (on press).

Ostrom, E. \& Ahn T. (2003). Una perspectiva del capital social desde las ciencias sociales: capital social y acción colectiva. México: Instituto de Investigaciones Sociales.

Pan American Development Foundation PADF (2016), available at: http://www.padf.org/history/ (accessed January 4 2017). 
Patel, R., Balakrishnan, R. \& Narayan, U. (2007). "Explorations on Human Rights". Feminist Economics, No.13, pp. 87-116.

Patel, R. (2009). “Food sovereignty”. Journal of Peasant Studies, No. 36, pp. 663-706.

Paterson, J. (2014). The Consolidation of Aid: Reducing Fragmentation in Canadian Development Assistance, available at:

https://umanitoba.ca/centres/mipr/media/7._Consolidation_of_Aid_Paterson.pdf (accessed November 14 2016).

Patton, M. (2002). Qualitative Research and Evaluation Methods. US: Sage Publications.

Pavía, M. (2013). "La economía y el desarrollo de los pueblos en caritas in veritate". Hospitalidad-Esdai. No. 24, pp. 137-161.

Pearson, F. \& Rochester, J. (2000). Relaciones Internacionales. Colombia: Ed. McGraw Hill.

Pétillon, Y. (2014). L’Aide Internationale au développement est-elle en danger? available at:

http://www.occah.org/DATA/PUBLICATION/108 v LLaide_internationale_au_developp ement_est-elle_en_danger_.pdf (accessed October 17 2016).

Pech, G. (2012). Análisis organizacional del proyecto comunitario ecoturístico Yuumtsil K'áax de Huaymay. Quintana Roo, México. México: UIMQROO.

Perea, I. (2014). "El papel del feminismo en el movimiento antiglobalización: contribuciones y desafíos", available at: http://www.raco.cat/index.php/RevistaCIDOB/article/viewFile/275691/363656 (accessed Feb 12 2016).

Pérez, M., Vázquez, V. \& Zapata, E. (2008). “Empoderamiento de las mujeres indígenas de Tabasco. El papel de los fondos regionales de la CDI”. Cuicuilco, No. 42, pp. 165-179.

Pinheiro, E. (1985). "Achievement motivation of women: effects of achievement and affiliation arousal", available at: http://pwq.sagepub.com/content/9/1/89.short (accessed August 2 2014).

PND Plan Nacional de Desarrollo, available at: http://pnd.gob.mx/ (accessed Feb 15 2017).

PNUD (2014). Indicadores de Desarrollo Humano y Género en México: Nueva Metodología. Identificar las barreras para lograr la igualdad, Programa de las Naciones Unidas para el Desarrollo, México, available at: http://www.mx.undp.org/content/dam/mexico/docs/Publicaciones/PublicacionesReduccion Pobreza/InformesDesarrolloHumano/DHyG\%20baja\%20res.pdf (accessed March 24 2015). 
PNUD Programa de las Naciones Unidas para el Desarrollo, available at: http://www.undp.org/es/ (accessed April 29 2017).

Pontificio Consejo Justicia y Paz (2004). Compendio de la Doctrina Social de la Iglesia. México: Ed. CEM.

Prado (2009). Teorías Positivistas y Críticas de las Relaciones Internacionales: Realismo y Constructivismo en la Cooperación Internacional, available at: http://www.academia.edu/4915877/Teor\%C3\%ADas_Positivistas_y_Cr\%C3\%ADticas_de _las_Relaciones_Internacionales_Realismo_y_Constructivismo_en_la_cooperaci\%C3\%B3 n_internacional (accessed November 5 2016).

Prebisch, R. (1961). La Respuesta de América Latina a una Nueve Política de Cooperación Económica Internacional, available at:

http://revistas.bancomext.gob.mx/rce/magazines/697/22/RCE_6.pdf (accessed October 21 2016).

Putnam, R. (2000). Bowling Alone: The Collapse and Revival of American Community. US: Simon \& Schuster.

Quezada, A. (2008). "Evaluación y perspectivas del Programa Organización Productiva para Mujeres Indígenas en el estado de Michoacán en el año 2006”, available at: http://www.redalyc.org/articulo.oa?id=32511865006 (accessed September 2 2015).

Quintal, E. (2016). Fiestas y gremios en el oriente de Yucatán, available at: http://www.mayas.uady.mx/articulos/fiestas.html (accessed May 25 2016).

Raj, A. (2016). Trudeau: Gender Inequality and Extreme Poverty Are Indisputably Linked, available at:

http://www.huffingtonpost.ca/2016/08/25/trudeau-poverty-sexist-feminist-gender equality_n_11688874.html (accessed November 17 2016).

Ralston, J. (2009). A Fair Country. Telling Truths about Canada. Canada: Ed. Penguin Group.

Rawls, J. (1999). A Theory of Justice. Oxford: Oxford University Press.

Reyes, O. y Barrera, M. (2014), "Estructura y desigualdad del ingreso en la zona maya de Quintana Roo. Un estudio de caso para las comunidades de José María Morelos y Sabán en Quintana Roo, México, 2011", available at:

http://www.revista.economia.uady.mx/2014/XXXI/82/4.pdf (accessed September 3 2014).

Reyes, O. Navarro, A. y Hernández, I. (2014). Informe sobre la estrategia de Desarrollo Agrícola 2013, Universidad Intercultural Maya de Quintana Roo-Centro Estatal de Evaluación y Seguimiento de la Calidad de los Servicios Profesionales (CECS) de Quintana Roo, México. 
Reventos, J. (1960). El movimiento cooperativo en España, Barcelona: Ariel.

Rojas, M. (2013). "Una Crítica a la perspectiva del capital social", available at: http://www.eseade.edu.ar/files/riim/RIIM_58/riim58_rojas.pdf (accessed September 10 2014).

Rojo, A. (2000). “Globalización, Integración Mundial y Federalismo”. Revista de Estudios Políticos Nueva Época. No. 109. Pp. 29-72.

Rosado, G. (2001). Mujer Maya: Siglos Tejiendo una Identidad, Conaculta, México.

Rose-Ackerman, S. (1999). Corruption and Government: Causes, Consequences and Reform Corruption and Government. UK:Cambridge University Press.

Rosette, A., Plunkett, L. (2010). Agentic Women and Communal Leadership: How Role Prescriptions Confer Advantage to Top Women Leaders, American Psychological Association, US.

Ruz, A. (2011). Los antiguos mayas, Fondo de Cultura Económica, México.

Sábato, J., Caputo, D. \& Sábalo, J. (1981). Cooperación para el desarrollo: Algunas reflexiones y propuestas, available at:

http://www.revistas.uchile.cl/files/journals/51/articles/16271/submission/copyedit/1627146445-1-CE.pdf (accessed September 17 2016).

SAGARPA Secretariat of Agriculture, Livestock, Rural Development, Fisheries and Food, available at:

http://www.gob.mx/sagarpa (accessed May 2 2017).

Sadi, M. \& Al-Ghazali, B. (2012). "The dynamics of entrepreneurial motivation among women: a comparative study of businesswomen in Saudi Arabia and Bahrain", available at: http://web.usm.my/aamj/17.1.2012/AAMJ_17.1.5.pdf (accessed August 28 2014).

Sánchez, F. (2003). "Planificación Estratégica y Gestión Pública por objetivos”. Instituto Latinoamericano y del Caribe de Planificación Económica y Social (ILPES). Serie Gestión Pública No. 32. Pp. 1-80.

Sánchez, M. (2012). Foro Internacional de Mujeres Indígenas. Discurso pronunciado durante la Sesión Quincuagésima Sexta de Comisión de la Condición Social y Jurídica de la Mujer (CSW) US: ONU Mujeres.

Sampedro J. (2009). Economía humanista. Algo más que cifras. Barcelona: Ed. Debate. Santacoloma, J. \& Aguado, R. (coords.) (2011). Economía y Humanismo Cristiano. España: Universidad de Deusto.

Savater, F. (1998). Ética, política, ciudadanía, México: Ed. Grijalbo. 
Schmitz, G. (2013). Canada and International Democracy Assistance. What Direction for the Harper Government's Foreign Policy? available at:

http://www.queensu.ca/cidp/sites/webpublish.queensu.ca.cidpwww/files/files/publications/ occasionalpapers/OP67.pdf (accessed August 14 2016).

Schwartz, N. \& Deruyttere, A. (1996). Consulta Comunitaria, Desarrollo Sostenible y el Banco Interamericano de Desarrollo: un Marco Conceptual, US:BID.

Scott, P. (2007). U.S. Relations with Latin America during the Clinton Years:

Opportunities Lost or Opportunities Squandered?, available at:

https://www.foreignaffairs.com/reviews/capsule-review/2007-05-01/us-relations-latinamerica-during-clinton-years-opportunities-lost (accessed September 14 2016).

Scott, S. (2015). The accidental birth of "official development assistance", available at: http://www.oecd-ilibrary.org/development/the-accidental-birth-of-official-developmentassistance_5jrs552w8736-en?crawler=true (accessed November 10 2016).

Secretaría de Desarrollo Agropecuario y Rural (2014), available at http://sedaru.qroo.gob.mx (accessed September 10 2014).

Seara, M. (1985). Política Exterior de México. México: Ed. Harper \& Row Publishers.

SEDESOL Secretariat of Social Development, available at:

http://www.gob.mx/sedesol (accessed May 2 2017).

Seglow, J. (2016). "Hate Speech, Dignity and Self-Respect”. Ethic Theory Moral Practice. No. 17, Pp. 1-18.

SEGOB (2006). Consideraciones básicas de la descentralización en México. INAFED: México.

SEP Secretaría de Educación Pública, available at: http://www.gob.mx/sep (accessed April 30 2017).

Shibley, J. \& Hyde, C. (2001). "Women, Motivation and Achievement", available at: http://onlinelibrary.wiley.com/doi/10.1111/1471-6402.00035/pdf

(accessed August 22 2014).

Simon, H. (1979). "Rational decision making in business organizations", American Economic Review, No. 69, pp. 493-513.

Socías, A. (2005). "El comercio justo: implicaciones económicas y solidarias". Revista de Economía Pública, Social y Cooperativa, núm. 51, pp. 7-24.

Sogge, D. (2009). Sistema de ayuda extranjera: ¿Régimen o vehículo hegemónico?, available at: http://www.relacionesinternacionales.info/ojs/article/view/170.html (accessed September 24 2016). 
Sogge, D. (2015). Los donantes se ayudan a sí mismos, available at: http://www.2015ymas.org/centro-de-documentacion/publicaciones/2015/1592/donantesque-se-ayudan-a-si-mismos/\#.WFqrf1PhAdU (accessed June 14 2016).

Sojo, C. (2006). Desarrollo Social, Integración y Políticas Públicas, available at: http://www.redalyc.org/pdf/745/74540106.pdf (accessed October 25 2016).

Soria, G., Palacio, V. \& Trujillo, L. (2014). "Redes de colaboración solidaria para la autosuficiencia alimentaria: propuesta para la población rural”. Estudios Sociales, No. 46, pp. 243-270.

Spear, R. (2001). "El balance social en la economía social. Enfoques y problemática". Revista de Economía Pública, Social y Cooperativa, núm. 39, pp. 9-24.

Strauss, A. \& Corbin, J. (2002). Basics of qualitative research. Techniques and procedures for developing grounded theory. US: Sage Publications.

Swiss, L. (2010). A New National Project for Canadian Development Cooperation, available at:

http://gordonfoundation.ca/sites/default/files/Swiss_NationalProjectForCdnDevCooperatio n.pdf (accessed November 13 2016).

Tarres, M. (2014). Observar, escuchar y comprender sobre la tradición cualitativa en la investigación social. México: Ed. Colmex/Flacso.

Teixeira, T. \& Soler, A. (2002). "La conformación del cooperativismo en Brasil: tendencias y desafíos en el Siglo XXI", available at:

http://www.redalyc.org/pdf/174/17404311.pdf (accessed Feb 2 2017).

The McLeod Group (2014), Canadian Development Assistance: The Issue of "Focus", available at:

http://www.mcleodgroup.ca/wp-content/uploads/2014/12/McLeod-Group-briefing-note-3\%E2\%80\%93-A-Question-of-Focus.pdf (accessed August 28 2016).

The World Bank, available at: http://web.worldbank.org (accessed June 20 2016).

Tiessen, R. (2014). Rethinking Canadian Aid Gender Equality and the "Two CIDAs": Successes and Setbacks, 1976-2013, available at: http://aix1.uottawa.ca/ brown/Brown,\%20den\%20Heyer\%20and\%20Black\%20\%20Rethin king\%20Canadian\%20Aid\%20(2014).pdf (accessed November 16 2016).

Treviño, L., Butterfield, K. \& Mcabe, D. (1998). "The ethical context in organizations: Influences on employee attitudes and behaviors", Business Ethics Quarterly, No. 8, pp. 447-476. 
Treviño, L.K., Hartman, L.P. \& Brown, M. (2000). "Moral person and moral manager: How executives develop a reputation for ethical leadership". California Management Review, No, 42, pp. 128-142.

Tocancipá, J. (2008). "El trueque: tradición, resistencia y fortalecimiento de la economía indígena en el Cauca". Revista de Estudios Sociales. No. 31, pp. 146-161.

Tomassini, L. (2006). "Estado, gobernabilidad y desarrollo", available at: http://www7.uc.cl/icp/revista/pdf/rev141/ar2.pdf (accessed October 22 2015).

Ulloa, A., Matilde Escobar, E., Donato, L. \& Escobar, P. (2008). Mujeres indígenas y cambio climático, UNAL-Fundación Natura de Colombia-UNODC, Colombia.

United Nations (UN), available at:

http://www.un.org/en/index.html (accessed May 25 2016).

United Nations Human Development Programme, available at: http://hdr.undp.org/en/humandev (accessed May 31 2016).

United Nations (2015). The Millenium Development Goals Report, available at: http://www.un.org/millenniumgoals/2015_MDG_Report/pdf/MDG\%202015\%20rev\%20(J uly\%201).pdf (accessed January 3 2017).

Uriarte, P. S.J. (1966). La Dinámica Profunda de la Vida Económica-Social. Bilbao: Ed. El Mensajero del Corazón de Jesús.

Villegas, E., Ortubia, E. \& Lillo, M. (2011). "La economía social solidaria como alternativa de trabajo posible: en busca del desarrollo territorial para Mendoza, Argentina". Tiempo y Espacio. No. 26, pp. 123-152.

Viteri, C. (2002). "Visión indígena del desarrollo en la Amazonía", Polis, Revista de la Universidad Bolivariana, vol. 1, núm. 3. Pp. 1-6.

Wallace, A. (1993). "Sowing Seeds of Hope: Wangari Maathai, Kenya”, Gancher, D., ed. Eco-Heroes: Twelve Tales of Environmental Victory, Mercury House, US.

Walsh-Dilley, M., Wolford, W. \& McCarthy, J. (2016). "Rights for resilience: food sovereignty, power, and resilience in development practice". Ecology and Society, No. 21, pp. 1-10.

Wangari, M. (2006). Unbowed. US: Anchor Books.

Wesley-Esquimaux, C. (2015). "Translating words into action", pp. 16-25 in Osorio, M. (ed.) Memorias del Coloquio sobre Educación Superior Indígena México-Canadá, en el marco del Día Internacional de las Lenguas Maternas. México: UIMQRoo. 
Westlund, H. (2006). Social Capital in the Knowledge Economy Theory and Empirics, Springer, US.

Wethersfield Institute (1992). When Conscience and Politics meet: A catholic view en Francis Canavan, S.J. Political Choice and Catholic Conscience San Francisco: Ignatius Press.

Widrow, W. (1918). "President Woodrow Wilson's Fourteen Points", available at: http://avalon.law.yale.edu/20th_century/wilson14.asp (accessed May 17 2017).

World Economic Forum (2014). Towards the circular economy: accelerating the scale-up across global supply chains. Switzerland: World Economic Forum.

World Food programme (2015), available at:

https://www.wfp.org/hunger/who-are (accessed April 13 2015).

World Forum on Food Sovereignty (2001). "For the peoples' right to produce, feed themselves and exercise their food sovereignty", available at:

www.ukabc.org/havanadeclaration.pdf (accessed May 26 2016).

World Heritage Encyclopedia (2016). Social-Economics. US: World Public Library Association.

Yúnez-Naude, A. y Taylor, J. (2004). "Los determinantes de las actividades y el ingreso no agrícola de los hogares rurales de México con énfasis en la educación", available at: http://www.cepal.org/publicaciones/xml/4/22444/12096e-yunez.pdf (accessed September 10 2014). 


\section{Annex 1}

\section{Questionnaire Field research/Women who work in cooperatives}

Paper: Promoting Food Sovereignty through a cooperative model in the Maya Region.

I. Food sovereignty (based on the Likert Scale)

1. To be part of a cooperative help me to eat better:

( ) Strongly agree

( ) Agree

( ) Undecided

( ) Disagree

( ) Strongly disagree

2. I do not exchange fruits and vegetables with my coworkers from the cooperative:

( ) Strongly agree

( ) Agree

( ) Undecided

( ) Disagree

( ) Strongly disagree

3. Because of my work in the cooperative now I eat meat often:

( ) Strongly agree

( ) Agree

( ) Undecided

( ) Disagree

( ) Strongly disagree

4. Although I work in the cooperative my children drink milk rarely:

( ) Strongly agree

( ) Agree

( ) Undecided

( ) Disagree

( ) Strongly disagree

5. I can't rely on the women who work with me in the cooperative if I don't have something to eat:

( ) Strongly agree

( ) Agree

( ) Undecided

( ) Disagree

( ) Strongly disagree

6. If I'm too busy my coworkers from the cooperative cook for me and my family:

( ) Strongly agree

( ) Agree

( ) Undecided

( ) Disagree

( ) Strongly disagree 
7. A major part of my income from my cooperative's activities is spent on food:

( ) Strongly agree

( ) Agree

( ) Undecided

( ) Disagree

( ) Strongly disagree

8. Members of my family have been sick related to deficiencies and imbalances in their diet:

( ) Strongly agree

( ) Agree

( ) Undecided

( ) Disagree

( ) Strongly disagree

9. As part of the cooperative I do not exchange food with my coworkers:

( ) Strongly agree

( ) Agree

( ) Undecided

( ) Disagree

( ) Strongly disagree

10. Because I'm part of the cooperative I do not worry about food anymore:

( ) Strongly agree

( ) Agree

( ) Undecided

( ) Disagree

( ) Strongly disagree

\section{Economic Factors}

11. As part of a cooperative my income has not improved:

( ) Strongly agree

( ) Agree

( ) Undecided

( ) Disagree

( ) Strongly disagree

12. Because I work in the cooperative I can sell my products more easily:

( ) Strongly agree

( ) Agree

( ) Undecided

( ) Disagree

( ) Strongly disagree 
13. Because I'm part of the cooperative now I feel more self-sufficient than before:

( ) Strongly agree

( ) Agree

( ) Undecided

( ) Disagree

( ) Strongly disagree

\section{Environment}

14. My activities in the cooperative are mindful with the environment:

( ) Strongly agree

( ) Agree

( ) Undecided

( ) Disagree

( ) Strongly disagree

15. My products are chemicals free:

( ) Strongly agree

( ) Agree

( ) Undecided

( ) Disagree

( ) Strongly disagree

\section{Self-esteem}

16. Because I'm part of the cooperative now I feel better with myself:

( ) Strongly agree

( ) Agree

( ) Undecided

( ) Disagree

( ) Strongly disagree

17. As part of the cooperative I do not feel valued by the community:

( ) Strongly agree

( ) Agree

( ) Undecided

( ) Disagree

( ) Strongly disagree

18. Since I work in the cooperative my husband respect me more:

( ) Strongly agree

( ) Agree

( ) Undecided

( ) Disagree

( ) Strongly disagree 
19. Although I work in the cooperative I do not feel appreciation from my relatives:

( ) Strongly agree

( ) Agree

( ) Undecided

( ) Disagree

( ) Strongly disagree

20. Since I work in the cooperatives my children encourage me and support me in my labors:

( ) Strongly agree

( ) Agree

( ) Undecided

( ) Disagree

( ) Strongly disagree 


\section{Questionnaire Field research/Women who work independently}

Paper: Promoting Food Sovereignty through a cooperative model in the Maya Region.

I. Food sovereignty (based on the Likert Scale)

1. To be part of the community help me to eat better:

( ) Strongly agree

( ) Agree

( ) Undecided

( ) Disagree

( ) Strongly disagree

2. I do not exchange fruits and vegetables with my neighbors:

( ) Strongly agree

( ) Agree

( ) Undecided

( ) Disagree

( ) Strongly disagree

3. Because of my work in the community I eat meat often:

( ) Strongly agree

( ) Agree

( ) Undecided

( ) Disagree

( ) Strongly disagree

4. Although I work my children drink milk rarely:

( ) Strongly agree

( ) Agree

( ) Undecided

( ) Disagree

( ) Strongly disagree

5. I can't rely on people from the community if I don't have something to eat:

( ) Strongly agree

( ) Agree

( ) Undecided

( ) Disagree

( ) Strongly disagree

6. If I'm too busy my neighbors cook for me and my family:

( ) Strongly agree

( ) Agree

( ) Undecided

( ) Disagree

( ) Strongly disagree 
7. A major part of my income is spent on food:

( ) Strongly agree

( ) Agree

( ) Undecided

( ) Disagree

( ) Strongly disagree

8. Members of my family have been sick related to deficiencies and imbalances in their diet:

( ) Strongly agree

( ) Agree

( ) Undecided

( ) Disagree

( ) Strongly disagree

9. I do not exchange food with my neighbors:

( ) Strongly agree

( ) Agree

( ) Undecided

( ) Disagree

( ) Strongly disagree

10. Because I'm part of this community I do not worry about food anymore:

( ) Strongly agree

( ) Agree

( ) Undecided

( ) Disagree

( ) Strongly disagree

\section{Economic Factors}

11. As part of the community my income has not improved:

( ) Strongly agree

( ) Agree

( ) Undecided

( ) Disagree

( ) Strongly disagree

12. Because I work in the community I can sell my products more easily:

( ) Strongly agree

( ) Agree

( ) Undecided

( ) Disagree

( ) Strongly disagree 
13. Because I'm part of this community now I feel more self-sufficient than before:

( ) Strongly agree

( ) Agree

( ) Undecided

( ) Disagree

( ) Strongly disagree

\section{Environment}

14. My activities are mindful with the environment:

( ) Strongly agree

( ) Agree

( ) Undecided

( ) Disagree

( ) Strongly disagree

15. My products are chemicals free:

( ) Strongly agree

( ) Agree

( ) Undecided

( ) Disagree

( ) Strongly disagree

\section{Self-esteem}

16. Because I'm part of this community now I feel better with myself:

( ) Strongly agree

( ) Agree

( ) Undecided

( ) Disagree

( ) Strongly disagree

17. I do not feel valued by the community:

( ) Strongly agree

( ) Agree

( ) Undecided

( ) Disagree

( ) Strongly disagree

18. Because I'm part of this community my husband respect me more:

( ) Strongly agree

( ) Agree

( ) Undecided

( ) Disagree

( ) Strongly disagree 
19. Although I work I do not feel appreciation from my relatives:

( ) Strongly agree

( ) Agree

( ) Undecided

( ) Disagree

( ) Strongly disagree

20. Since I work my children encourage me and support me in my labors:
( ) Strongly agree
( ) Agree
( ) Undecided
( ) Disagree
( ) Strongly disagree 


\section{Summary}

With the aim of contributing to the development of Mayan women living in the Yucatan Peninsula, this research focused on determine the factors that support or inhibit the sustainability of micro-businesses cooperatives, which are organizations with innovative elements that allow Mayan women to work within their communities with flexible schedules, which contributes to family unity, strengthening their self-esteem and community recognition. However, many of these initiatives hardly remain in the market, due to this, the research investigated the motivations of the Mayan women to undertake these microbusinesses, the elements of success that indicate the best practices in this type of initiatives, the implementation process of a national and foreign fund using Contextual Interaction Theory as a frame of reference and, finally, the contribution of cooperatives to the food sovereignty of Mayan women.

This dissertation is divided into chapters whose elements are described as follows:

Chapter 1 provides an overview of the study presenting the theoretical framework and methodology selected, as well the research questions which guided the dissertation. The theoretical framework was diverse, with a strong influence of the Theory of Social Economy in relation to Buen Vivir, which is a cosmogonic vision of the indigenous peoples, where the human being is interrelated with the environment, taking into account that natural resources are indispensable for their survival. The reflections of Freire, Seglow, Bandura and Simon among others, enriched this work which maintained a perspective of gender equity and social inclusion.

Chapter 2 reflects on the motivations of the women participating in these micro-businesses cooperatives, which go beyond of obtaining an additional income, the women think and make choices as mothers in a constant search for the well-being of their children, although sometimes, forgetting their own. The education and nutrition of their children are their priority, working to avoid family disintegration as a consequence of the migration of their husbands and sons, which are also relevant factors.

Chapter 3 describes success stories found in the region, considering success in relation to business sustainability over time. These cases were distinguished by continuing in the market, which was confirmed until the end of this investigation. The elements found were social capital, understood as support networks that benefited the permanence of microbusiness in the market, monitoring or follow-up activities carried out by representatives of the organizations that supported these initiatives economically, and ethical leadership, which represents an alternative of doing businesses based on honest work in counterpart with the serious problems of corruption that Mexican society has to dealt with.

Chapter 4 and Chapter 5 are complementary, since they serve to make a comparison between the implementation of national and international funds in the same region. Both are productive programs whose beneficiaries were indigenous Mayan women living in rural areas. The programs analyzed were the Program of Productive Organization for Indigenous Women (POPMI), which was administered by the National Commission for the 
Development of Indigenous Peoples (CDI) and the Canada Fund for Local Initiatives (CFLI) a program which was part of the Canadian International Development Agency (CIDA). CIDA was a Canadian federal agency which, until 2013, promoted female entrepreneurship initiatives among Maya women in the Yucatan Peninsula. Both programs were analyzed using Contextual Interaction Theory.

Chapter 6 analyzes the contribution of working in cooperatives to among others the food sovereignty of the participants, with women who work in groups in relation to those who work independently in the same communities. In these villages with strong patriarchal structures, the independence of women is not easily accepted and is even questioned by other women. Because of that, it was interesting to contrast their perceptions on what the work brought them, which deepened the knowledge about self-reliance aspects related to food sovereignty.

Chapter 7 makes a final reflection in the form of a response to the research questions, formulating recommendations for the implementation of public policies and productive programs both at regional and international levels, taking into account empirical evidence found in field research activities.

This information will be available to the organizations who contribute to the welfare of indigenous women, since entrepreneurship is one of the available ways to foster development. 


\section{Samenvatting}

Met het oogmerk om bij te dragen aan de ontwikkeling van Maya vrouwen op het Yucatan schiereiland, richtte dit onderzoek zich op factoren die de duurzaamheid ondersteunen of beletten van coöperatieve micro-ondernemingen. Dit zijn organisaties met innovatieve elementen die Maya vrouwen in staat stellen om binnen hun eigen gemeenschappen te werken en met een flexibel rooster. Dat draagt bij aan de saamhorigheid van het gezin en versterkt hun zelfwaardering en de waardering door hun gemeenschap. Echter, veel van deze initiatieven behouden niet of moeizaam hun plaats in de markt. Daarom onderzocht deze studie de motieven van de Maya vrouwen om deze microbedrijven te starten, de succesfactoren die de 'best practices' voor dit soort initiatieven laten zien, de implementatieprocessen van een nationaal en een internationaal steunfonds, met behulp van de Contextuele Interactie Theorie, en tot slot de bijdrage van de coöperatieven aan de voedselsoevereiniteit van de Maya vrouwen.

De dissertatie is verdeeld in hoofdstukken waarvan de inhoud als volgt kan worden beschreven:

Hoofdstuk 1 geeft een overzicht van de studie en presenteert het geselecteerde theoretische raamwerk en methodologie, en daarnaast de onderzoeksvragen die de dissertatie richting geven. Het theoretische raamwerk is divers, met een sterke invloed van de theorie van sociale economie in relatie tot het Buen Vivir concept. Dit is de kosmogonische visie van de inheemse volken, waarin een menselijk wezen verbonden is met de omgeving en er rekening mee houdt dat natuurlijke hulpbronnen onmisbaar zijn voor overleving. De gedachtegangen van onder meer Freire, Seglow, Bandura en Simon verrijkten dit werk, dat zich daarbij oriënteert op gender gelijkheid en sociale inclusie.

Hoofdstuk 2 gaat in op de motivaties van de vrouwen die deelnemen in deze coöperatieve microbedrijven. Deze gaan verder dan het verkrijgen van extra inkomen. De vrouwen denken en kiezen als moeders die steeds streven naar het welzijn van hun kinderen, zelfs als ze daarbij soms dat van henzelf verwaarlozen. De opleiding en voeding van hun kinderen vormen hun prioriteit, terwijl ze hun best doen om het uiteenvallen van hun gezin door migratie van hun echtgenoten en zonen te voorkomen.

Hoofdstuk 3 beschrijft enkele succesverhalen uit de regio, waarbij succes wordt opgevat als langdurig stabiele bedrijfsvoering. Deze gevallen onderscheidden zich door continuïteit in de markt, die tot minstens het einde van dit onderzoek bleef voortduren. De succesfactoren die werden gevonden waren sociaal kapitaal, begrepen als een steunnetwerk dat de permanentie van het microbedrijf in de markt ten goede komt, monitoring of andere vervolgactiviteiten van vertegenwoordigers van organisaties die deze initiatieven financieel hebben ondersteund, en ethisch leiderschap, een alternatieve manier om zaken te doen, gebaseerd op eerlijk werk tegenover de ernstige problemen met corruptie waar de Mexicaanse samenleving mee te maken heeft. 
De hoofdstukken 4 en 5 zijn complementair, omdat ze dienen om een vergelijking te kunnen maken tussen de implementatie van nationale en internationale ondersteuningsfondsen in hetzelfde gebied. Beide zijn ondersteuningsprogramma's voor Maya vrouwen in plattelandsgebieden. De bestudeerde programma's zijn het Mexicaanse Programma voor Productieve Organisatie voor Inheemse Vrouwen (POPMI) en het Canada Fonds voor Lokale Initiatieven (CFLI), een programma van het Canadese Internationale Ontwikkelingsagentschap (CIDA). CIDA was een Canadees federaal agentschap dat tot 2013 vrouwelijk ondernemerschap onder Maya vrouwen op het Yucatan schiereiland promootte. Beide programma's werden geanalyseerd met behulp van de Contextuele Interactie Theorie.

Hoofdstuk 6 onderzoekt de bijdrage van coöperatieven aan onder meer de voedselsoevereiniteit van de deelnemers door vrouwen die in groepen werken te vergelijken met andere vrouwen in dezelfde gemeenschappen die zelfstandig werken. In deze dorpen met hun sterk patriarchale structuren wordt de onafhankelijkheid van vrouwen niet gemakkelijk geaccepteerd en wordt er zelfs door andere vrouwen vraagtekens bij gezet. Daarom was het interessant om de opvattingen van deze twee groepen over wat het werk hen bracht met elkaar te vergelijken. Dit verdiepte ook de kennis over aspecten van zelfvoorzienendheid in relatie tot voedselsoevereiniteit.

Hoofdstuk 7 biedt concluderende overwegingen in de vorm van antwoorden op de onderzoeksvragen en formuleert aanbevelingen voor het ontwerpen van beleidsprogramma's zowel op regionaal als op internationaal niveau, rekening houdend met de empirische bevindingen uit het veldonderzoek.

Deze informatie zal worden doorgespeeld aan de organisaties die bijdragen aan het welzijn van de inheemse vrouwen. Ondernemerschap is immers een van de mogelijke manieren om ontwikkeling te bevorderen. 


\section{About the Author}

\section{Maria Cristina Osorio Vazquez}

Born in Merida, Yucatan, Mexico, the author has a degree in International Relations from the Universidad de Quintana Roo (UQRoo) and a Master in Economics and Public Administration from the School of Economics at the Autonomous University of Yucatan (UADY).

The author has accumulated over 17 years of work and research experience in public and private educational institutions. As a student, she was involved in projects related to sustainable development of coastal resources with the University of Rhode Island and also collaborated in public policies with the School of Public and Environmental Affairs at Indiana University supported by the US Agency for International Development (USAID). She is the author of several papers and projects promoting the inclusion of minority students in international academic exchanges supported by the US Department of State, to promote indigenous education in Canada and Mexico with financial support from the Mexican Secretariat of Education, and has also published work on food sovereignty and entrepreneurial activities among Maya women, supported by the Nestle Foundation.

Currently, she is working on a research project with the support of the Center for Universal Education (CUE) at The Brookings Institution with the aim of improving girls' education in Mexico, as part of the Echidna Global Scholar Program.

She is now employed at the Universidad Anahuac Mayab, in the School of Economics and Business. In addition, she has been collaborating with the School of Economics in the Master's Degree program in Government and Public Policies at the Autonomous University of Yucatan in Merida, Mexico for several years. 
